UROTHERAPY

a critical evaluation

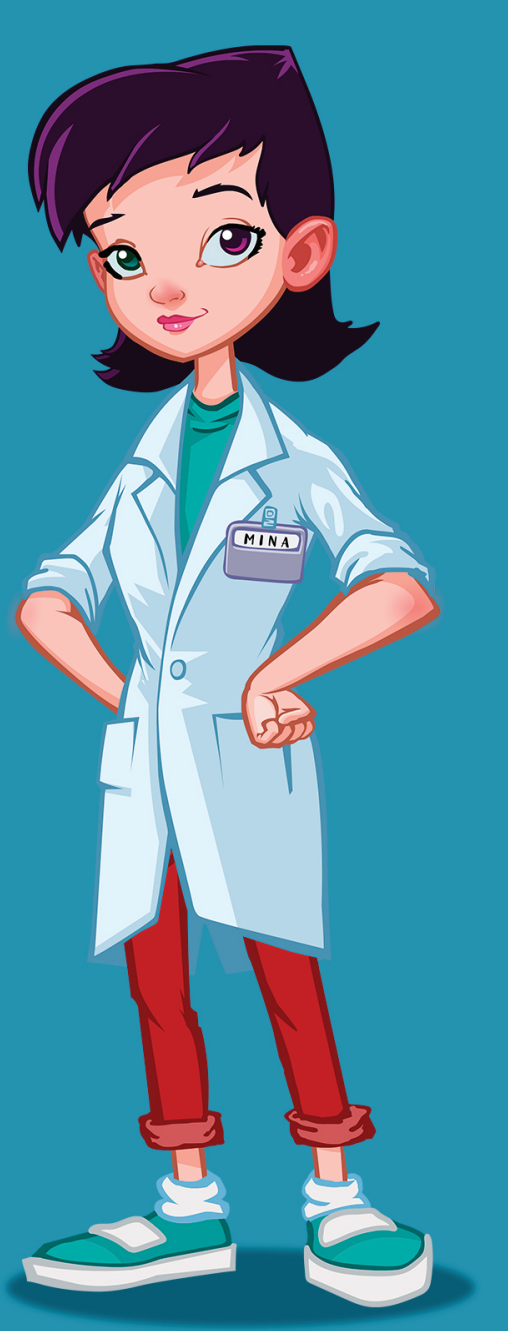

Anka Nieuwhof-Leppink 
○

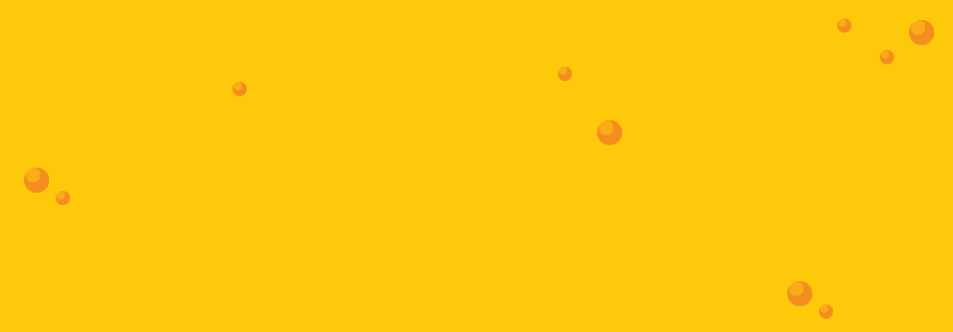

๑

$0^{0}$

-

。

$0^{0}$

$e^{\ominus}$

๑

-



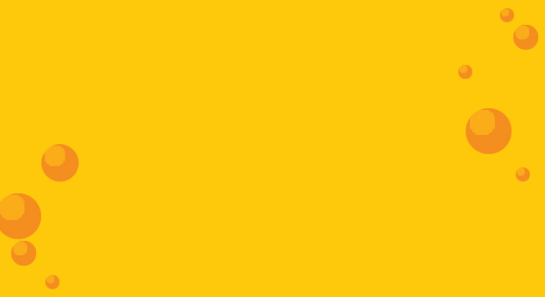

○

$0^{\infty}$

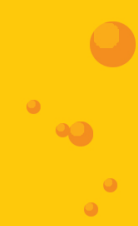

0

0

อ

a

O

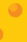

$\ominus$

-<smiles>[Co]Cc1ccccc1</smiles> 


\section{Urotherapy: a critical evaluation}

Anka Nieuwhof-Leppink 
Cover

Layout

Printing

ISBN
Dimme | Monkeybizniz

Renate Siebes | Proefschrift.nu

ProefschriftMaken.nl

978-90-393-7281-4

\section{(C) 2020 Anka Nieuwhof-Leppink}

All rights reserved. No part of this publication may be reproduced or transmitted in any form or by any means, electronically or mechanically, including photocopying, recording, or any information storage or retrieval system, without the prior permission of the author. 


\title{
Urotherapy: a critical evaluation
}

\author{
Urotherapie: een kritische evaluatie \\ (met een samenvatting in het Nederlands)
}

\begin{abstract}
Proefschrift
ter verkrijging van de graad van doctor aan de Universiteit Utrecht op gezag van de rector magnificus, prof.dr. H.R.B.M. Kummeling, ingevolge het besluit van het college voor promoties in het openbaar te verdedigen op donderdag 19 november 2020 des middags te 12.45 uur

door
\end{abstract}

Antje Janke Nieuwhof-Leppink

geboren op 13 januari 1975

te Delfzijl 
Promotoren:

Prof.dr. T.P.V.M. de Jong

Prof.dr. E.M. van de Putte

Copromotor:

Dr. R. Schappin 


\section{Contents}

PART 1: WHAT IS FUNCTIONAL INCONTINENCE AND HOW TO TREAT IT?

Chapter 1 General introduction 9

Chapter 2 Daytime urinary incontinence in children and adolescents $\quad 19$

PART 2: RESULTS OF SPECIALIZED UROTHERAPY

Chapter 3 Central inhibition of refractory overactive bladder complaints:

Results of an inpatient training program

PART 3: A CRITICAL APPRAISAL AND INNOVATIONS IN UROTHERAPY

Chapter 4 SENS-U: clinical evaluation of a full bladder notification -

A pilot study

Chapter 5 Pelvic floor rehabilitation in children with functional LUTD:

Does it improve outcome?

Chapter 6 Does a serious game increase intrinsic motivation in children receiving urotherapy?

\section{PART 4: DISCUSSION}

Chapter $7 \quad$ General discussion

Summary

Samenvatting (Summary in Dutch)

Dankwoord

About the author

Curriculum vitae

Publications 



\section{What is functional incontinence
and how to treat it? What is functional incontinence
and how to treat it?

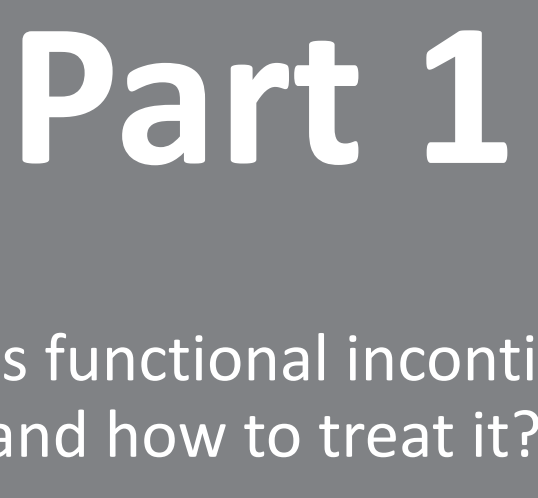 \\ What is functional incontinence
and how to treat it? \\ What is functional incontinence
and how to treat it?}

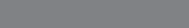

(1)

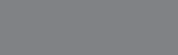

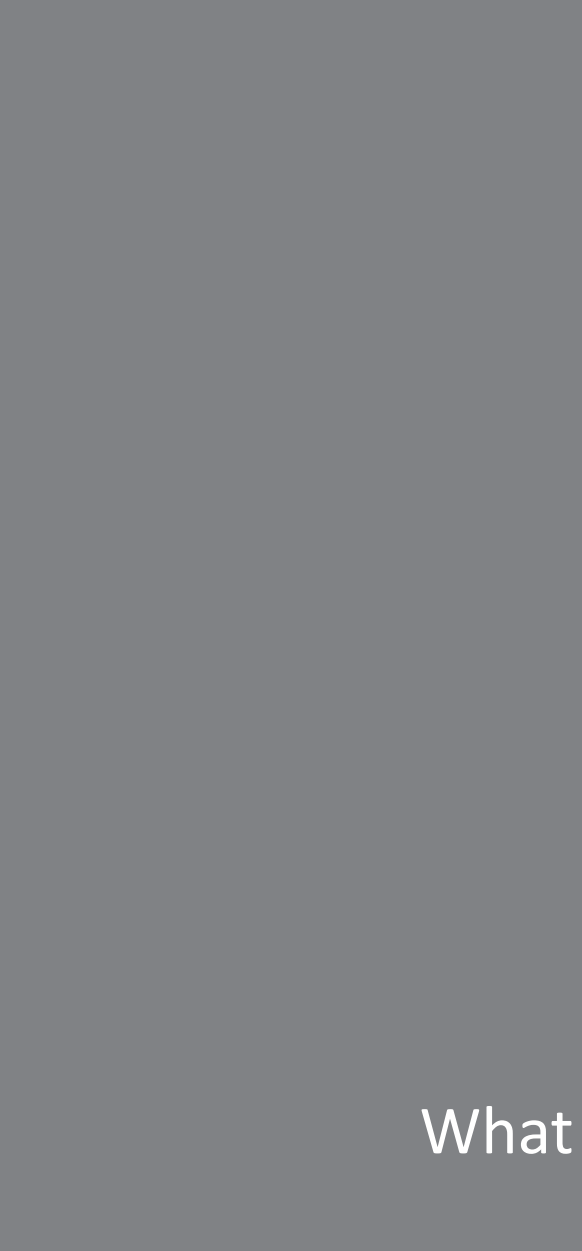

(a)

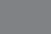

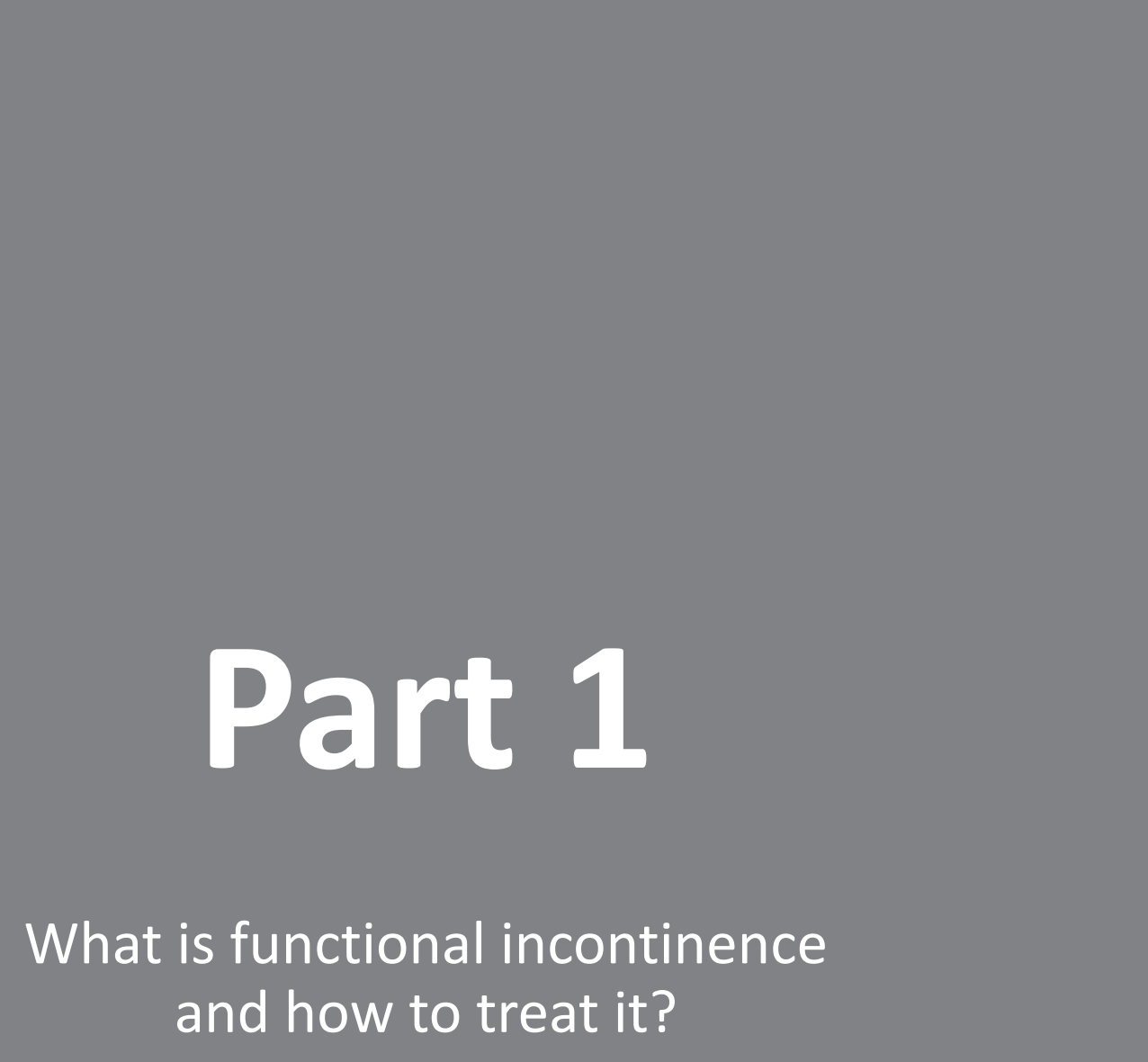

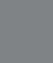

(1)

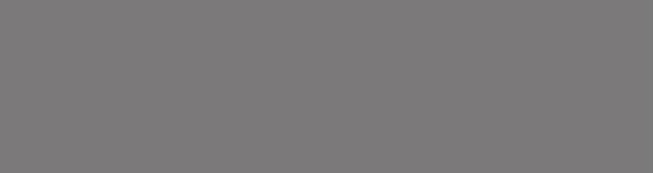

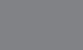

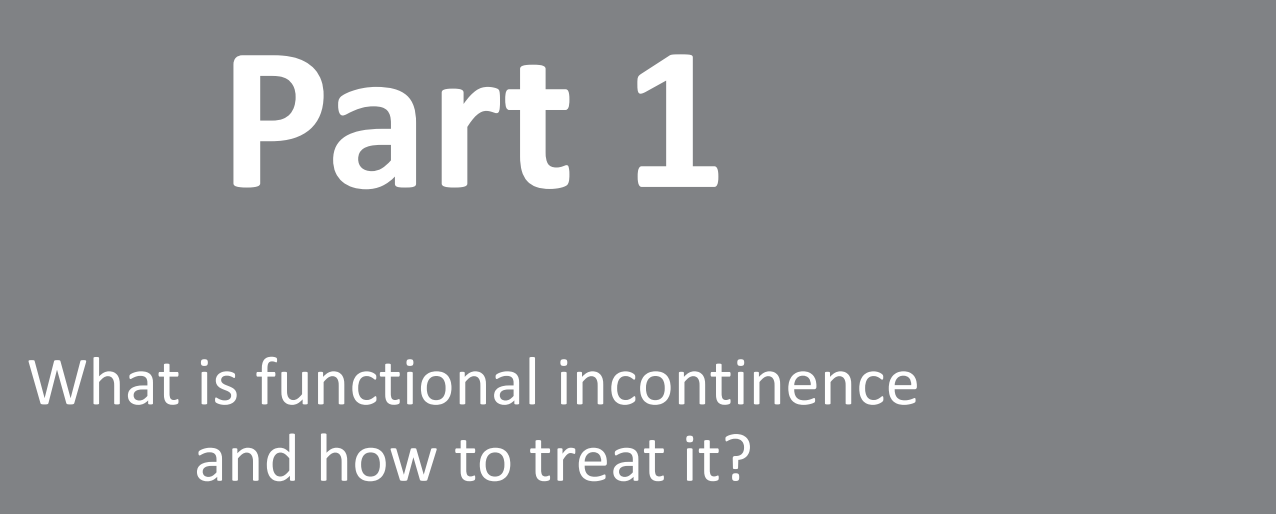



General introduction 



\section{GENERAL INTRODUCTION}

Toilet training is an important developmental milestone that most children accomplish with the assistance of their parents and caregivers. It is not always easy to achieve and many parents seek advice from family and friends. When serious toilet training problems arise, parents often turn to their general practitioner for help. ${ }^{1}$ Children who have been toilet trained should be able to control their bladder and bowels. When wetting accidents still occur regularly at age 5 years or older, this is called incontinence.

The definition of functional urinary incontinence is the unintentional passing of urine, at least once a week, in children aged 5 years or older. The term functional indicates that the incontinence is not caused by disease, injury, or congenital malformation. Functional incontinence implies incontinence due to imperative urge (strong desire to void) and/or improper contraction of the pelvic floor during emptying of the bladder which causes children to lose accurate recognition of their bladder signal. ${ }^{2}$ Functional incontinence is also called LUTD (lower urinary tract dysfuntion), which is the umbrella term for all bladder and sphincter dysfunctions.

\section{IMPACT OF INCONTINENCE}

Wetting accidents have a negative impact on children's self-esteem, they are felt as shameful and stressful. Incontinent children need to be continuously alert to prevent wetting accidents and to prevent their 'secret' becoming public. They have several coping strategies to protect themselves from the possible event of having wet pants. Most children try to deny or learn to neglect the problem or limit their fluid intake, while others prevent wetting accidents by frequent toilet visits. The latter strategy is specifically used by children with imperative urge incontinence or small bladder volumes. Their frequent toilet visits single them out, especially in the classroom.

Incontinence also induces stress in parents. They are concerned about the physical and emotional wellbeing of their child. Parents may feel guilty and embarrassed about failing toilet training. Furthermore, parents are worried about the social implications such as avoidance of social activities by their children because of the wetting accidents. Another frequently expressed parental concern is that their child will be bullied.

Lack of parents' understanding of the causes of incontinence may frustrate children and therefore play a role in sustaining incontinence. For example, when children with urge incontinence show typical holding manoeuvres parents will naturally send them to the toilet, while children know from experience that moving during urge will cause leaking 
and they know that usually the urge will disappear by itself. ${ }^{1,3,4}$ Parents need to understand that their child has a legitimate problem that is not under the child's control, and that treatment is necessary and usually effective. The assumption that incontinence is the result of psychological issues needs to be refuted. Although psychological symptoms such as anxiety and depression are often associated with urinary incontinence, it is important that parents know that psychological distress is not a cause but can be a consequence of incontinence.

In school, misapprehension may also play a role in sustaining incontinence and incorrect voiding behaviour. For example, strict rules about leaving the classroom to go to the toilet may cause postponement behaviour. In addition, dirty toilets or partially open toilet doors can make the toilet a no-go area for many children and adolescents. ${ }^{5-7}$

\section{UROTHERAPY}

Treatment of incontinence is often effective and increases the quality of life of children and their parents, improves skills to deal with symptoms, and helps to increase self-confidence.

When anatomical and neurological causes are ruled out, children with incontinence are first treated with standard urotherapy. The aim is to cure or alleviate incontinence and comorbid symptoms of lower urinary tract dysfunction. Urotherapy is a profession, as well as a practice, which has become the preferred treatment not only for daytime urinary incontinence, but also for children with recurrent urinary tract infections, nocturnal enuresis, functional constipation, and faecal incontinence. ${ }^{8}$ Urotherapy is an effective treatment which achieves continence in $56 \%$ of children within a year, whilst the spontaneous cure rate of incontinence is $15 \%$ per year. ${ }^{9}$

In our third line referral center, children with treatment-resistant daytime incontinence symptoms receive specific urotherapy tailored to their type of lower urinary tract dysfunction. Specific urotherapy is the topic of this thesis and has been given in our hospital since 1982. It consists of a personalized inpatient program which may include: alarm treatment, pelvic floor rehabilitation, biofeedback training, neurostimulation, or clean intermittent catheterization. This may be supported by pharmaceutical treatment of bladder overactivity, constipation and urinary tract infections. ${ }^{10,11}$ The effectiveness of specific urotherapy in our center has been previously published, with a success rate of approximately $70 \%$ shortly after the end of treatment and $75 \%$ success at long-term follow-up. ${ }^{11-13}$ 


\section{A SHORT HISTORY OF INCONTINENCE TREATMENT}

At the beginning of the $20^{\text {th }}$ century, treatment of incontinence in children focused on bedwetting. Children were successfully treated with different versions of the original Mower (1938) wet alarm pad. During alarm pad treatment, the child slept on a pad which could detect moisture. When the child started voiding, the pad set off an alarm to wake the child so that the child can stop voiding and go to the toilet. Mower proposed that the underlying behavioural mechanism was Pavlovian conditioning, in which conscious sphincter contraction eventually led to automatic sphincter contraction upon the alarm. ${ }^{14}$ This treatment was further developed and refined in the 1960s and 1970s. ${ }^{15}$ The theoretical explanation for successful bedwetting treatment shifted from a Pavlovian model aimed at correcting physiological reflexes to a model of operant conditioning. Azrin and Fox (1974) developed the 'dry bed method' in which they combined alarm treatment and positive reinforcement for correct voiding behaviour. ${ }^{16}$ Other aspects of this method were increasing the child's motivation to become dry, training in rapid awakening, practising toileting, increasing fluid intake, and self-correction of accidents (changing wet sheets). ${ }^{17}$

In the 1980s, the dry bed method evolved and physiological interventions such as resisting urge and thus increasing bladder volume (retention control training) were added. The latter was also the treatment for children with daytime incontinence. Practitioners observed a difference in the effectiveness of wet bed alarm treatment with or without retention control training for children with daytime and nighttime wetting. ${ }^{18,19}$ Fielding found that alarm training alone was effective for children with nighttime wetting, but that alarm training with retention control training was even more effective. ${ }^{18}$ For children with daytime wetting, alarm training plus retention control training had limited effects. Given this, it became clear that daytime incontinence was not only caused by small bladder volumes. This insight led to a growing recognition that daytime and nighttime wetting required different treatment regimens. ${ }^{20}$

The introduction of urodynamics provided new insights into the physical components of incontinence. ${ }^{21}$ It became possible to measure and to define normal and obstructed voiding, which led to a reappraisal of earlier, more psychological notions of incontinence and the introduction of medication. Urodynamics showed that incontinent children often had bladder and/or sphincter dysfunction. ${ }^{22}$ Two main categories were distinguished: detrusor activity during the filling phase of the bladder (instead of when the bladder is full; overactive bladder) and inappropriate pelvic floor contractions during the emptying phase of the bladder (instead of relaxation; dysfunctional voiding). ${ }^{23}$ 
In the 1990s, the treatment of incontinence became an interplay between physical and behavioural components. Bladder rehabilitation programs for daytime wetting were first described by Hellström in Gothenburg and Vijverberg in Utrecht. ${ }^{20,11,24}$ The term urotherapy was introduced as the non-pharmacological treatment of functional incontinence. Urotherapy concerns the relearning and training of normal responses to bladder signals.

In recent years, spurred by increasing evidence of its effectiveness, urotherapy has become the treatment of choice for functional incontinence problems in children.

\section{THE FUTURE OF INCONTINENCE TREATMENT}

Although urotherapy is successful, the success rate is not $100 \%$ and the treatment is intensive and lengthy. New technologies provide multiple opportunities to improve urotherapy. Through multimedia, children and their parents can always access up-todate information about incontinence and treatment in both written and visual (pictures, video's) form. Furthermore, online bladder diaries and output from wearable devices can be directly sent to the urotherapist, enabling the direct adjustment of treatment to the child's progress.

Specific urotherapy will shift from inpatient treatment to treatment at home, making this treatment for children with treatment-resistant incontinence more widely available. Further development of portable flowmetry and wearable devices such as continuous ultrasound to monitor bladder filling can provide specialist information at home. When linked to a bladder-training app that visualizes toilet visits and voiding volumes, children receive direct feedback about their voiding behaviour. When the urotherapists also receives this information, she can provide coaching just as she would during inpatient treatment. Shaping the bladder-app into a serious game with an interactive story may keep children involved during the training period. In such a game, the story only develops when the child reaches training goals, helping children to sustain treatment and improve adherence.

Despite all technological innovations, for an effective treatment, the attention for the child's problem and the therapeutic relationship will always be of paramount importance. ${ }^{26}$ The therapist is able to look closely to the child, his problems, and his environment, and uses this to adapt treatment to be most effective for each unique child. 


\section{CONTENT OF THE THESIS}

The aim of this thesis was to study specific urotherapy as treatment of functional incontinence in children, to improve our care for incontinent children. This thesis is written from a clinical, psychological, and urological point of view in a third line healthcare setting.

Part I, What is functional incontinence and how to treat it, concerns the etiology, definition, and treatment of daytime urinary incontinence. Chapter 2: Daytime incontinence in children and adolescents, is a review that provides an overview of recent literature about functional incontinence and its treatment from a urological, paediatric, and urotherapeutic point of view.

In Part II, Results of specific urotherapy, the outcome of specific inpatient urotherapy for children with overactive bladder problems are evaluated. Chapter 3: Central inhibition of refractory overactive bladder complaints, results of an inpatient training program presents the effectiveness of central inhibition training in the Wilhelmina Children's Hospital.

Part III, A critical appraisal and innovations in urotherapy discusses current practices and innovations in urotherapy. Chapter 4: Pelvic floor rehabilitation in children with functional LUTD: does it improve outcome? presents the additional effect of intensive pelvic floor rehabilitation on inpatient urotherapy in children with daytime incontinence. Chapter 5: SENS-U: clinical evaluation of a full-bladder notification - a pilot study is a feasibility study on the efficacy of a wearable ultrasound for continuous bladder monitoring. Chapter 6: Does a serious game increase intrinsic motivation in children receiving urotherapy? describes whether a bladder training app improves intrinsic motivation to adhere to treatment in children receiving urotherapy. Disease-specific quality of life after urotherapy treatment is also reported.

Part IV, Overview provides an overview of the findings presented in this thesis followed by a discussion on future prospects. Chapter 7: General discussion summarizes the research in this thesis and provides a general discussion about the findings. 


\section{REFERENCES}

1. Jansson UB, Danielson E, Hellström AL. Parents' Experiences of Their Children Achieving Bladder Control. J Pediatr Nurs 2008; 23(6): 471-8.

2. Austin PF, Bauer SB, Bower W, Chase J, Franco I, Hoebeke P, et al. The standardization of terminology of lower urinary tract function in children and adolescents: Update report from the standardization committee of the International Children's Continence Society. Neurourol Urodyn 2016; 35(4): 471-81.

3. Kodman-Jones C, Hawkins L, Schulman SL. Behavioral characteristics of children with daytime wetting. J Urol 2001; 166(6): 2392-5.

4. Thibodeau BA, Metcalfe P, Koop P, Moore K. Urinary incontinence and quality of life in children. J Pediatr Urol 2013; 9(1): 78-83.

5. Kistner M. Dysfunctional elimination behaviors and associated complications in school-age children. J Sch Nurs 2009; 25(2): 108-16.

6. Lundblad B, Hellström AL. Perceptions of school toilets as a cause for irregular toilet habits among schoolchildren aged 6 to 16 years. J Sch Health 2005; 75(4): 125-8.

7. Vernon S, Lundblad B, Hellstrom AL. Children's experiences of school toilets present a risk to their physical and psychological health. Child Care Health Dev 2003; 29(1): 47-53.

8. Chang S, Van Laecke E, Bauer SB, Von Gontard A, Bagli D, Bower WF, et al. Treatment of Daytime Urinary Incontinence: A Standardization Document From the International Children's Continence Society. Neurourol Urodyn 2017; 36(1): 43-50.

9. Schäfer SK, Niemczyk J, von Gontard A, Pospeschill M, Becker N, Equit M. Standard urotherapy as first-line intervention for daytime incontinence: a meta-analysis. Eur Child Adolesc Psychiatry 2018; 27(8): 949-64.

10. Chang S-J, Van Laecke E, Bauer SB, von Gontard A, Bagli D, Bower WF, et al. Treatment of daytime urinary incontinence: A standardization document from the International Children's Continence Society. Neurourol Urodyn 2017; 36(1): 43-50.

11. Vijverberg MA, Elzinga-Plomp A, Messer AP, van Gool JD, de Jong TP. Bladder rehabilitation, the effect of a cognitive training programme on urge incontinence. Eur Urol 1997; 31(1): 68-72.

12. Vijverberg MAW, Stortelder E, De Kort LMO, Kok ET, De Jong TPVM. Long-term follow-up of incontinence and urge complaints after intensive urotherapy in childhood (75 patients followed up for 16.2-21.8 years). Urology 2011; 78(6): 1391-6.

13. Meijer EFJ, Nieuwhof-Leppink AJ, Dekker-Vasse E, De Joode-Smink GCJ, De Jong TPVM. Central inhibition of refractory overactive bladder complaints, results of an inpatient training program. J Pediatr Urol 2015; 11(1): 21.e1-5.

14. Mowrer OH, Mowrer WM. Enuresis-A method for its study and treatment. Am J Orthopsychiatry 1938; 8(3): 436-59.

15. Peterson RA, Wright RLD, Hanlon CC. The effects of extending the CS-UCS interval on the effectiveness of the conditioning treatment for nocturnal enuresis. Behav Res Ther 1969; 7(4): 351-7.

16. Azrin NH, Sneed TJ, Foxx TM. Dry-Bed Training : Rapid Elimination Childhood Enuresis. Behav Res Ther 1974; 12: 147-56.

17. van Londen A, van Londen-Barentsen MWM, van Son MJM, Mulder GALA. Arousal training for children suffering from nocturnal enuresis: a 2 1/2 year follow-up. Behav Res Ther 1993; 31(6): 613-5.

18. Fielding D. An analysis of the behaviour of day- and night-wetting children: Towards a model of micturition control. Behav Res Ther 1982; 20(1): 49-60. 
19. Fielding $\mathrm{D}$. The response of day and night wetting children and children who wet only at night to retention control training and the enuresis alarm. Behav Res Ther 1980; 18(4): 30517.

20. Kruse S, Hellström AL, Hjälmås K. Daytime bladder dysfunction in therapy-resistant nocturnal enuresis: A pilot study in urotherapy. Scand J Urol Nephrol 1999; 33(1): 49-52.

21. Bael A, Lax H, de Jong TPVM, Hoebeke P, Nijman RJM, Sixt R, et al. The Relevance of Urodynamic Studies for Urge Syndrome and Dysfunctional Voiding: A Multicenter Controlled Trial in Children. J Urol 2008; 180(4): 1486-93.

22. Sugar EC, Firlit CF. Urodynamic Biofeedback: A New Therapeutic Approach for Childhood Incontinence/Infection (Vesical Voluntary Sphincter Dyssynergia). J Urol 1982; 128(6): 12538.

23. van Gool JD, De Jonge GA. Urge syndrome and urge incontinence. Arch Dis Child 1989; 64: 1629-34.

24. Hellstrom AL, Hjalmas K, Jodal U. Rehabilitation of the dysfunctional bladder in children: Method and 3-year followup. J Urol 1987; 138(4): 847-9.

26. Hoebeke P. Twenty years of urotherapy in children: What have we learned? Eur Urol 2006; 49(3): 426-8. 



\section{Daytime urinary incontinence in children and adolescents}

Anka J. Nieuwhof-Leppink Rogier P.J. Schroeder Elise M. van de Putte Tom P.V.M. de Jong Renske Schappin 
Daytime urinary incontinence is common in the paediatric population and affects approximately $7-10 \%$ of children (aged 5-13 years). Several subtypes of daytime incontinence, which are classified according to their relation to the storage and voiding phases of bladder function, exist. Risk factors for these subtypes of incontinence can be genetic, demographic, environmental, behavioural, or physical. Therefore, treatment is multidisciplinary and needs an adequate diagnosis to be successful. Urotherapy is the first-line treatment for all types of daytime incontinence. It can be defined as bladder re-education or rehabilitation, aiming at correcting the filling and voiding function of the bladder-sphincter unit. Comorbid problems, such as constipation, urinary tract infections, and behavioural problems should also be treated during urotherapy. For comorbidities and severe bladder overactivity, medication might be necessary. Although usually effective, treatment of daytime urinary incontinence in children is often complex and requires patience. Nonetheless, patients and parents are usually motivated for urotherapy, since quality of life is severely reduced in in children with incontinence. 


\section{BACKGROUND}

Lower urinary tract dysfunction is a broad term that encompasses subsets of bladder and sphincter dysfunction with different manifestations. The disorder is defined as a condition involving abnormalities during filling or emptying of the bladder and can come with urinary incontinence, urge complaints, or urinary tract infections. In most cases, paediatric lower urinary tract dysfunction occurs in children without anatomical or neurological lesions. Rarely, the disorder is part of underlying anatomical or neurological anomalies. About $10 \%$ of school-age children (aged $5-13$ years) are seen by a specialist for recurrent urinary tract infections, urinary incontinence, or both because of non-neurogenic lower urinary tract dysfunction. Quality of life is often severely reduced in these children.

In this Review, we discuss the prevalence, diagnosis, and management of lower urinary tract dysfunction in children and adolescents.

\section{SUBTYPES OF LOWER URINARY TRACT DYSFUNCTION}

The International Children's Continence Society (ICCS) recommends the term bladder and bowel dysfunction for a combination of bladder and bowel disturbances. Bladder and bowel dysfunction is an umbrella term that can be subcategorised into lower urinary tract dysfunction and bowel dysfunction. ${ }^{1,2}$ Lower urinary tract dysfunction symptoms are classified according to their relation to the storage and voiding phases of bladder function. Lower urinary tract symptoms can manifest as urgency, frequency, incontinence, or recurrent urinary tract infection. The possible diagnoses in children with lower urinary tract symptoms are overactive bladder, dysfunctional voiding, underactive bladder, voiding postponement, stress incontinence, giggle incontinence, vesico-vaginal incontinence, and enuresis nocturna (Table 2.1). , $^{3,4}$

Overactive bladder is characterised by symptoms of urgency, with or without frequent urinary incontinence (the involuntary loss of urine associated with urgency) or enuresis nocturna. According to ICCS guidelines, the diagnosis of overactive bladder does not require a test such as urodynamics. Autonomic dysfunction (detrusor overactivity) can be of crucial importance in the pathogenesis of overactive bladder in childhood and can be evaluated with cystometrics. ${ }^{4,5}$

The dysfunctional voiding subtype occurs often in girls and rarely in boys. The subtype is associated with repeated contractions of the pelvic floor muscles or urethral sphincter during voiding. Consequently, children show prolonged staccato micturition with subsequent residual urine after voiding, increasing the risk of urinary tract infection. 
Table 2.1: Symptoms and signs of four main subtypes of lower urinary tract dysfunction

\begin{tabular}{lll}
\hline & Symptoms & Signs \\
\hline Overactive bladder & $\begin{array}{l}\text { (Cystometric) detrusor overactivity, } \\
\text { frequency, voiding urgency, } \\
\text { incontinence, constipation, enuresis }\end{array}$ & $\begin{array}{l}\text { Holding maneuvers, normal flow } \\
\text { pattern, thick bladder wall, low- } \\
\text { volume voids }\end{array}$ \\
Dysfunctional voiding & $\begin{array}{l}\text { Failure to relax the sphincter during } \\
\text { voiding, normal micturition } \\
\text { frequency, incontinence, } \\
\text { constipation, urinary tract infections, } \\
\text { enuresis }\end{array}$ & $\begin{array}{l}\text { Post-void residue, staccato or } \\
\text { interrupted flow pattern, normal } \\
\text { frequency of voids }\end{array}$ \\
& $\begin{array}{l}\text { (Cystometric) weak detrusor } \\
\text { contractions, low micturition } \\
\text { frequency, incontinence, } \\
\text { constipation, urinary tract infections }\end{array}$ & $\begin{array}{l}\text { Post void residue, staccato or } \\
\text { interrupted flow pattern, frequent } \\
\text { large-volume voids }\end{array}$ \\
& $\begin{array}{l}\text { Low micturition frequency, } \\
\text { incontinence }\end{array}$ & Normal flow pattern \\
\hline
\end{tabular}

Classification of daytime lower urinary tract dysfunction, assessment and documentation should be based on following parameters; incontinence (presence or absence, and symptom frequency), voiding frequency, voiding urgency, voided volumes, and fluid intake. ${ }^{3}$

Inability to perceive the filling state of both the bladder and the rectum characterises dysfunctional voiding, and incontinence occurs due to overflow as a result of voiding postponement or bladder overactivity in an overdistended bladder. ${ }^{2,4}$

The term underactive bladder substitutes the old term lazy bladder. This condition is characterised by insufficient or unsustained detrusor contraction during emptying. Children with underactive bladder do not feel that their bladder is full and needs emptying, resulting in incontinence due to overflow. Children might show infrequent micturition and an interrupted flow pattern. They need to strain during voiding and raise intra-abdominal pressure to initiate, maintain, or complete voiding. The residue after voiding is usually so large that recurrent urinary tract infections occur. A diagnosis of underactive bladder is usually confirmed with urodynamics. ${ }^{4,5}$

Voiding postponement has been defined as a habitual postponement of micturition using holding manoeuvres. Children might postpone because they do not want to interrupt activities like playing or gaming. Voiding postponement can present both as a symptom and a condition, and includes low micturition frequency, a feeling of urgency, and possibly incontinence from an overflowing bladder. ${ }^{4,6}$

Stress incontinence is the involuntary leakage of small amounts of urine upon physical exertion that increases intra-abdominal pressure, for example coughing or sneezing. 
Giggle incontinence is a rare condition in which extensive emptying or leakage occurs during or immediately after laughing, although bladder function is otherwise normal. For both stress and giggle incontinence, exact causes are unknown.

Vesico-vaginal (or urethro-vaginal) reflux is a condition which typically occurs in prepubescent girls. The urinary stream is directed towards the vagina because of the position of the urethral opening, entrapment of urine by the labia, or poor toilet posture with compression by the thighs. Wetting occurs later, frequently during physical activities, when trapped urine leaks from vagina. The hallmark of this condition is post-void wetting.

Besides daytime urinary incontinence, there is also nocturnal enuresis, which is defined as all urinary incontinence during sleep. Monosymptomatic nocturnal enuresis means bedwetting without any other lower urinary tract symptoms, and non-monosymptomatic nocturnal enuresis represents bedwetting with any daytime lower urinary tract symptoms. ${ }^{3}$ Three main causes of nocturnal enuresis have been identified: nocturnal polyuria, detrusor overactivity, and an increased arousal threshold during sleep. ${ }^{7}$

\section{PREVALENCE OF DAYTIME INCONTINENCE}

Daytime urinary incontinence is common in the paediatric population, but determining the exact prevalence is difficult since bladder control develops gradually during childhood. Over the past 25 years, 19 studies documented the prevalence of daytime urinary incontinence. ${ }^{8}$ The overall prevalence rate of any daytime urinary incontinence in 7-year-old children varies from $3.2 \%$ to $9.0 \%,{ }^{9-13}$ and approximately $1.0 \%$ have severe (daily) daytime urinary incontinence. ${ }^{14}$ In children aged $11-13$ years, prevalence is lower: between $1.1 \%$ and $4.2 \%$, decreasing to $1.2-3.0 \%$ at $15-17$ years. ${ }^{9,15}$ Prevalence is higher in girls than boys, probably because of anatomical differences. ${ }^{10-12,15}$ Persistent wetting in childhood is associated with an increased risk of daytime incontinence in adolescence and even adulthood, although prevalence of the disorder at these older ages is low. ${ }^{11,15}$ Similarities between the two largest cohort studies from the UK and Korea show an increase in daytime urinary incontinence in children between 5 years and 9 years of age. ${ }^{11,14}$ The UK study found that daytime incontinence is common between 4.5 and 9.5 years of age. ${ }^{11}$ The prevalence of any daytime urinary incontinence declined from $15.5 \%$ at 4.5 years of age to $4.9 \%$ at 9.5 years of age. ${ }^{11}$ Prevalence of daytime urinary incontinence in the Korean cohort of children aged 5-13 years was $11.2 \%$, and prevalence of urge incontinence was $16.8 \%$. The prevalence of any daytime urinary incontinence declined from $31 \%$ at 5 years of age to $13.7 \%$ at 9 years of age. ${ }^{14}$ 
Comparisons between these types of studies are difficult because of differing age groups and definitions of urgency, frequency, and severity of incontinence. Most studies are cross-sectional and are based on proxy reports from parents. Variations in prevalence might also result from cultural differences.

Lower urinary tract dysfunction often coexists with constipation. Either constipation or faecal incontinence is present in one in three children with daytime urinary incontinence. ${ }^{13,14,16}$ Daytime incontinence occurs in association with nocturnal enuresis. Nocturnal enuresis is a common condition that affects approximately one of ten 7-year-old children. ${ }^{17}$

\section{RISK FACTORS FOR LOWER URINARY TRACT SYMPTOMS}

Multiple factors associated with lower urinary tract dysfunction have been identified, but consensus on which are important does not exist. Risk factors can be divided into genetic, demographic, environmental, behavioural, and physical.

Nocturnal enuresis and subtypes of daytime urinary incontinence appear to be heritable. Family studies have repeatedly shown that nocturnal enuresis is a highly familial disorder. Approximately $20-40 \%$ of fathers, $20-25 \%$ of mothers, and $60-70 \%$ of relatives of children with nocturnal enuresis also experienced night-time wetting. ${ }^{17}$ An association also exists between overactive bladder symptoms in children and their parents. ${ }^{17-19}$

Demographic and environmental factors, such as family history and female gender are also associated with daytime incontinence. Daytime urinary incontinence in a child's father or brother increases the risk of occurrence-parents of children with an overactive bladder and dysfunctional voiding have had similar symptoms in their own childhoodas does being female. ${ }^{19,20}$ The effect of socioeconomic status and educational level on the prevalence of lower urinary tract dysfunction varies, but low socioeconomic status and low educational level seem to be risk factors for daytime urinary incontinence. ${ }^{9,21}$ Attending school might also be a risk factor for daytime urinary incontinence since school teachers might limit bathroom use leading to voiding postponement, and children often have a negative perception of school toilets..$^{22,23}$

Behavioural causes of daytime urinary incontinence might also exist. In children whose wetting was frequent, studies found double the prevalence of problems associated with anxiety, attention, hyperactivity, oppositional behaviour, and conduct compared with the general population. ${ }^{24,25}$ Children with daytime urinary incontinence also exhibit sensorymotor difficulties, which could explain both behavioural problems and an inability to adequately act upon bladder signals. ${ }^{26}$ 
A physical cause of daytime urinary incontinence can be benign generalised joint hypermobility, which occurs in approximately $15 \%$ of school age children. ${ }^{27,28}$ Children with generalised joint hypermobility seem to have a higher prevalence of voiding dysfunction than otherwise healthy children, probably due to their lax pelvic floor ligaments. In girls with generalised joint hypermobility, the prevalence of daytime urinary incontinence, nocturnal enuresis, and urinary tract infection is higher than in otherwise healthy girls. ${ }^{29}$ For boys with generalised joint hypermobility, constipation and faecal incontinence are more prevalent. ${ }^{29}$

Another physical cause of voiding problems is obesity, which can cause constipation due to dietary habits, low activity, hormonal effects, and autonomic dysfunction. Obesity is associated with lower urinary tract symptoms, but this association is probably mediated by the higher rate of constipation. . $^{30,31}$

\section{DIAGNOSTICS}

The diagnosis lower urinary tract dysfunction can be made based on history, physical examination, uroflowmetries, non-invasive ultrasound, and voiding diaries (Appendix 2.1). ${ }^{5}$ The cornerstone of good diagnostics is primarily an extensive micturition history. Frequency, urgency, when and how incontinence occurs, ways of dealing with bladder overactivity, history of febrile urinary tract infections, and toileting position, all need to be assessed. Defaecation history focused on the Rome IV criteria for constipation should also be considered. ${ }^{2}$ Because of a high rate of comorbid behavioural disorders in children with incontinence, screening for psychological symptoms should also be considered. ${ }^{5,6}$ In girls, special attention needs to be given to the direction of the urinary stream. Lower urinary tract dysfunction might be provoked by an anteriorly deflected urinary stream, due to triggering of the bulbocavernosus reflex by the stream on the clitoris, or by breaking the stream unconsciously with the pelvic floor to prevent wetting of legs, buttocks, and the toilet rim (Figure 2.1). ${ }^{32}$

A 2-day frequency and volume diary and a one-week defaecation diary are necessary to evaluate lower urinary tract dysfunction. A 7-night recording of night-time incontinence episodes should be used to evaluate enuresis., ${ }^{4,33} \mathrm{~A}$ complete bladder diary consists of a daytime frequency and volume chart, incontinence episodes, and night-time urine volume measurements. , $33,34^{2}$

The second step of diagnosis is physical examination of the abdomen and inspection of the genital regions to exclude congenital malformations. Special attention should be paid 

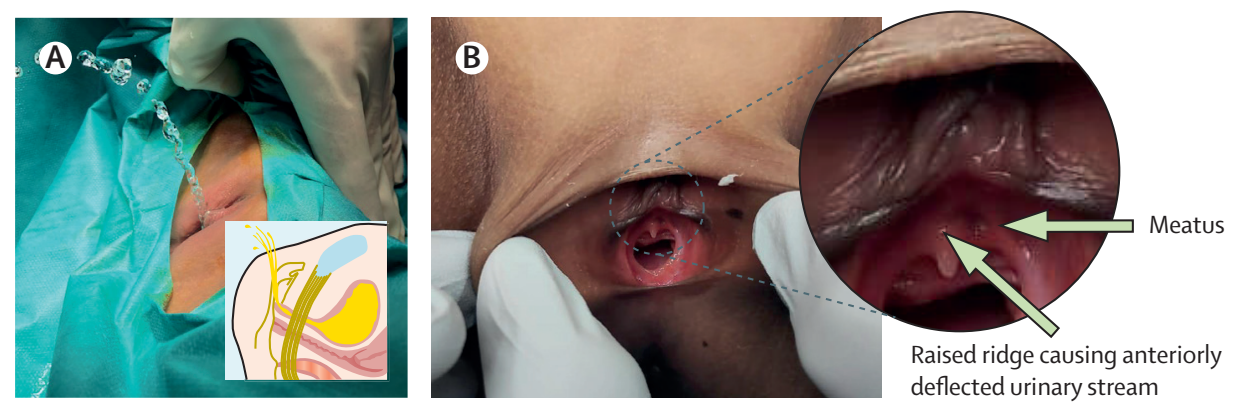

Figure 2.1: Anteriorly deflected urinary stream.

(A) Anterior direction of the stream. (B) Meatus with raised ridge at 6 o'clock.

to the lumbosacral region and lumbosacral neurology. ${ }^{34,35}$ Specific urogenital diagnoses (e.g., meatus stenosis) can be found upon physical examination.

As a third step, uroflowmetry should be done. This is the graphical recording of the urinary stream, which gives information on voided volume, flow time, velocity at start of the stream, maximal flow (expressed in $\mathrm{mL} / \mathrm{s}$ ), and flow pattern. Interpretation of the flow curve shape provides accurate information for diagnosis and treatment options. ${ }^{3} \mathrm{~A}$ normal flow will have a bell-shaped pattern and will be completed within $20 \mathrm{~s}$. Dysfunctional voiding typically comes with a staccato or interrupted flow pattern resulting in residual urine (Figure 2.2).

Adding electromyography to the uroflowmetry allows for the assessment of pelvic floor activity during voiding. The ICCS discourages uroflowmetry without electromyography, because an interrupted or staccato flow can also be caused by a non-relaxing external sphincter instead of pelvic floor activity. ${ }^{5}$ Furthermore, uroflowmetry with electromyography can distinguish between dysfunctional voiding and overactive bladder. In dysfunctional voiding, the electromyograph is active while in overactive bladder the electromyograph is quiet and the detrusor is overactive. Uroflowmetry alone, without the addition of pelvic floor electromyography, is inadequate and often misleading, resulting in inappropriate therapies. ${ }^{36}$ However, the reliability of electromyography alone is notorious, because electromyography can even be affected by posture, talking, breathing, and especially cross-talk from surrounding muscles. ${ }^{37}$ Ideally, after uroflowmetry an ultrasound is done to check residual urine in the bladder. According the ICCS at least two uroflowmetries with typical staccato or interrupted flow patterns, followed by an ultrasound to measure the residual urine, are needed to come to the diagnosis of dysfunctional voiding. ${ }^{3,4,35}$

Ultrasound can be used for more detailed diagnostic evaluations. Transabdominal ultrasound can be used to visualise the bladder, bladder wall thickness, an open or closed 

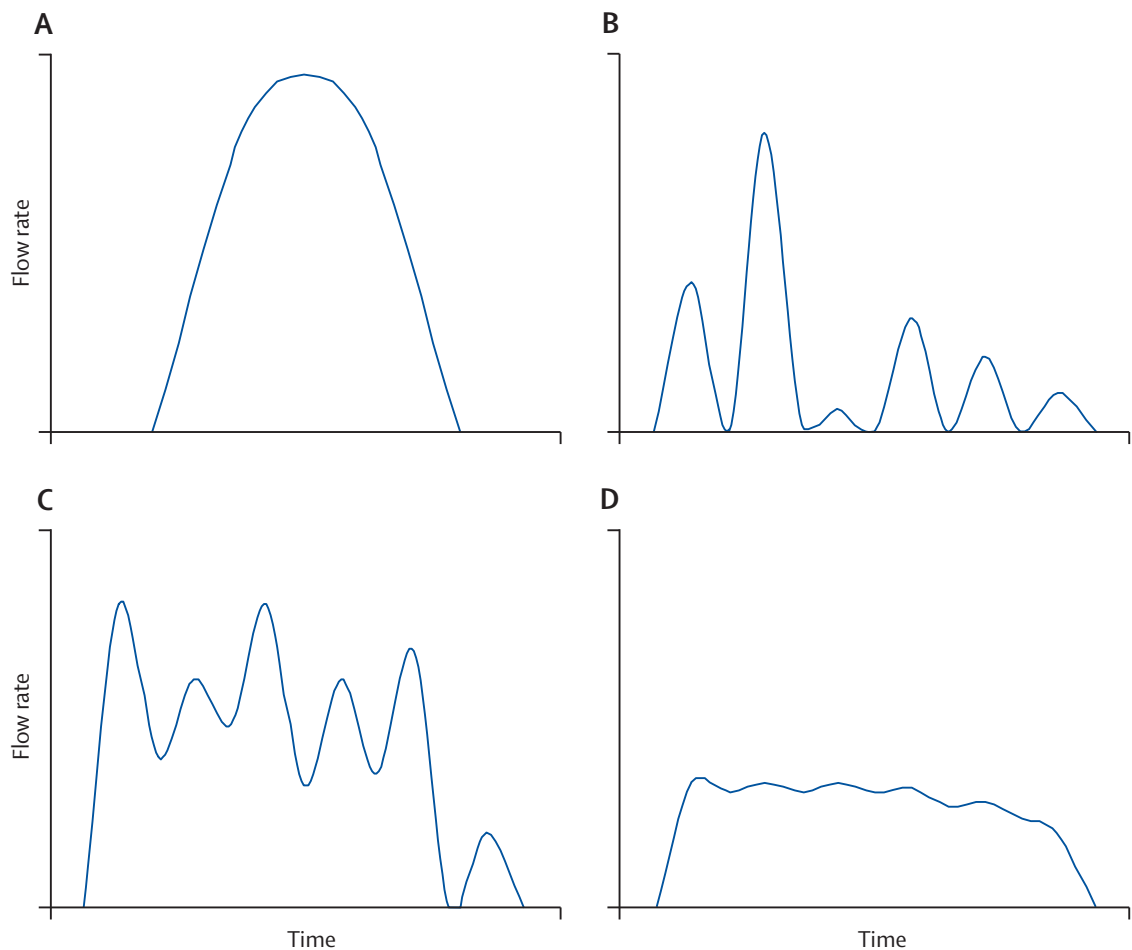

Figure 2.2: Flow patterns.

Four most common flow patterns. (A) Normal. (B) Fractioned. (C) Staccato. (D) Plateau.

bladder neck, the diameter of the rectum, and post-void residuals.38 The measurement of the transverse diameter of the rectum shows the presence or absence of rectal faecal impaction..$^{39-41}$ Ultrasound of the pelvic floor enables the visualisation and measurement of urethral length and pelvic floor musculature activity in real time. ${ }^{37,42,43}$ The most important information is whether or not the child is able to command the pelvic floor musculature at will. ${ }^{43}$

Invasive urodynamics should only be done when the outcome is likely to affect treatment or when conservative treatment is not successful. Cystometry and urodynamics (or video-urodynamics) are used for patients suspected of gross reflux, or refractory cases suspected of substantial bladder neck pathology. ${ }^{5}$ In boys, urodynamic studies can be done to detect high voiding pressures, which are indicative of urethral obstruction. Finally, during invasive video-urodynamic studies with fluoroscopy, the child can be asked to do a hold-up manoeuvre to detect whether the child can command the pelvic floor musculature correctly. 


\section{QUESTIONNAIRES}

Severity of lower urinary tract dysfunction can be assessed with several validated questionnaires. The Dysfunctional Voiding Symptom Score is the most commonly used tool to evaluate and monitor treatment progress. ${ }^{44,45}$ Often, simple tools such as bowel and bladder diaries provide enough information to evaluate lower urinary tract dysfunction. Furthermore, behavioural questionnaires and quality of life questionnaires are important tools to evaluate children's functioning. ${ }^{25,46}$ In 2018, the ICCS published an overview on existing tools for the assessment and measurement of bladder and bowel dysfunction. ${ }^{47}$

\section{PSYCHOLOGICAL ISSUES}

An increased rate of psychological and behavioural problems exists among children with lower urinary tract dysfunction. ${ }^{48,49}$ These issues interfere with treatment and result in less favourable outcomes. ${ }^{50}$ Whether the psychological and behavioural problems are a cause, a consequence, or have shared aetiology with daytime urinary incontinence is uncertain. Persistent wetting (day and night) in childhood is associated with increased psychosocial problems in adolescence. ${ }^{25,51}$ Approximately $20-40 \%$ of children with nocturnal enuresis and daytime urinary incontinence have clinically relevant behavioural problems either as a cause or result of nocturnal enuresis and daytime urinary incontinence. In the largest epidemiological study on lower urinary tract dysfunction, children with incontinence had increased rates of psychological disorders. ${ }^{11}$ The most common disorders were separation anxiety (11.4\%), attention deficit hyperactivity disorder (24.8\%), oppositional behaviour (10.9\%), and conduct problems (11.8\%)..$^{51}$

Children with attention deficit hyperactivity disorder have more extensive lower urinary tract symptoms. Furthermore, the disorder can negatively affect compliance and outcome. These children also have maturational deficits in the CNS that lead to problems with sensory processing, which might be the shared cause of both incontinence and attention deficit hyperactivity disorder. ${ }^{25,26,52}$ Additional studies have shown that children with autism spectrum disorder have increased rates of nocturnal enuresis and daytime urinary incontinence in comparison to healthy children. ${ }^{48,53}$

The psychological effects of lower urinary tract symptoms are important to understand. Quality of life is severely reduced in children with incontinence. ${ }^{54}$ Due to their symptoms, many children have low self-esteem, low self-confidence, and psychological distress. Incontinence affects a child's family life and social life. Children are at risk of social isolation, peer conflict, teasing, and classroom challenges. ${ }^{54,55}$ One study showed 
that bullying is significantly associated with childhood lower urinary tract symptoms, and affected children have more school-related anxiety than their peers without lower urinary tract symptoms. ${ }^{56}$ Associations between child defecation incontinence or urinary incontinence and abuse (including sexual abuse) exist but data are too scarce to make firm conclusions. To our knowledge, only two studies have been done, and both describe a significant association between constipation and physical, sexual, or emotional abuse. ${ }^{57}$ However, one study found that the soiling rate in the abused group differed significantly from the normative group, but not from a group of children with psychiatric problems. ${ }^{58}$ Only two studies assessed the association between abuse and urinary incontinence in children, both reported no difference between the proportion of incontinent children in the abused and non-abused groups..$^{59,60}$

\section{TREATMENT STRATEGIES}

The ICCS recommends urotherapy as first-line treatment for all types of daytime urinary incontinence. Urotherapy is a non-surgical, non-pharmacological treatment for lower urinary tract function involving bladder re-education or rehabilitation aimed at correcting the filling and voiding function of the bladder-sphincter unit. Studies on the effectiveness of urotherapy report success rates between $40 \%$ and $90 \% .{ }^{61,62} \mathrm{~A} 2018$ meta-analytic evaluation of incontinence interventions reported that urotherapy is an effective treatment for daytime urinary incontinence. ${ }^{63}$ However, no agreement exists on which elements of urotherapy are essential for its effectiveness. Focused attention to the problem from a trained professional seems to be key to success. Age also appears to be an important factor: children older than 8 years achieve better results than younger children. ${ }^{64} \mathrm{Children}$ younger than 6 years do not have sufficient body-awareness, discipline, or the ability to self-reflect. Therefore, these children should not receive intensive urotherapy, and instead, explaining to parents how to support their child is more important.

\section{Urotherapy}

Standard urotherapy combines education and demystification, behavioural modification instructions, lifestyle advice regarding fluid intake, registration of voiding frequencies, voiding volumes, and incontinence episodes, and support and encouragement for children and their parents. ${ }^{63}$ The therapy starts with an age-appropriate explanation of bladder and bowel function and dysfunction, to explain the causes of incontinence (Figure 2.3). Parents need to know that the child does not have the ability to stay dry. Overactive bladder is especially unpredictable for the child, who might be surprised by the occurrence 


\section{The wee factory}

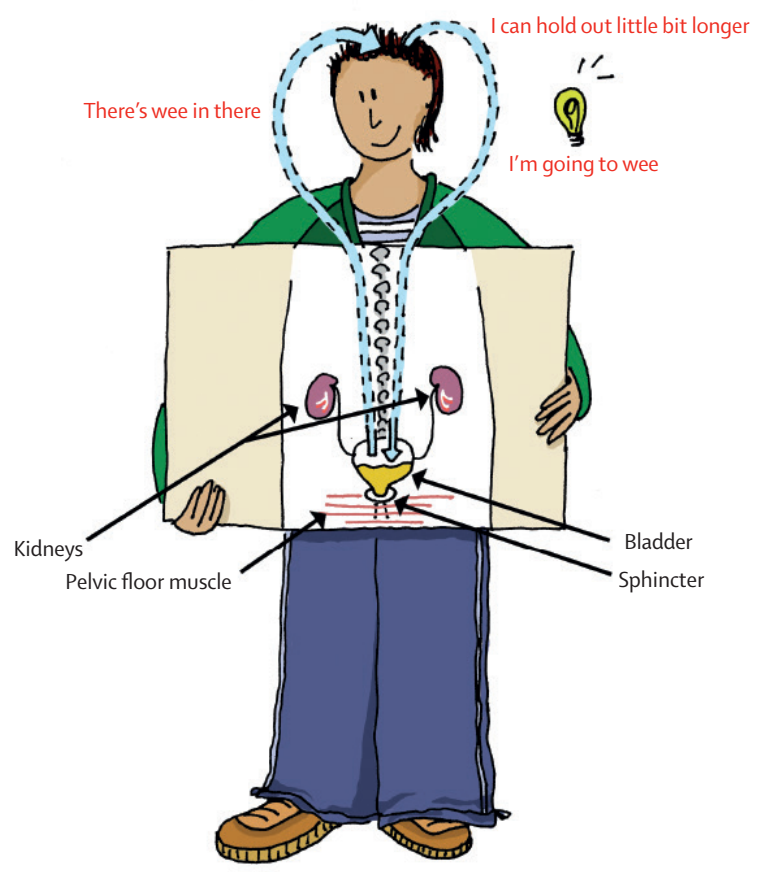

Figure 2.3: Example of an educational illustration.

A picture to explain to a child how a normal bladder works. Image credit: the Urotherapy team, Wilhelmina Children's Hospital, University Medical Center Utrecht, Utrecht, Netherlands.

of urgent sensations, which can only be stopped by a hold-up manoeuvre. Parents often perceive this action as a sign that the child knows when to urinate, but they must be helped to understand that this is not the case. Furthermore, instructions should be given on appropriate fluid intake and regular voiding during the day. Another part of urotherapy is explanation of the correct toilet posture, teaching a proper press-breathing technique (i.e., not pressing during voiding but breathing [or whistling] to prevent the child from contracting their abdominal or pelvic floor muscles during voiding), and advice to use a stepping stool for feet support. A bladder diary should be kept for self-monitoring and motivation, and to provide the child and parents with insight into treatment progress.

After introducing the elements of urotherapy to the child and their parents, the child practices at home for a maximum of three months. During this practice period, counselling is given during weekly follow-up appointments, which can be done in person, by telephone, or by email. Regular visits to the clinic are recommended to evaluate progress or to change the treatment plan, when necessary. 
Comorbid constipation should be addressed before treating daytime incontinence. Management of constipation and reduction of faecal impaction can reduce pressure on the bladder neck and urethra, causing lower urinary tract dysfunction. ${ }^{2,16,65}$ In addition, the educational components of constipation resemble those for urotherapy. In toilet training for constipation, the child is advised to go to the toilet for $5 \mathrm{~min}$ after meals to try to defecate. The results are recorded in a defecation diary, distinguishing between spontaneous defecation and planned daefecation during toilet-sit. This will help the child to relearn the sense of urgency. Besides toilet training, the importance of physical exercise for good motility of the intestines, healthy food, and sufficient drinking should be discussed. ${ }^{65} \mathrm{~A}$ minority of children have such a dilated rectum without sense of fillingstate that wash-out enemas are needed. ${ }^{41}$

Standard treatment of urinary tract infections by prophylaxis starts, in case of residuals as a causing factor, before the start of urotherapy. ${ }^{2,3}$ Treatment results can be objectively assessed on the basis of the ICCS criteria: no response (0-49\% reduction of symptoms), partial response (50-99\% reduction of symptoms, or complete response (100\% improvement). However, especially important for determining treatment success is the extent that the child and parents are satisfied with the results. Satisfaction and improved quality of life can be a reason to end treatment instead of persistently striving for optimal results. When treatment is not successful, identifying the reason is important, in order to avoid unnecessarily prolonged treatment. For example, young children might not have the cognitive skills or motor abilities to understand and complete the training, and children with comorbid behavioural problems such as attention deficit hyperactivity disorder might struggle with understanding and following instructions.

When the results of standard urotherapy are unsatisfactory, specific urotherapy is recommended. Specific urotherapy is multidisciplinary and combines specialist interventions such as biofeedback from the pelvic floor, cognitive behavioural therapy, psychotherapy, and education. In essence, the children learn how to void, when to void, and how often they have to void. To reach optimal training results, these three learning elements need to be repeatedly practised together. ${ }^{66,67}$ Depending on the diagnosis, one or more of these elements will be emphasised. For example, children with voiding postponement focus on timed voiding while children with dysfunctional voiding focus on toilet posture and emptying the bladder well.

Timed voiding is an important tool in specific urotherapy for children with voiding postponement. These children need to learn to urinate at the appropriate time, and not when they sense urgency. In this way, the child will learn to avoid waiting until the bladder is too full and instead attempt to void with a more relaxed pelvic floor. A timer can help to 
remind the child to go to the toilet, thereby increasing compliance. One study reported that with timer-assisted urotherapy, $60 \%$ of children achieved a greater decrease in incontinence episodes than without a timer. ${ }^{68}$

Children who urinate very often due to an extremely small bladder volume require another approach. Initially, training is aimed at remaining dry by maintaining a high frequency of micturition. When the child is confident that they can be dry, the second stage of training begins, aimed at improving bladder volume. The child is instructed to gradually increase the time to hold their urine.

Children with behavioural problems require a plan tailored to the unique needs of the child. A child psychologist should be involved to establish this plan and to coach the involved health professionals in having effective interactions with the child. Furthermore, treating the symptoms of behavioural problems before the start of specific urotherapy, if possible, is advised. ${ }^{49}$

Within specific urotherapy, a physical therapist can evaluate pelvic muscle function. ${ }^{69}$ Physical therapy focuses on strengthening and relaxing the supportive muscles of the urinary system, primarily the pelvic floor muscles, consequently improving continence..$^{70,71}$ Evidence exists that nearly all children older than 6 years can learn how to use their pelvic floor muscles. ${ }^{61,61,70}$

Biofeedback on the voiding pattern is an essential element of specific urotherapy. It improves the physiological processes of micturition by teaching children how to urinate with a relaxed pelvic floor and other good bladder-emptying techniques. Feedback on correct voiding can be given in the following ways. First, real-time flowmetry in which the child is able to observe the flow curve during voiding. In this method, children are taught to recognise when they urinate incorrectly and are instructed to keep trying (through a relaxed posture and softly blowing or whistling to relax the pelvic floor) until they achieve a continuous, bell-shaped curve. Eventually the child learns to urinate with a relaxed pelvic floor and normal urine volume. Second, ultrasound can be used to check if the bladder is empty after urination and this measure can be reported to the child. ${ }^{37}$ Finally, electromyography provides additional information on the use of the pelvic floor during voiding, and can be used to teach the child to contract and relax the pelvic floor muscles at will. An anal plug or surface electrodes can be used to register muscle activity. It should be noted that some electromyographs give an unreliable picture, and analysing this type of biofeedback requires some experience. In addition, electromyography is strongly dependent on correct placement of the surface electrodes. 
Alarm therapy can also be a part of specific urotherapy. Although well documented in children suffering from nocturnal enuresis, treatment is rarely used for daytime urinary incontinence. Children with persistent daytime urinary incontinence often do not notice wet garments. The daytime alarm can be used to restore this awareness and teach the child to react adequately to their bladder signal. As this therapy is rather confronting for the child, it should be only offered in a socially safe setting, preferably during clinical treatment. ${ }^{64,67}$

When specific urotherapy is not effective, the reason should be identified. Evaluating whether the initial diagnosis was correct is advisable, for example by doing an additional physical examination and urodynamics. Psychosocial or behavioural problems can also influence effectiveness of training and might require psychiatric evaluation or family therapy (Appendix 2.2).

\section{PHARMACOLOGICAL TREATMENT}

Medication might be needed to control bladder overactivity, constipation, and urinary tract infections.

Polyethylene glycol-based preparations are the most commonly used laxatives for constipation. Children with recurrent urinary tract infections, especially girls with dysfunctional voiding, might be depending on prophylaxis to bring down the number of infections.

Medication for daytime urinary incontinence is only suitable for children with an overactive bladder. According to the ICCS, before medication is considered, conservative standard treatment has to be completed. Furthermore, pharmacological treatment should always be used in combination with other treatment modalities for refractory overactive bladder.

Currently, oxybutynin is the only antimuscarinic approved by the US Food and Drug Administration for the treatment of overactive bladder symptoms in children older than 5 years. Several studies have shown a significant improvement of symptoms with oxybutynin..$^{72}$ Oxybutinin is an unselective antimuscarinic drug and has a high side-effect ratio especially in children, including dry mouth, constipation, abnormal vision, and sporadic changes in behaviour. Contrary to all other anticholinergics, oxybutynin is short acting, and dosage can be titrated to the time of maximal complaints.

Propiverine is a selective antimuscarinic, which is suggested to be both an anticholinergic and a calcium channel blocker. This medication is considered to be more effective and better tolerated in children with overactive bladder than oxybutynin. ${ }^{35}$ 
Tolterodine was introduced as a bladder-selective agent for overactive bladder. The drug has been tested in children and was considered safe, but efficacy results were disappointing. ${ }^{35,72}$ Initial retrospective studies in children seemed promising, confirming the superiority of tolterodine over oxybutynin in terms of side-effects. However, subsequent randomised, double-blinded clinical trials (e.g., NCT03575702, NCT00795509, NCT02476175, and NCT00332137) did not show tolterodine's effectiveness. ${ }^{73}$

Solifenacin is a selective antimuscarinic with moderate selectivity for M3 over M2 receptors. The medication has not been approved for paediatric use, but studies have shown a good response (i.e., in decreasing complaints like incontinence and frequency), and have shown tolerance of this agent in children previously resistant to oxybutynin or tolterodine. ${ }^{74}$ Besides solifenacin, several other anticholinergic medicines exist (e.g., mirabegron and imipramine).

Mirabegron is a promising novel drug, which is the first ß3-adrenergic receptor agonist that can be used for the treatment of overactive bladder. The treatment is efficacious and safe in adult patients with overactive bladder, but its effectiveness has not been established in children with the refractory form of the disorder. ${ }^{75}$

In the past, imipramine, which is a tricyclic antidepressant was prescribed for daytime urinary incontinence. However, the ICCS considers the evidence for the drug's effectiveness weak, and it has serious sideeffects such as tachycardia. ${ }^{4}$

For severe symptoms of overactive bladder, the aforementioned medications might not be sufficient in single use. Double anticholinergic therapy is an efficient and serious alternative to optimise the pharmacotherapeutic therapy for children in whom single agent anticholinergic therapy has not worked. ${ }^{76}$

Botulinum A toxin injections are a third-line option for children with idiopathic detrusor overactivity, refractory to non-invasive procedures such as urotherapy, pelvic floor musculature training, pharmacotherapy, and neuromodulation. Studies show that botulinum $A$ toxin is safe and useful in these children. ${ }^{77}$

\section{NEUROMODULATION}

Neuromodulation can be administered as monotherapy or additional therapy in children who prefer this treatment, children who refuse medication, and children in whom anti-muscarinics are insufficient or have to be stopped because of side-effects. The treatment methods currently available include parasacral transcutaneous electrical nerve 
stimulation, percutaneous tibial nerve stimulation or Stoller afferent neurostimulation, and implanted sacral nerve stimulation. The most commonly used therapy is home-based transcutaneous electrical nerve stimulation with transcutaneous electrodes. ${ }^{78,79}$

The neuromodulation technique is based on the principle that electrical current directly affects the CNS by artificially activating neural structures, facilitating both neural plasticity and normative afferent and efferent activity of the lower urinary tract. Several studies suggest that neuromodulation is safe and useful for inhibiting detrusor contractions, ${ }^{80,81}$ although some controlled studies showed contrasting results-one with only a very high placebo effect based on the attention given to the child's problem, ${ }^{82}$ one with convincing differences between groups. ${ }^{83}$

\section{ADDITIONAL SURGICAL TREATMENT}

Surgical interventions should be considered for girls with a meatal anomaly. Half of these girls become asymptomatic after meatotomy to correct the direction of the urinary stream. ${ }^{32}$ For boys, surgery is indicated when they are suspect for infravesical obstruction, on the basis of physical examination (meatal stenosis), uroflowmetry (plateau-shaped and prolonged uroflowmetry curve), or urodynamics (high pressures during voiding). Cystoscopy relieves the obstruction, when present. ${ }^{84,85}$ Finally, a small group of girls exist with congenital bladder neck insufficiency, mostly combined with generalised joint hypermobility. These individuals might benefit from a laparoscopic colposuspension, which is beyond the scope of this Review.

\section{CONCLUSION}

Treatment for daytime urinary incontinence is multidisciplinary and requires expert knowledge. Urotherapy is a conservative treatment, which is the first choice for all types of daytime incontinence. An essential element of urotherapy is focused attention to the problem from a trained professional. Although usually successful, urotherapy is not always effective due to the complex nature of incontinence problems. Causes of incontinence can be intertwined, making it difficult to decide which problems should be tackled first. Therefore, during urotherapy constant evaluation of progress to prevent overly long treatment is important. In some cases, postponing treatment might be an option, for example when children are too young to participate in the therapy. Quality of life of both child and parents is essential in making treatment decisions. 


\section{Search strategy and selection criteria}

We searched the Cochrane Library, MEDLINE, Embase, and relevant specialty journals for articles published between Jan 1, 2008, and Jan 1, 2018, with the terms: ("urinary incontinence" [MESH] OR "incontinence" [title or abstract (tiab)] OR "wetting" [tiab] OR "lower urinary tract symptoms" [MESH] OR "dysfunctional voiding" [tiab]) AND ("pediatrics" [MESH] OR "pediatric" [tiab] OR "paediatric" [tiab] OR "children" [tiab] OR "infant" [tiab]) NOT "urinary bladder", "neurogenic" [MESH] NOT "spinal dysraphism" [MESH] NOT "neural tube defects" [MESH] NOT "nocturnal enuresis" [MESH] OR "under 10 years"). We reviewed all publications from 2008 to 2018, and prioritised those published after 2012; however, commonly cited and highly regarded (defined by high citation count and journal impact factor) older publications were included. We searched for articles published in English, or those translated into English. We also searched the reference lists of articles identified by this strategy, and selected those we judged relevant. Randomised controlled trials, observational studies, retrospective studies, metaanalyses, review articles, and editorials, were included.

\section{Key messages}

- Daytime urinary incontinence is a common problem in school-aged children, which severely affects quality of life

- Subtypes of daytime incontinence are overactive bladder, dysfunctional voiding, underactive bladder, voiding postponement, stress incontinence, giggle incontinence, vesico-vaginal incontinence, and nocturnal enuresis

- Comorbidities of urinary incontinence are constipation, urinary tract infections, and behavioural problems

- Diagnostic tools include medical history, bladder diaries, questionnaires, flowmetry, and ultrasound

- The treatment of first choice is urotherapy, a conservative treatment which combines education and demystification, behavioural modification instructions, lifestyle advice regarding fluid intake, and registration of voiding frequencies, voiding volumes, and incontinence episodes, with added support and encouragement for children and their parents

- Urotherapy can be supported by medication for constipation, infection prophylaxis, and specific medication for overactive bladder

- Constant evaluation of progress is recommended for preventing prolonged treatment and motivating patients and parents

\section{Acknowlegdement}

Prof. dr. Tom P. V. M. de Jong was invited for this review. The first and last author want to thank him for the opportunity to work together on this publication.

\section{Contributors}

AJN-L wrote the manuscript with input from RPJS, EMvdP, TPVMdJ, and RS. TPVMdJ contributed to the sections on pharmacological treatment and surgical treatment. RS contributed to text editing. All authors contributed to the final version of this Review before submission.

\section{Declaration of interests}

We declare no competing interests. 


\section{REFERENCES}

1 Santos JD, Lopes RI, Koyle MA. Bladder and bowel dysfunction in children: an update on the diagnosis and treatment of a common, but underdiagnosed pediatric problem. Can Urol Assoc J 2017; 11 (suppl 1): S64-72.

2 Yang S, Chua ME, Bauer S, et al. Diagnosis and management of bladder bowel dysfunction in children with urinary tract infections: a position statement from the International Children's Continence Society. Pediatr Nephrol 2017; 33: 2207-19.

3 Austin PF, Bauer SB, Bower W, et al. The standardization of terminology of lower urinary tract function in children and adolescents: update report from the standardization committee of the International Children's Continence Society. Neurourol Urodyn 2016; 35: 471-81.

4 Chang S-J, Van Laecke E, Bauer SB, et al. Treatment of daytime urinary incontinence: a standardization document from the International Children's Continence Society. Neurourol Urodyn 2017; 36: 43-50.

5 Bauer SB, Nijman RJM, Drzewiecki BA, Sillen U, Hoebeke P. International Children's Continence Society Standardization report on urodynamic studies of the lower urinary tract in children. 2015; 647: 640-47.

6 Von Gontard A, Niemczyk J, Wagner C, Equit M. Voiding postponement in children-a systematic review. Eur Child Adolesc Psychiatry 2016; 25: 809-20.

7 Neveus T. Nocturnal enuresis - theoretic background and practical guidelines. Pediatr Nephrol 2011; 26: 1207-14.

8 Franco I, Austin PF, Bauer SB, von Gontard A. Pediatric incontinence: evaluation and clinical management. Chichester: John Wiley \& Sons Ltd, 2015.

9 Sureshkumar P, Jones M, Cumming R, Craig J. A population based study of 2856 school-age children with urinary incontinence. J Urol 2009; 181: 808-16.

10 Sureshkumar P, Craig JC, Roy LP, Knight JF. Daytime urinary incontinence in primary school children: a population-based survey. J Pediatr 2000; 137: 814-18.

11 Swithinbank L V, Heron J, Von Gontard A, Abrams P. The natural history of daytime urinary incontinence in children: a large British cohort. Acta Paediatr Int J Paediatr 2010; 99: 1031-36.

12 Yüksel S, Yurdakul AÇ, Zencir M, Çördük N. Evaluation of lower urinary tract dysfunction in Turkish primary schoolchildren: an epidemiological study. J Pediatr Urol 2014; 10: 1181-6.

13 Sureshkumar P, Jones M, Cumming R, Craig JC, Joinson C, Heron J, et al. Bladder and bowel dysfunctions in 1748 children referred to pelvic physiotherapy: clinical characteristics and locomotor problems in primary, secondary, and tertiary healthcare settings. Eur J Pediatr 2017; 176: 207-16.

14 Chung JM, Lee SD, Kang D, et al. An epidemiologic study of voiding and bowel habits in Korean children: a nationwide multicenter study. Urology 2010; 76: 215-19.

15 Heron J, Grzeda MT, Von Gontard A, Wright A, Joinson C. Trajectories of urinary incontinence in childhood and bladder and bowel symptoms in adolescence: prospective cohort study. BMJ Open 2017; 7: e014238.

16 Burgers R, de Jong TPVM, Visser M, Di Lorenzo C, Dijkgraaf MGW, Benninga MA. Functional defecation disorders in children with lower urinary tract symptoms. J Urol 2013; 189: 1886-91.

17 Gontard A Von, Heron J, Joinson C. Family history of nocturnal enuresis and urinary incontinence: results from a large epidemiological study. J Urol 2011; 185: 2303-07.

18 Fitzgerald MP, Thom DH, Wassel-Fyr C, Subak L, Brubaker L, Van Den Eeden SK, et al. Childhood urinary symptoms predict adult overactive bladder symptoms. J Urol 2006; 175: 989-93.

19 Labrie J, de Jong TPVM, Nieuwhof-Leppink A, van der Deure J, Vijverberg MAW, van der Vaart $\mathrm{CH}$. The relationship between children with voiding problems and their parents. J Urol 2010; 183: 1887-91. 
20 Montaldo P, Tafuro L, Narciso V, et al. Correlations between enuresis in children and nocturia in mothers. Scand J Urol Nephrol 2010; 44: 101-15.

21 Chung JM, Lee SD, Kang D, et al. An epidemiologic study of voiding and bowel habits in Korean children: a nationwide multicenter study. Urology 2010; 76: 215-19.

22 Palmer $\mathrm{M}$, Athanasopoulos $\mathrm{A}$, Lee $\mathrm{K}$, et al. Sociocultural and environmental influences in bladder health. Int J Clin Pract 2012; 66: 1132-38.

23 Vernon, S, Lundblad, B, Hellstrom, AL. Children's experiences of school toilets present a risk to their physical and psychological health. Child Care Health Dev 2003; 29: 47-53.

24 Von Gontard A, Equit M. Comorbidity of ADHD and incontinence in children. Eur Child Adolesc Psychiatry 2014; 24: 127-40.

25 Von Gontard A, Baeyens D, Van Hoecke E, Warzak WJ, Bachmann C. Psychological and psychiatric issues in urinary and fecal incontinence. J Urol 2011; 185: 1432-36.

26 Cupelli ET, Escallier L, Galambos N, Xiang S, Franco I. Sensory processing differences and urinary incontinence in school-aged children. J Pediatr Urol 2014; 10: 880-85.

27 Wellink L, Dongen PWJ Van. Hypermobility in two Dutch school poulations. Eur J Obstet Gynecol Reprod Biol 1997; 73: 15-18.

28 Clinch J, Deere K, Sayers A, et al. Epidemiology of generalized joint laxity (hypermobility) in fourteen-year-old children from the UK a population-based evaluation. Arthritis Rheum 2011; 63: 2819-27.

29 de Kort LMO, Verhulst JAPM, Engelbert RHH, Uiterwaal CSPM, de Jong TPVM. Lower urinary tract dysfunction in children with generalized hypermobility of joints. J Urol 2003; 170: 1971-74.

30 Fraga LGA, Sampaio A, Boa-Sorte N, Veiga ML, Nascimento Martinelli Braga AA, Barroso U. Obesity and lower urinary tract dysfunction in children and adolescents: further research into new relationships. J Pediatr Urol 2017; 13: 387.e1-6.

31 Wagner C, Equit M, Niemczyk J, Von Gontard A. Obesity, overweight, and eating problems in children with incontinence. J Pediatr Urol 2015; 11: 202-07.

32 Klijn AJ, Bochove-Overgaauw D, Winkler-Seinstra PL, Dik P, de Jong TPVM. Urethral meatus deformities in girls as a factor in dysfunctional voiding. Neurourol Urodyn 2012; 31: 1161-64.

33 Lopes I, Veiga ML, Braga AANM, Brasil CA, Hoffmann A, Barroso U. A two-day bladder diary for children: is it enough? J Pediatr Urol 2015; 11: 348.e1-4.

34 Maternik M, Krzeminska K, Zurowska A. The management of childhood urinary incontinence. Pediatr Nephrol 2015; 30: 41-50.

35 Chang S, Van Laecke E, Bauer SB, et al. Treatment of daytime urinary incontinence : a standardization document from the International Children's Continence Society. Neurourol Urodyn 2017; 36: 43-50.

36 Wenske S, Combs AJ, Van Batavia JP, Glassberg KI. Can staccato and interrupted/fractionated uroflow patterns alone correctly identify the underlying lower urinary tract condition? J Urol 2012; 187: 2188-93.

37 Chase J, Schrale L. Childhood incontinence and pelvic floor muscle function: Can we learn from adult research? J Pediatr Urol 2017; 13: 94-101.

38 Beksac AT, Koni A, Bozaci AC, Dogan HS, Tekgul S. Postvoidal residual urine is the most significant non-invasive diagnostic test to predict the treatment outcome in children with non-neurogenic lower urinary tract dysfunction. J Pediatr Urol 2016; 12: 215.e1-8.

39 Klijn AJ, Asselman M, Vijververberg MA, Dik P, de Jong TP. The diameter of the rectum on ultrasonography as a diagnostic tool for constipation in children with dysfunctional voiding. J Urol 2004; 172: 1986-88.

40 Choi YJ, Seo BS, Lee JH, Jeong SJ. Treatment of fecal retention is important in the management of overactive bladder in children. Neurourol Urodyn 2017; 494: 490-94. 
41 Bekkali N, Berg D, Dijkgraaf MGW, Wijk P Van, Bongers MEJ, Benninga MA. Rectal fecal impaction treatment in childhood constipation: enemas versus high doses oral PEG. Pediatrics 2009; 124: e1108-15.

42 Bö K, Sherburn M, Allen T. Transabdominal ultrasound measurement of pelvic floor muscle activity when activated directly or via a transversus abdominis muscle contraction. Neurourol Urodyn 2003; 588: 582-88.

43 Schroeder R, de Mooij K, Groen L, et al. Static and dynamic ultrasound imaging to visualize the bladder, bladder neck, urethra, and pelvic floor in children with daytime incontinence. Front Pediatr 2017; 5: 1-5.

44 Goknar N, Oktem F, Demir AD, Vehapoglu A, Silay MS. Comparison of two validated voiding questionnaires and clinical impression in children with lower urinary tract symptoms: ICIQCLUTS versus Akbal survey. Urology 2016; 94: 214-17.

45 De Gennaro M, Niero M, Capitanucci ML, et al. Validity of the International Consultation on Incontinence Questionnaire-Pediatric Lower Urinary Tract Symptoms: a screening questionnaire for children. J Urol 2010; 184: 1662-67.

46 Bower WF, Sit FKY, Bluyssen N, Wong EMC, Yeung CK. PinQ: a valid, reliable and reproducible quality-of-life measure in children with bladder dysfunction. J Pediatr Urol 2006; 2: 185-89.

47 Chase J, Bower W, Gibb S, Schaeffer A, von Gontard A. Diagnostic scores, questionnaires, quality of life, and outcome measures in pediatric continence: a review of available tools from the International Children's Continence Society. J Pediatr Urol 2018; 14: 98-107.

48 Von Gontard A, de Jong TPVM, Badawi JK, et al. Psychological and physical environmental factors in the development of incontinence in adults and children: a comprehensive review. J Wound Ostomy Cont Nurs 2017; 44: E1.

49 Grzeda MT, Heron J, von Gontard A, Joinson C. Effects of urinary incontinence on psychosocial outcomes in adolescence. Eur Child Adolesc Psychiatry 2017; 26: 649-58.

50 MacNeily AE. Should psychological assessment be a part of incontinence management in children and adolescents? J Urol 2016; 195: 1327-78.

51 Joinson C, Heron J, von Gontard A. Psychological problems in children with daytime wetting. Pediatrics 2006; 118: 1985-93.

52 Niemczyk J, Equit M, Hoffmann L, Von Gontard A. Incontinence in children with treated attention-deficit/hyperactivity disorder. J Pediatr Urol 2015; 11: 141.e1-6.

53 Von Gontard A, Pirrung M, Niemczyk J, Equit M. Incontinence in children with autism spectrum disorder. J Pediatr Urol 2015; 11: 264.e1-7.

54 Veloso LA, Mello MJG de, Ribeiro Neto JPM, Barbosa LNF, Silva EJ. Quality of life, cognitive level and school performance in children with functional lower urinary tract dysfunction. $J$ Bras Nefrol 2016; 38: 234-44.

55 Thibodeau BA, Metcalfe P, Koop P, Moore K. Urinary incontinence and quality of life in children. J Pediatr Urol 2013; 9: 78-83.

56 Ching $\mathrm{CB}$, Lee $\mathrm{H}$, Mason $\mathrm{MD}$, et al. Bullying and lower urinary tract symptoms: why the pediatric urologist should care about school bullying. J Urol 2015; 193: 650-54.

57 Rajindrajith S, Devanarayana NM, Lakmini C, Subasinghe V, De Silva DGH, Benninga MA. Association between child maltreatment and constipation: a school-based survey using Rome III criteria. J Pediatr Gastroenterol Nutr 2014; 58: 486-90.

58 Rajindrajith S, Devanarayana NM, Benninga MA. Fecal incontinence in adolescents is associated with child abuse, somatization, and poor health-related quality of life. J Pediatr Gastroenterol Nutr 2016; 62: 698-703.

59 Yildirim A, Uluocak N, Atilgan D, Ozcetin M, Erdemir F, Boztepe O. Evaluation of lower urinary tract symptoms in children exposed to sexual abuse. Urol J 2011; 8: 38-42. 
60 Anderson B, Thimmesch I, Aardsma N, Ed D MT, Carstater S, Schober J. The prevalence of abnormal genital findings, vulvovaginitis, enuresis and encopresis in children who present with allegations of sexual abuse. J Pediatr Urol 2014; 10: 1216-21.

61 Oktar T, Dönmez MI, Özkuvanci Ü, Ander H, Ziylan O. Animated versus non-animated biofeedback therapy for dysfunctional voiding treatment: does it change the outcome? J Pediatr Surg 2018; 53: 825-27.

62 Drzewiecki BA, Kelly PR, Marinaccio B, et al. Biofeedback training for lower urinary tract symptoms: factors affecting efficacy. J Urol 2009; 182: 2050-55.

63 Schäfer SK, Niemczyk J, von Gontard A, Pospeschill M, Becker N, Equit M. Standard urotherapy as first-line intervention for daytime incontinence: a meta-analysis. Eur Child Adolesc Psychiatry 2018; 27: 949-64.

64 Meijer EFJ, Nieuwhof-Leppink AJ, Dekker-Vasse E, de Joode-Smink GCJ, de Jong TPVM. Central inhibition of refractory overactive bladder complaints, results of an inpatient training program. J Pediatr Urol 2015; 11: 21.e1-5.

65 Borch L, Hagstroem S, Bower WF, Siggaard Rittig C, Rittig S. Bladder and bowel dysfunction and the resolution of urinary incontinence with successful management of bowel symptoms in children. Acta Paediatr Int J Paediatr 2013; 102: 215-20.

66 Rivers $\mathrm{CL}$. School nurse interventions in managing functional urinary incontinence in schoolage children. J Sch Nurs 2010; 26: 115-20.

67 Mattsson GG, Brännström M, Eldh M, Mattsson S. Voiding school for children with idiopathic urinary incontinence and/or bladder dysfunction. J Pediatr Urol 2010; 6: 490-95.

68 Hagstroem S, Rittig S, Kamperis K, Djurhuus JC. Timer watch assisted urotherapy in children: a randomized controlled trial. J Urol 2010; 184: 1482-88.

69 Chase J, Schrale L. Childhood incontinence and pelvic floor muscle function: can we learn from adult research? J Pediatr Urol 2017; 13: 94-101.

70 Ladi Seyedian SS, Sharifi-Rad L, Ebadi M, Kajbafzadeh AM. Combined functional pelvic floor muscle exercises with Swiss ball and urotherapy for management of dysfunctional voiding in children: a randomized clinical trial. Eur J Pediatr 2014; 173: 1347-53.

71 Bower WF, Chase JW, Stillman BC. Normative pelvic floor parameters in children assessed by transabdominal ultrasound. J Urol 2006; 176: 337-41.

72 Schröder A, Thüroff JW. New strategies for medical management of overactive bladder in children. Curr Opin Urol 2010; 20: 313-17.

73 Medhi B, Mittal N, Bansal D, Prakash A, Sarangi SC, Nirthi B. Comparison of tolterodine with standard treatment in pediatric patients with non-neurogenic dysfunctional voiding/over active bladder: a systematic review. Indian J Physiol Pharmacol 2013; 57: 343-53.

74 Hoebeke P, De Pooter J, De Caestecker K, et al. Solifenacin for therapy resistant overactive bladder. J Urol 2009; 182: 2040-44.

75 Maggiore ULR, Cardozo L, Ferrero S, et al. Mirabegron in the treatment of overactive bladder. Expert Opin Pharmacother 2014; 15: 873-87.

76 Bolduc S, Moore K, Lebel S, Lamontagne P, Hamel M. Double anticholinergic therapy for refractory overactive bladder. J Urol 2009; 182: 2033-38.

77 Marte A, Borrelli M, Sabatino MD, et al. Effectiveness of botulinum-A toxin for the treatment of refractory overactive bladder in children. Eur J Pediatr Surg 2010; 20: 153-57.

78 Boudaoud N, Binet A, Line A, et al. Management of refractory overactive bladder in children by transcutaneous posterior tibial nerve stimulation: a controlled study. J Pediatr Urol 2015; 11: 138.e1-10.

79 Kajbafzadeh AM, Sharifi-Rad L, Ladi-Seyedian SS, Mozafarpour S. Transcutaneous interferential electrical stimulation for the management of non-neuropathic underactive bladder in children: a randomised clinical trial. BJU Int 2016; 117: 793-800. 
80 Hagstroem S, Mahler B, Madsen B, Djurhuus JC, Rittig S. Transcutaneous electrical nerve stimulation for refractory daytime urinary urge incontinence. J Urol 2009; 182 (suppl 4): 2072-78.

81 Tugtepe H, Thomas DT, Ergun R, Kalyoncu A, Kaynak A, Kastarli C, Dagli TE. The effectiveness of transcutaneous electrical neural stimulation therapy in patients with urinary incontinence resistant to initial medical treatment or biofeedback. J Pediatr Urol 2015; 11: 137.e1-5.

82 Sillén U1 Arwidsson C, Doroszkiewicz $M$, et al. Effects of transcutaneous neuromodulation (TENS) on overactive bladder symptoms in children: a randomized controlled trial. J Pediatr Urol 2014; 10: 1100-05.

83 Borch L, Hagstroem S, Kamperis K, Siggaard CV, Rittig S. Transcutaneous electrical nerve stimulation combined with oxybutynin is superior to monotherapy in children with urge incontinence: a randomized, placebo controlled study. J Urol 2017; 198: 430-35.

84 de Jong TPVM, Kuijper CF, Chrzan R, Dik P, Klijn AJ, Vijverberg MA. Efficacy and safety of urethral de-obstruction in boys with overactive bladder complaints. J Pediatr Urol 2013; 9: 1072-76.

85 Nakai H, Hyuga T, Kawai S, Kubo T, Nakamura S. Aggressive diagnosis and treatment for posterior urethral valve as an etiology for vesicoureteral reflux or urge incontinence in children. Investig Clin Urol 2017; 58: 46-53. 


\section{APPENDIX 2.1: ASSESSMENT AND DIAGNOSIS}

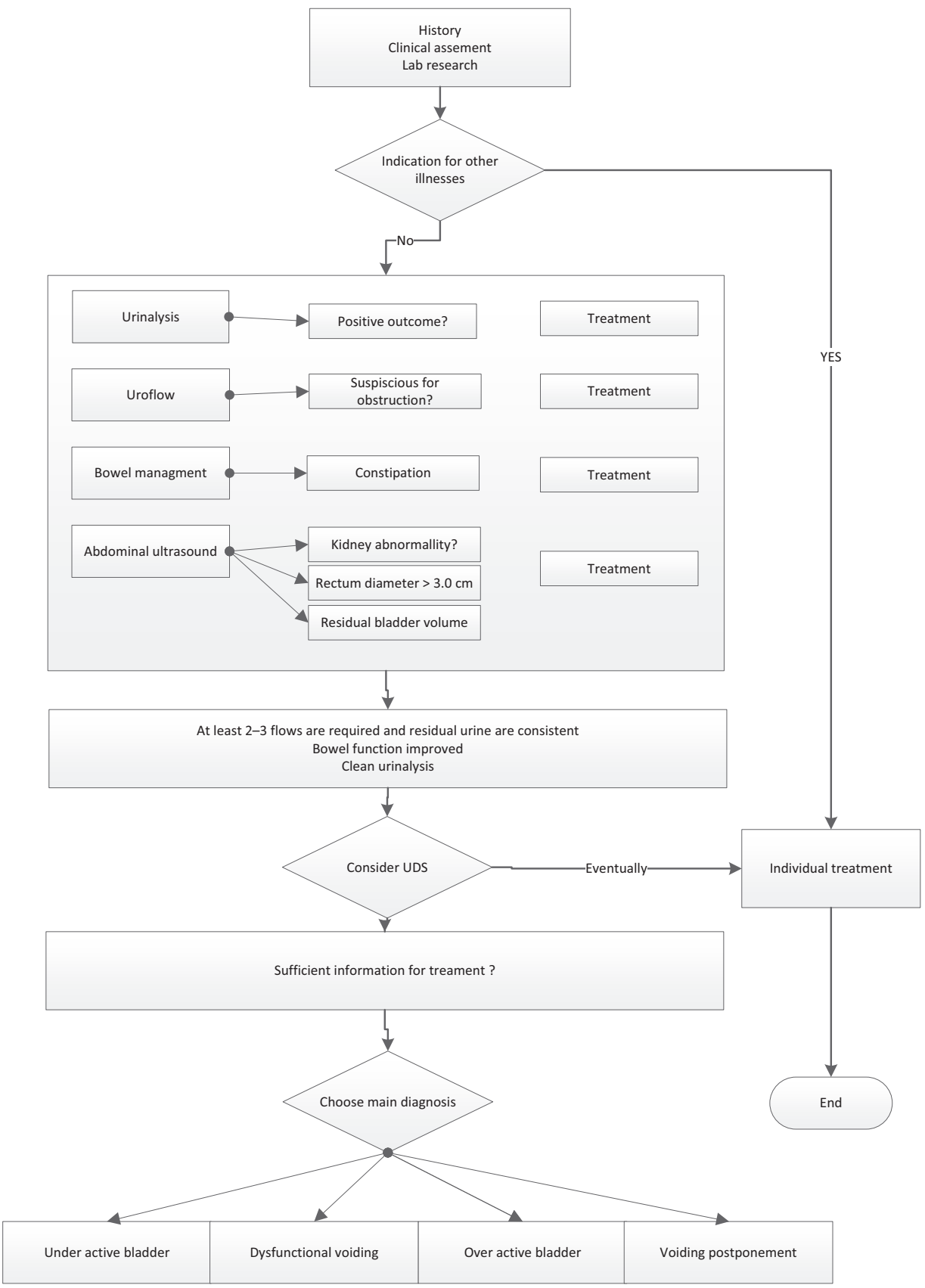




\section{APPENDIX 2.2: UROTHERAPY}

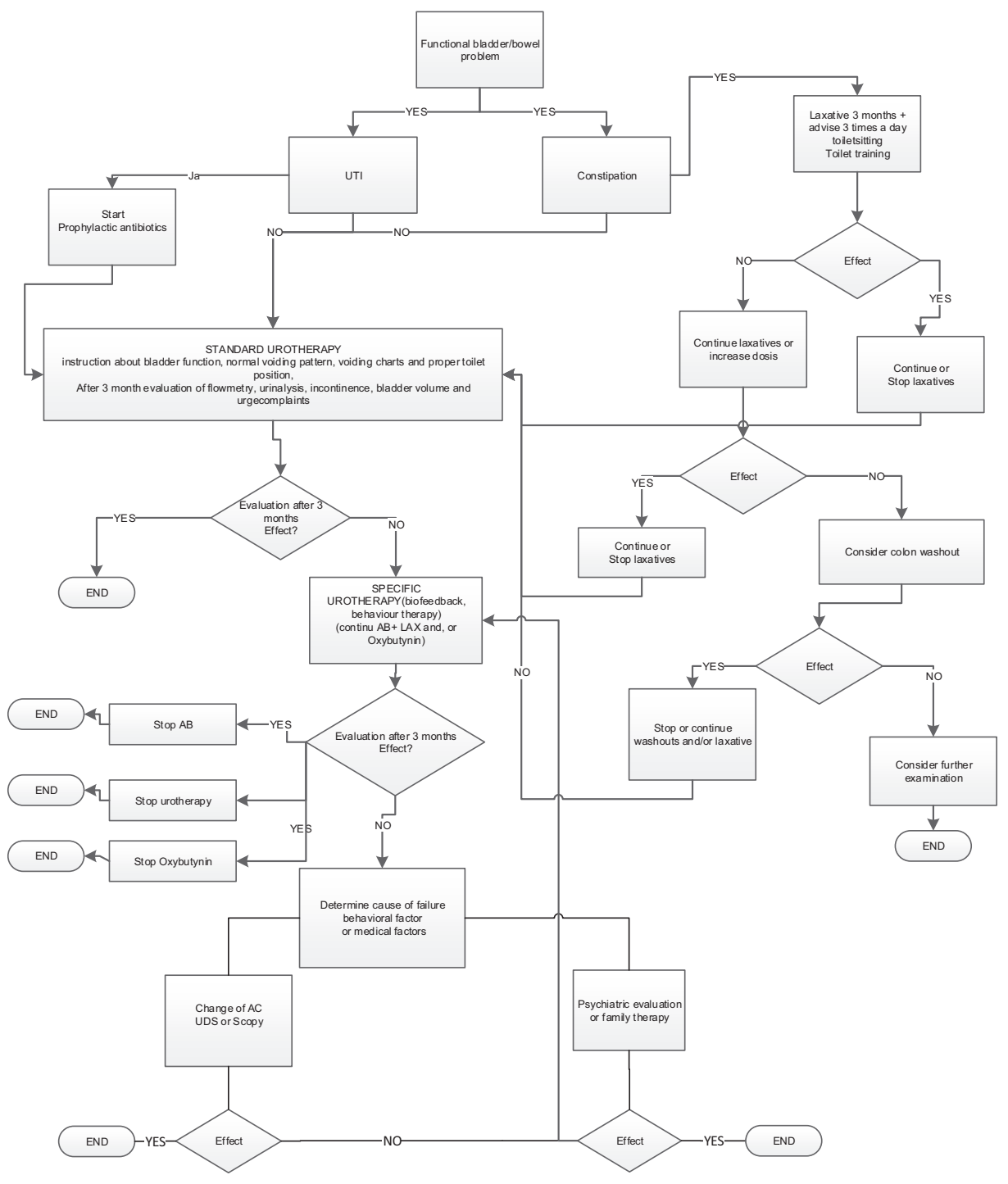






\section{Central inhibition of refractory overactive bladder complaints: Results of an inpatient training program}

Eelco F.J. Meijer Anka J. Nieuwhof-Leppink

Edith Dekker-Vassa

Gerrie de Joode-Smink

Tom P.V.M. de Jong 
Short introduction: Overactive bladder $(O A B)$ in children has an overall reported incidence of $16.6-17.8 \%$, with its prevalence of $0.2-9 \%$ varying largely between age and gender. $O A B$ is the most important burden in pediatric urology because of the limited effect of treatment. $O A B$ with imperative urge and/or urge incontinence can often be successfully treated with urotherapy and pharmacological treatment. Nevertheless, approximately $20 \%$ of patients are considered to be therapy resistant for common treatment options. For the latter group, an inpatient cognitive and biofeedback training program for children has been developed.

Objective: To evaluate the effect of an inpatient cognitive and biofeedback training program for children with urge complaints and urge incontinence based on overactive bladder (OAB) after failed earlier treatment by anticholinergic medication and by outpatient urotherapy. A search for predictors for success of treatment outcome is included in the study.

Patients and methods: 70 children with therapy refractory incontinence based on OAB went through a 10-day in-hospital training program between 2007 and 2010. Age was between 7 and 13 years, mean 9.29 years. Essential part of this program is teaching the children central inhibition of their bladder to suppress bladder overactivity. Patients had, on average, 41.1 months of fruitless treatment by urotherapy and medication before attending this training program. Training result was evaluated 6 months after completion of the inpatient training program. A questionnaire was subsequently conducted 2 years after the training to evaluate the long-term efficacy of this program.

Results: Evaluation 6 months after training of these 70 patients diagnosed with OAB showed that 30 patients (42.9\%) were free of complaints, 22 (31.4\%) had an important reduction of complaints and 18 (25.7\%) failed to have any improvement. Logistic regression analysis was used to look at several variables predicting training outcome. A higher age during clinical training was found to be a predictor for a good training outcome. After 2 years, 44 (62.9 $\%)$ patients were reached for long-term follow-up. Of these patients, 28 (63.6\%) reported a good effect of the training and $13(29.5 \%)$ experienced no improvement in symptoms when compared to before clinical training. Objectively, 26 (59.1\%) were dry and 18 (40.9\%) were incontinent to some extent. A total of fourteen (31.8\%) patients had relapsed into urge complaints.

Conclusion: The inpatient cognitive and biofeedback training program for refractory $O A B$ complaints has demonstrated to cure or improve $74.3 \%$ of patients and conveyed favourable long-term results in approximately $70.5 \%$ of patients. A higher age during clinical training was found to be a predictor for a good training outcome.

Summary of results, $n=70$, mean age 9.3 years $(S D=1.46$, Min $=7$ years, $M a x=13$ years $)$

\begin{tabular}{lllll}
\hline \multirow{2}{*}{ Variables } & Result & Frequency & $\begin{array}{l}\text { Percent } \\
(100 \%)\end{array}$ & $P$-value \\
\hline Result inpatient training short-term & Bad & $18 / 70$ & 25.7 & $\mathrm{n} / \mathrm{a}$ \\
& Improvement & $22 / 70$ & 31.4 & $\mathrm{n} / \mathrm{a}$ \\
& Good & $30 / 70$ & 42.9 & $\mathrm{n} / \mathrm{a}$ \\
Multiple variables predicting training outcome & Higher age & $\mathrm{n} / \mathrm{a}$ & $\mathrm{n} / \mathrm{a}$ & $0.034^{\mathrm{a}}$ \\
Result inpatient training long-term & Bad & $11 / 44$ & 25 & $\mathrm{n} / \mathrm{a}$ \\
& Improvement & $5 / 44$ & 11.4 & $\mathrm{n} / \mathrm{a}$ \\
Urge complaints 2 years after training & Good & $28 / 44$ & 63.6 & $\mathrm{n} / \mathrm{a}$ \\
& Yes & $14 / 44$ & 31.8 & $<0.05^{\mathrm{b}}$ \\
\hline
\end{tabular}

${ }^{a}$ Using logistic regression analysis. ${ }^{\mathrm{b}}$ Using McNemar's test. 


\section{INTRODUCTION}

Overactive bladder $(\mathrm{OAB})$ in children has an overall reported incidence of $16.6-17.8 \%^{1}$ with its prevalence $(0.2-9 \%)^{2}$ varying largely between age and gender. OAB is the most important burden in paediatric urology because of the limited effect of treatment. Roughly half the patients benefit from conservative therapy. This over activity of the bladder with imperative urge and/or urge incontinence can often be successfully treated with urotherapy, mostly combined with pharmacological treatment. Urotherapy is defined by the International Children's Continence Society (ICCS) ${ }^{3}$ as "treatment for children with functional incontinence," consisting of "instructions and lifestyle advice regarding micturation frequency, fluid intake, toilet posture, and prevention of constipation, which is complemented in more serious cases by biofeedback training, behavioural therapy, and physiotherapy". ${ }^{4}$ Frustrating fact for therapists and patients is that success rates of this treatment rarely pass $50 \%$ where a specific search and treatment of urethral anomalies in boys may get this percentage up to $75 \% .{ }^{5}$ This leaves a $20 \%$ group of patients that are considered to be therapy resistant for common treatment options.

Since 1982, at our hospital, if standard outpatient urotherapy is unsuccessful, patients are offered inpatient urotherapy. ${ }^{4,6,7}$ This inpatient 10-day cognitive training program (voiding school) is the most intensive form of urotherapy and is reserved for the therapy resistant patients. Children with $\mathrm{OAB}$ complaints under the age of 9 are preferably not enrolled in this training program as their lack of motivation can be detrimental to the success of both the upcoming and future training.

During this cognitive training program a urotherapist gives instructions on voiding habits, toilet position, constipation and urinary tract infection prevention combined with extensive daily supervision, motivational techniques, biofeedback of the pelvic floor, psychological counselling and behavioural modification. Voiding patterns are objectively recorded by using uroflowmetry and wetting is recorded by underwear ringing an alarm when wet, allowing the children to develop awareness of the incontinence incidents, voiding frequency and flow patterns.

Six months after the training, the training result is evaluated and documented by using ICCS guidelines. The result is considered 'good' when complaints have been reduced by $90 \%$ or more. A reduction of complaints by 50 to $89 \%$ is considered 'improvement' and below $50 \%$ is considered as a 'bad' result; treatment failure.

In this study the inpatient urotherapy and follow-up results are reported from 70 therapy refractory patients suffering from $O A B$, in an attempt to demonstrate the efficacy of the method on both short and long-term in this difficult-to-treat cohort. A search for predictors for success of treatment outcome is also described. 


\section{PATIENTS AND METHODS}

After having received permission from the local ethical committee, anonymous data of the patients were retrospectively collected from their medical files. All patients with overactive bladder complaints who underwent the inpatient cognitive and biofeedback training program between years 2007 and 2010 were analysed for inclusion $(n=80)$. Patients with neurological disorders or patients who underwent earlier surgery for urological congenital anatomical abnormalities other than meatus correction or endoscopic desobstruction of posterior urethral valves, were excluded from analysis $(n=10)$.

Data retrieved from the medical files were age, sex, diagnosis, outpatient training result, clinical training result, location of outpatient training, age at first contact, months from first contact until clinical training, urodynamic test results, anticholinergic drug effects and type of surgery. Before starting clinical training, all patients had good uroflowmetry curves and had tried anticholinergic drugs. A complete list can be found in Table 3.1.

Subsequently, all 70 patients and their parents/caretakers were sent an application form by mail asking for permission to call them and conduct a questionnaire by phone. This questionnaire contained questions regarding follow-up, including current incontinence status. All non-responders received a phone call from one of the urotherapists asking whether they would fill out the application form. From all 70 patients, 44 patients accepted the invitation whilst 14 patients declined and 12 patients could not be reached. Data analysis was performed using IBM SPSS Statistics, version 22.

\section{RESULTS}

Mean age of the 70 children during hospitalized training was 9.29 years ( $S D=1.46$, Min $=7$ years, $\operatorname{Max}=13$ years) and $48(68.6 \%)$ were male. All patients were diagnosed with urge complaints and $10 \%$ suffered from additional frequency complaints. All 70 patients had earlier outpatient training, with bad result in 51 (72.9\%) patients, some improvement in $4(5.7 \%)$, and temporary good result with relapse in 2 (2.9\%). Of all patients, 38 (54.3\%) had their outpatient training in our hospital and the remaining group received urotherapy in other centres. The mean age of first contact was 5.8 years (SD $=2.12$, Min $=0$ years, $\operatorname{Max}=10$ years) defined as the age on the day of surgery before age 4 or the first outpatient visit for urine incontinence. The months between first contact and clinical training were mean 41.1 (SD = 22.98, Min = 11 months, Max = 126 months). Looking at previous treatment, 44 patients $(62.8 \%)$ had surgery before outpatient training, 16 (22.9\%) underwent surgery after outpatient training but before clinical training, 1 (1.4\%) 
Table 3.1: Demographics data retrieved from medical files, $n=70$, mean age 9.3 years $(S D=1.46, \operatorname{Min}=7$ years, $\operatorname{Max}=13$ years)

\begin{tabular}{|c|c|c|c|}
\hline Variables & $N=70$ & Frequency & Percent $(100 \%)$ \\
\hline \multirow[t]{2}{*}{ Sex } & Male & 48 & 68.6 \\
\hline & Female & 22 & 31.4 \\
\hline \multirow[t]{2}{*}{ Diagnosis } & Urge + frequency & 7 & 10 \\
\hline & Urge & 63 & 90 \\
\hline \multirow[t]{2}{*}{ Outpatient training } & Our hospital & 38 & 54.3 \\
\hline & Elsewhere & 32 & 45.7 \\
\hline \multirow[t]{4}{*}{ Outpatient training result } & Bad & 51 & 72.9 \\
\hline & Improved & 4 & 5.7 \\
\hline & Good & 2 & 2.9 \\
\hline & Unknown & 13 & 18.6 \\
\hline \multirow[t]{3}{*}{ Anticholinergics } & Used, did not help & 29 & 41.4 \\
\hline & Used, did help & 33 & 47.1 \\
\hline & Used, unknown former result & 8 & 11.4 \\
\hline \multirow[t]{6}{*}{ Urodynamics study (UDS) } & No UDS & 22 & 31.4 \\
\hline & Normal UDS & 4 & 5.7 \\
\hline & $O A B$ & 13 & 18.6 \\
\hline & Dyssynergy & 2 & 2.9 \\
\hline & Obstruction & 14 & 20.0 \\
\hline & UDS only after clinical training & 7 & 10.0 \\
\hline \multirow[t]{6}{*}{ Surgery } & No surgery & 8 & 11.4 \\
\hline & Endoscopy & 5 & 7.1 \\
\hline & Endoscopy + valve resection & 34 & 48.6 \\
\hline & Endoscopy + meatotomy & 15 & 21.4 \\
\hline & Other & 4 & 5.7 \\
\hline & Valve resection + meatotomy & 4 & 5.7 \\
\hline \multirow[t]{3}{*}{ Result inpatient training } & Bad & 18 & 25.7 \\
\hline & Improvement & 22 & 31.4 \\
\hline & Good & 30 & 42.9 \\
\hline
\end{tabular}

received surgery after clinical training and 9 (12.9\%) did not receive any surgery at all. Out of 70 patients, 33 (47.1\%) had an earlier endoscopic urethral desobstruction, 14 (20\%) a meatal plasty, 4 (5.7\%) received both, in 5 patients (7.1\%) cystoscopy did not reveal any anomalies, 5 patients (7.1\%) underwent larger surgery and the remaining 9 (12.9\%) did not receive any surgery. In 42 (60\%) of all patients a urodynamic study was done before clinical training demonstrating pure $\mathrm{OAB}$ in 13 (31.0\%), OAB plus another diagnosis in 9 (21.4\%), detrusor- sphincter dyssynergia in 2 (4.8\%) patients and obstruction in 14 (33.3\%) patients. Before starting clinical training, all patients had used anticholinergic drugs which had a temporary positive effect in $34(48.6 \%)$ of patients, no effect in 29 (41.4\%) and 
for the other 7 (10\%) patients there was no effect and it was unknown whether earlier temporary effect existed (Table 3.1).

Clinical training of the 70 patients diagnosed with OAB demonstrated that, 6 months after training, 30 patients (42.9\%) were free of complaints, 22 (31.4\%) had improved and $18(25.7 \%)$ had treatment failure. Hence, $74.3 \%$ of all patients had significant profit from hospitalized urotherapy.

Logistic regression analysis was used to evaluate whether any of the variables could predict training outcome. Firstly, as can be seen in Table 3.2, training outcomes 'improvement' and 'bad' were grouped and compared with a 'good' training outcome. Age was found to be a predictor, with a higher age being more predictive for a good training outcome $(P$ $=0.034$; odds ratio 1.646). Secondly, the predictive value of the effect of anticholinergic drugs and urodynamic test results on the training outcome was evaluated (data not shown). No significant effect was found.

After 2 years, 44 (62.9\%) patients were reached for long-term follow-up. Of these patients, 28 (63.6\%) reported a good effect of the training and 13 (29.5\%) experienced no improvement in symptoms when compared to before clinical training. Objectively, 26 (59.1\%) were dry and 18 (40.9\%) were incontinent to some extent. A total of 14 (31.8\%) of these patients had relapsed into urge complaints. Thus after 2 years $70.5 \%$ still demonstrated improvement in symptoms.

Table 3.2: Multiple logistic regression analyses $(n=70)$ predicting the change of being categorized as having good results after inpatient training vs having improved or bad effect

\begin{tabular}{lccccc}
\hline & & \multicolumn{3}{c}{$95 \%$ Cl for Odds Ratio } & \\
\cline { 3 - 5 } Covariable & B (SE) & Lower & Odds Ratio & Upper & $P$-value $\left(\chi^{2}\right)$ \\
\hline Age & $0.498(0.234)$ & 1.039 & 1.646 & 2.606 & $0.034^{*}$ \\
Sex & $0.201(0.669)$ & 0.329 & 1.223 & 4.542 & 0.763 \\
Surgery & $0.737(0.719)$ & 0.511 & 2.090 & 8.552 & 0.305 \\
Outpatient training & $-0.526(0.557)$ & 0.198 & 0.591 & 1.760 & 0.345 \\
Diagnosis & $-0.800(0.912)$ & 0.075 & 0.450 & 2.687 & 0.381 \\
Months until clinical & $-0.025(0.013)$ & 0.950 & 0.976 & 1.001 & 0.064 \\
training & & & & & 0.164 \\
Constant & $-3.628(2.607)$ & & 0.027 & & 0.064 \\
\hline
\end{tabular}

$\mathrm{R}^{2}=.14$ (Cox \& Snell), .19 ( Nagelkerke). * Significant. 
The Fishers exact test was used to compare the training result after six months as reported by the urotherapist versus the child and/or parents (Table 3.3). Significant difference could not be identified $\left(\chi^{2}=3.44, P=0.068\right)$, hence indicating that the opinion of the child and/ or parent were analogous with the reported results from the urotherapists. Additionally, a McNemar's test was performed to evaluate whether a good clinical training result at the end of the 10-day inpatient training would not be indicative of the child staying dry for six months (Table 3.4). No significant result was obtained even though 11 children had relapsed after 6 months, again indicating a definite positive effect of the training. This test was also used to compare urge complaints before training and two years after training. The result was highly significant $\left(\chi^{2}=2.24, P<0.05\right)$ indicating that far fewer children are suffering from urge complaints (Table 3.4 ).

Table 3.3: Comparison of training result recorded by urotherapist versus the child and/or parents

\begin{tabular}{lcc}
\hline $\mathrm{N}=44(100 \%)$ & Good/ improved result & Bad result \\
\hline Urotherapist & $32(72.7 \%)$ & $12(27.3 \%)$ \\
Child/parents & $28(63.6 \%)$ & $16(36.4 \%)$ \\
\hline
\end{tabular}

Fisher's exact test, $\chi^{2}(1)=3.44, P=0.068$.

Table 3.4: Selection of pre- and post-training questions on questionnaire

\begin{tabular}{lccc}
\hline $\mathrm{N}=44(100 \%)$ & Yes & No & $\chi^{2}(1)(P)$ \\
\hline Urge complaints before training? & $35(79.5 \%)$ & $9(20.5 \%)$ & $>0.05$ \\
Urge complaints 6 months after training? & $30(68.2 \%)$ & $14(31.8 \%)$ & $>0.05$ \\
Urge complaints 2 years after training? & $14(31.8 \%)$ & $30(68.2 \%)$ & $<0.05^{\mathrm{a}}$ \\
Wet during last 6 months? & $18(40.9 \%$ & $26(59.1 \%)$ & $>0.05$ \\
\hline
\end{tabular}

${ }^{a}$ McNemar's test $\chi^{2}(1)=2.24, P<0.05$.

\section{DISCUSSION}

It is impossible to unequivocally determine the key factors of success in this training program. The children receive a tremendous amount of attention combined with constant cognitive training on bladder and voiding habits to help them recognize and centrally suppress bladder over activity, rather than using all available help musculature as an emergency break. Regardless, age at clinical training, age at first contact, and months until clinical training were expected to predict training outcome. Children under the age of 9 are preferably not enrolled in this training program as their lack of motivation 
can be detrimental to the success of future training and a low age at first contact could possibly indicate a more complex or serious underlying cause of the urine incontinence. Also, certain types of surgery could indicate a more severe underlying problem and were therefore expected to influence training outcome. Age was found to be a predictor of a good training result, which is in line with the findings of other publications where children above the age of 8 demonstrate better and faster training results. ${ }^{1,6}$ The low number of participants may interfere with decent statistical analysis of any sub-group, possibly explaining how other variables could not be found to predict training outcome.

This training by experienced staff with intensive daily supervision, feedback and guidance has proven very effective. Of note, because of the years of clinical experience of the urotherapists and the intention to treat, children considered lacking appropriate age and/or motivation are not placed on the waiting list for clinical training yet as a certain cognitive level and motivation is deemed mandatory for successful completion of both the upcoming and future training. Questions that arise are whether a longer trajectory of professional help enhances clinical training results by simply adding up to what has been learned already by the children, or whether a longer trajectory is disadvantageous for the motivation and confidence of the child and/or parents yielding worse clinical training results. Hopefully, future research will demonstrate what is best for this therapy refractory group. Based on clinical experience, a shorter trajectory of professional help is expected to be favourable for the child's psychological development. Moreover, a shorter trajectory would also reduce medical expenses. Therefore, tertiary referral as soon as possible after outpatient treatment failure might be of paramount importance as the urotherapists in a tertiary referral centre have the best clinical experience to identify the optimal moment for a patient to enrol in a clinical training program.

Of note, in this report only outpatient urotherapy by a trained urotherapist is considered as true outpatient training. Medical advices or paramedical treatment is not considered as such. No difference in outpatient therapy results were observed between patients having received earlier outpatient urotherapy in our hospital when compared to being trained elsewhere. This is coherent with previous research indicating that for outpatient training, the attention offered to the child is of paramount importance. ${ }^{8}$

Additionally, a lower bladder volume observed in urodynamic testing when compared to age was expected to indicate a more severe clinical substrate and thus predict treatment outcome. Unfortunately, necessary data could not be retrieved as some medical files were incomplete. This will be evaluated in the near future. The training does not merely battle urine incontinence and $\mathrm{OAB}$ complaints. By treating urine incontinence, children have noticed less bullying at school and parents have noticed increased bonding with their 
child. ${ }^{9}$ Although not proven in a study when related to clinical training, one can imagine the psychological burden of bullying and parental emotional detachment on a child.

Regarding long-term follow-up, a good effect of the training was seen with a clear reduction in incontinence complaints. Far fewer children are suffering from urge complaints, although some patient had a relapse in complaints. An attempt to compare these results with the literature was unsuccessful as other publications combine patients with $\mathrm{OAB}$ and dysfunctional voiding. ${ }^{2,9}$ In this study, 26 (27.1\%) patients could not be reached for follow-up and the reasons are unknown. Regardless, an intensive and expensive clinical treatment conveys favorable long-term results on symptoms, quality of life and psychological well-being of the child. ${ }^{9}$ Taking these factors into account together with the reduction of hospital visits, surgery and the use of medication, one may wonder whether this inpatient training should be seen as expensive or rather as an investment.

\section{Limitations}

Retrospective study limitations and accompanying limited external validity apply to this report. The absolute number of participants to perform statistical analysis on was low, even though it was the number maximally achievable in this cohort. All patients were carefully selected by urotherapists and doctors for eligibility for the clinical training. The questions asked during follow-up regarding subjective experiences of patients and parents were not posed before training onset hence introducing bias due to reliance on memory. Lastly, long-term follow-up patient numbers were incomplete.

\section{Perspective}

Trusting on clinical experience, the number of months until clinical training is expected to be relevant for clinical training outcome. This could not be demonstrated in the entire 70 patient cohort but was observed in several cases individually. To further elaborate on the effects of the clinical training on quality of life. ${ }^{10}$ behavioral changes and the possible predictors of treatment outcome in patients suffering from $O A B$, a controlled trial will be set up with more patients in the near future.

\section{CONCLUSIONS}

This inpatient cognitive and biofeedback training program for refractory OAB complaints has demonstrated to cure or improve $74.3 \%$ of patients and conveyed favourable longterm results in approximately $70.5 \%$ of patients. A higher age during clinical training 
was found to be a predictor for a good training outcome. Other predictors could not be identified and will be re-evaluated in the near future. For now, swift tertiary referral in children with $O A B$ and failed outpatient training is suggested.

\section{Acknowledgements}

We would like to thank E van Rhenen and R Schappin, Paediatric Urology Centre WKZ Utrecht, for their help with the statistical analysis. 


\section{REFERENCES}

1 Chung JM, Lee SD, Kang DI, et al. Prevalence and associated factors of overactive bladder in Korean children 5-13 years old: A nationwide multicenter study. J Urology 2009; 73: 63-9.

2. Bachmann $\mathrm{CJ}$, Heilenkötter $\mathrm{K}$, Janhsen $\mathrm{E}$, et al. Long-term effects of a urotherapy training program in children with functional urinary incontinence: A 2-year follow-up. Scand J Urol Nephrol 2008; 42: 333-43.

3 Nevéus T, von Gontard A, Hoebeke P, et al. The standardization of terminology of lower urinary tract function in childrenand adolescents: report from the Standardisation Committee of the International Children's Continence Society. J Urol 2006; 176: 314-24.

4 Vijverberg MA, Elzinga-Plomp A, Messer AP, van Gool JD, de Jong TP. Bladder rehabilitation, the effect of a cognitive training programme on urge incontinence. Eur Urol 1997; 31: 68-72.

5 van Gool JD, de Jong TP, Winkler-Seinstra P, et al. Multi-center randomized controlled trial of cognitive treatment, placebo, oxybutynin, bladder training, and pelvic floor training in children with functional urinary incontinence. Neurourol Urodynam 2014; 33: 482-7.

6 Heilenkötter K, Bachmann C, Janhsen E, et al. Prospective evaluation of inpatient and outpatient bladder training in children with functional urinary incontinence. Urology 2006; 67: 176-80.

7 Yamanishi T, Yasuda K, Murayama N, Sakakibara R, Uchiyama T, Ito H. Biofeedback training for detrusor overactivity in children. J Urol 2000; 164: 1686-90.

8 Hoebeke P. Twenty years of urotherapy in children: What have we learned? Eur Urol 2006; 49: 426-8.

9 Vijverberg MA, Stortelder E, de Kort LM, Kok ET, de Jong TP. Long-term follow-up of incontinence and urge complaints after intensive urotherapy in childhood (75 patients followed Up for 16.2-21.8 years). Urology 2011; 78: 1391-6.

10 Bower WF, Wong EMC, Yeung CK. Development of a validated quality of life tool specific to children with bladder dysfunction. Neurourol Urodynam 2006; 25: 221-7.

11 Wiener JS, Scales MT, Hampton J, King LR, Surwit R, Edwards CL. Long-term efficacy of simple behavioral therapy for daytime wetting in children. J Urol 2000; 64: 786-90. 




\section{SENS-U: clinical evaluation of a full bladder notification - A pilot study}

Paul G. van Leuteren Anka J. Nieuwhof-Leppink Pieter Dik 
Introduction: Urinary incontinence is one of the most commonly treated disorders in children at school age. Recently, a new, wearable bladder sensor became available, the SENS-U Bladder Sensor. The SENS-U is a small, wireless ultrasonic sensor, which continuously monitors the bladder filling and provides a personalized notification when it is time to go to the toilet. In this study, the aim is to examine the performance of the SENS-U as a full-bladder-based notification system in children during daily life activities.

Patients and methods: In this pilot study, children (6-16 years) who were admitted for an inpatient bladder training were included. Parallel to one training day, the child would wear the SENS-U to estimate the bladder filling and it informed the child when the bladder was almost full. When the child received a full-bladder notification, the child was taught to inform the urotherapist/researcher, in order to determine the level of response.

Results: Fifteen patients (boys/girls: 7/8; mean age: $11.5 \pm 1.7$ years) were included. Based on a personalized volume-based threshold, the SENS-U notified these children of a full bladder with a median notification rate of $92.9 \%$. In the remaining cases, children voided before the threshold was reached (e.g. defecation). Children responded positively to the notification of the SENS-U, resulting in a median level of response equal to $100 \%$.

Conclusion: The SENS-U was able to monitor the natural bladder filling accurately during activities of daily living and provided a personalized notification to the children when it was almost time to go to the toilet. Future research will focus on investigating the efficacy of the SENS-U compared to daily clinical practices. 


\section{INTRODUCTION}

One of the most commonly treated disorders in children remains urinary incontinence. The reported prevalence of daytime wetting varies from 6-9\% at school age (6-10 years) and decreases with age. ${ }^{1}$ In accordance with the International Children's Continence Society, urotherapy is recommened for treating incontinence in children. Urotherapy is conservative-based management program for lower urinary tract dysfunction. Urotherapy includes explanation, demystification, lifestyle advice, pelvic floor training, biofeedback, and behavioral modification. ${ }^{2}$ An important part of the treatment is that children are taught how to respond adequately to their bladder filling and bladder signal.

Recently, a new, wearable ultrasonic bladder sensor became available, the SENS-U Bladder Sensor (SENS-U) (Novioscan, Nijmegen, the Netherlands), which is intended to support children who have involuntary urine loss by increasing their awareness of a full-bladder sensation. By continuously (i.e. 30 s) monitoring the bladder filling status, the SENS-U provides the child a personalized notification when it is almost time to go to the toilet.

The SENS-U has previously been clinically evaluated in 30 children during (video) urodynamics. ${ }^{3}$ Parallel to the standard cystometric procedure, the SENS-U estimated the anterior-posterior (A-P) bladder dimension to evaluate the filling status and relate it to the infused volume. This resulted in a full-bladder detection rate of more than $90 \%$ over a broad range of maximum voided volumes (71-463 $\mathrm{ml}$ ). Next, relating the infused volume to the estimated bladder dimensions resulted in a strong, positive correlation (median $r_{\mathrm{s}}=$ 0.94). ${ }^{3}$ Despite accurate performance during the (video) urodynamics, there were several differences when comparing it to using the SENS-U in daily (clinical) practice. First, the children maintained a static sitting position throughout the entire procedure. Next, the personalized notifications of the SENS-U were deactivated to minimize the impact on the clinically required (video) urodynamic procedure. Finally, (video) urodynamics is not the same as natural bladder filling, which may result in a different voiding behavior compared to daily life activities (e.g. differences in maximum voided volume). Therefore, this pilot study clinically evaluated the performance of the SENS-U in a group of children during regular physical activity and natural bladder filling. It was hypothesized that the SENS-U would be equally accurate during activities of daily living as during (video) urodynamics. In addition, the level of response to the provided full-bladder notification was assessed. 


\section{PATIENTS AND METHODS}

\section{SENS-U bladder sensor}

The SENS-U is a small ( $95 \times 55 \times 16 \mathrm{~mm})$, wearable, battery-operated sensor, which is positioned on the lower abdomen (each day) using a double-sided adhesive (combined with standard ultrasound gel) (Figure 4.1). The sensor is based on a combination of four ultrasonic transducers, arranged with a field of view of $30^{\circ} .^{3}$ The SENS-U transmits ultrasonic waves towards the bladder region and an internal algorithm automatically processes the received ultrasonic reflections of the bladder walls. This results in an average A-P bladder dimension which is related to estimate the bladder filling status. ${ }^{3}$ Based on the patient's maximum voided volume, a personalized threshold is set by the medical professional (i.e. pediatric urologist or a urotherapist) using the SENS-U mobile application. The SENS-U uses Bluetooth ${ }^{\circledR}$ Low Energy to wirelessly connect with the mobile application, which also allows the child, his or her caregivers and his or her physician to be informed of the bladder filling status in real time. As soon as the personalized threshold is (almost, at $80 \%$ ) reached (at $100 \%$ ), the SENS-U will provide a vibration notification on the child's abdomen and a message is sent to the mobile application, allowing to the child to go to the toilet in time.

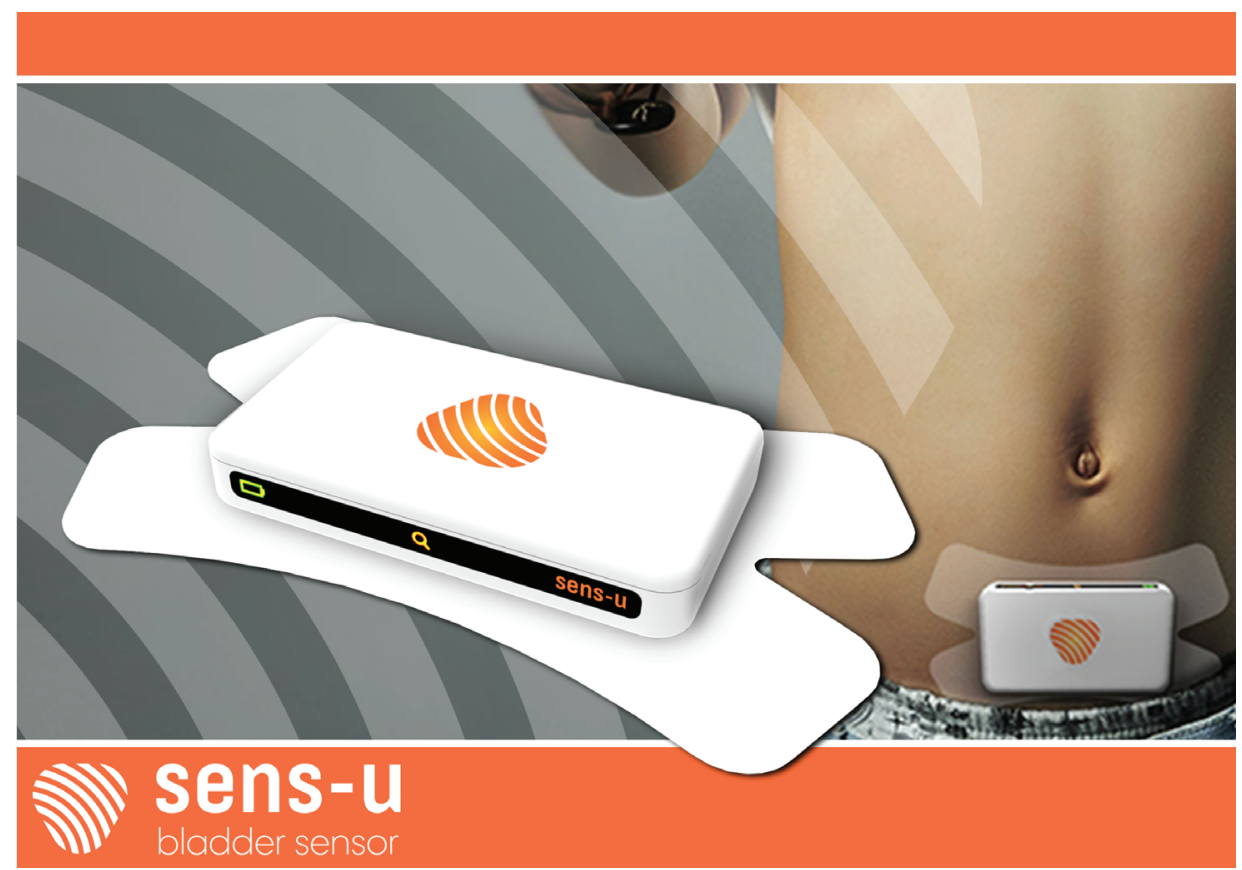

Figure 4.1: The SENS-U ${ }^{\circledR}$ Bladder Sensor is positioned on the lower abdomen by a skin-friendly adhesive and provides the child a personalized (vibration) notification when it is almost time to go to the toilet. 


\section{Experimental protocol}

To evaluate the SENS-U as a full-bladder-based notification system during activities of daily living, 15 patients were consecutively enrolled who were admitted to the Department of Pediatric Urology (University Medical Centre Utrecht) for an intensive inpatient bladder training program, which focuses on relearning, concentration, and awareness of the bladder filling. ${ }^{4}$

Patients were included between the ages of 6 to 16 years. With a sample size of 15 patients, it would be possible to estimate a full-bladder notification rate of $90 \%$ within a $95 \%$ confidence interval of $\pm 15.2 \%$, which was considered to be acceptable in this pilot study. ${ }^{5}$ Patients were excluded based on their body mass index (BMI) (obese $>95^{\text {th }}$ percentile, according to age and gender) and when they had abnormalities in the suprapubic skin region (e.g. breached skin, open wounds, sutures or a suprapubic catheter). ${ }^{6}$ These two factors influence proper sensor positioning and therefore the accuracy of the SENS-U. ${ }^{3}$

After written informed consent was obtained, the patient wore the SENS-U during one (daytime) training day, parallel to the inpatient bladder training. At the start of the training day, the SENS-U was positioned on the lower abdomen using the required double-sided adhesive (combined with standard ultrasound gel) just above $(1 \mathrm{~cm})$ the pubic bone, by palpation of the pubic symphysis. For each child, a personalized threshold was set, based on the uroflowmetry recordings from the previous training days. At $80 \%$ of this threshold, the SENS-U would provide the first notification, enabling the patient to go to the toilet in time. If the patient postponed micturition and ignored the device, a second notification (at $100 \%$ of the threshold) would be given once more to remind and to encourage the patient to go to the toilet. The patient was instructed to inform the urotherapist (or researcher) when the (vibration) notification was provided by the SENS-U, in order to determine the level of response. Furthermore, each time the patient needed to void, uroflowmetry was performed in order to assess the voiding pattern and voided volume.

During the procedure, data were documented on age, gender, length, weight, diagnoses (for medical files), micturition frequency, measured voided volumes, time of voiding, number of wet incidents, the notification frequency, and the response rate using an online case report form (Castor Electronic Data Capture, Ciwit BV, Amsterdam, the Netherlands). The acquired data were analyzed by descriptive statistics using SPSS (version 25.0; SPSS Inc., IBM Corp., USA). At the end of the training day, the SENS-U was removed from the lower abdomen and a short usability questionnaire was completed, examining the patient's experience on receiving the current type of notification. The patient was asked if he/she clearly felt the vibration notification and what kind of notification he/she would 
Table 4.1: Reponses to the Usability Questionnaire

\begin{tabular}{lll}
\hline $\mathrm{N}=15$ & Yes & No \\
\hline Did you feel the vibration notification clearly? & $13(87 \%)$ & $2(13 \%)$ \\
\hline What kind of notification do you prefer? & Vibration & $14(93 \%)$ \\
& $\begin{array}{l}\text { Push notification } \\
\text { (mobile app) }\end{array}$ & $2(13 \%)$ \\
Other, such as... & $3(20 \%)$ (i.e. sound) \\
\hline
\end{tabular}

prefer (Table 4.1). The SENS-U data itself were stored for offline postprocessing using MATLAB R2018 (MathWorks, Natick, MA). This study was approved by the Local Ethical Committee of the University Medical Centre Utrecht.

\section{RESULTS}

\section{Population}

In total, 15 patients (7 boys, 8 girls; mean age: $11.5 \pm 1.7$ years; mean BMI: $18.5 \pm 2.9$ $\mathrm{kg} / \mathrm{m}^{2}$, range: $15.2-25.7 \mathrm{~kg} / \mathrm{m}^{2}$ ] have been enrolled. Categorizing the population on (differential) diagnosis results in the following distribution: $47 \%$ urge incontinence/ overactive bladder, $27 \%$ dysfunctional voiding and $26 \%$ others (i.e. underactive bladder, small bladder capacity).

In this study, 56 uroflowmetry recordings were documented while the volume-based threshold was activated. In $78.6 \%$ ( $n=11 / 14$ patients), the uroflow pattern was smooth and bell shaped. In the remaining patients $(21.4 \%, n=3 / 14)$ the uroflow pattern was tower shaped $(n=1)$, plateau shaped $(n=1)$, and staccato $(n=1)$. One patient was excluded from analysis (patient no. 4, voided twice, plateau shaped) because despite receiving an accurate notification of the SENS-U, he was unable to empty his bladder properly due to his underactive bladder. As a result, the SENS-U kept on reminding this patient of a full bladder. To minimize the impact on his bladder training, the full-bladder notification of the SENS-U was deactivated (only used for observational purposes). Relating the each child's maximum voided volume (based on the 56 uroflowmetry recordings) to its expected bladder capacity $(\mathrm{EBC})^{7}$ resulted in 11 children $(78.6 \%)$ with a small maximum voided volume $(<65 \%$ of $E B C)$. For the other children $(n=3,21.4 \%)$, the maximum voided volume was considered normal (65-150\% of EBC). Only in 1 of 56 uroflowmetry recordings, a minor wet accident occurred (a few drops of urine). 


\section{Notification rate (\%)}

In this study, the SENS-U was able to monitor the natural bladder filling during activities of daily living $(n=14)$. It notified the child of a full bladder (based on the preset volumebased threshold) with a median notification rate equal to 92.9\% (range: 0-100\%) (Table 4.2 , left skewed distribution). Patient no. 5 did not receive any notification ( $n=2 / 56$ micturitions, outlier [ $>1.5 \cdot$ interquartile range $\{I Q R\}]$ ). In the remaining cases (13 of 56), children voided before the volume-based threshold was reached.

To illustrate the functionality of the SENS-U in clinical practice, Figure 4.2 presents several consecutive natural filling cycles of subject no. 13, a 10-year-old girl.

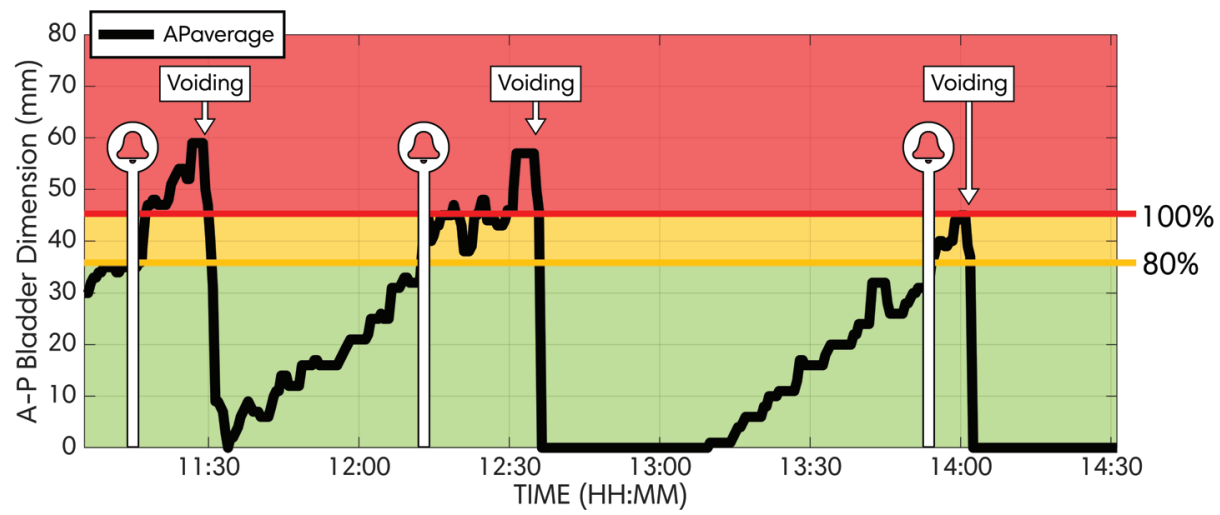

Figure 4.2: Three consecutive natural filling cycles stating the time of a provided, personalized notifications ([ $[$ ], at $80 \%$ (orange area) and at $100 \%$ (red area)) and the moment of voiding.

\section{Level of response (\%)}

In total, 13 children received a (vibration) notification of the SENS-U, prior to voiding, resulting in a total of 41 provided notifications. The children responded positively to the notifications ( $n=39 / 41$ ), resulting in a median level of response equal to $100.0 \%$ (range: $0-100 \%$ ) (Table 4.2, left skewed distribution). However, for one time, both patient no. 1 and no. 11 did not notify the urotherapist (or researcher) of a provided full-bladder (vibration) notification ( $n=2 / 41$, both outliers [> $1.5 \cdot I Q R])$.

Considering the final usability questionnaire, children clearly had a preference for the discrete, vibration notification (93\%) (Table 4.1). Next, $13 \%$ of the patients thought the smartphone notification would be beneficial. Finally, $20 \%$ of the children also had other ideas for a notification, like a (minor) sound, similar to the wetting alarms, or direct notification between the device and the urotherapist (or researcher). 
Table 4.2: Descriptive statistics for the notification $\operatorname{rate}^{1}(\%)$ and the level of response ${ }^{1}(\%)$

\begin{tabular}{|c|c|c|c|c|}
\hline & Median & $\begin{array}{c}\text { Range } \\
\text { (min-max) }\end{array}$ & $\begin{array}{c}\text { IQR } \\
\left(25^{\text {th }}-75^{\text {th }}\right. \\
\text { percentile })\end{array}$ & $\begin{array}{c}\text { Outliers } \\
(>1.5 \cdot \mathrm{IQR})\end{array}$ \\
\hline Notification rate (\%) [n = 14] & 92.9 & $0-100$ & $61.7-100$ & Patient no. $5(0 \%)$ \\
\hline Level of response (\%) [n = 13] & 100.0 & $0-100$ & $100-100$ & $\begin{array}{c}\text { Patient no. } 1(0 \%) \\
\text { Patient no. } 11(66.7 \%)\end{array}$ \\
\hline
\end{tabular}

${ }^{1}$ Left skewed distribution. IQR, interquartile range; min, minimum; max, maximum.

\section{DISCUSSION}

The current pilot study was initiated to clinically assess the performance of the SENS-U for monitoring natural bladder filling in children during activities of daily living. This evaluation demonstrated that the SENS-U is an accurate, easy to use, and patient-accepted method for detecting the bladder filling and notifying children before a full bladder.

\section{Notification rate (\%)}

However, in several cases, the SENS-U did not provide the child with a notification before he/she went to the bathroom. Reasons for this can be divided into two categories: device related and study design related. Considering device-related reasons, two patients (no. 2 and 5) were identified for whom the device could not detect the bladder properly because of a (relatively) obese abdomen, resulting in a misalignment between the bladder position and the field of view of the SENS-U. ${ }^{3}$ Despite excluding subjects based on their BMI (obese $>95^{\text {th }}$ percentile, according to age and gender), these two patients were still classified as overweight $\left(85^{\text {th }}-95^{\text {th }}\right.$ percentile). Therefore, it is advised to be aware of the influence of the abdominal curvature when implementing the SENS-U during clinical practice. Next, initial sensor positioning also influenced the notification rate in some patients. For example, in patient no. 9 and 12, the device was positioned slightly too low, resulting in the acoustic interaction between the SENS-U and the pubic bone. As a result, the SENS-U did not monitor the entire bladder region, underestimating the actual bladder volume present and therefore unable to reach the personalized preset threshold. It is advised to further optimize the internal algorithm to compensate for partial sensor misplacement.

When considering study designerelated reasons, first of all, the SENS-U was positioned at the start of the training day, when the bladder was (often) empty after the firstmorning void. Therefore, often no position verification (device functionality) could be initiated because it requires a certain amount of volume present. Secondly, to minimize the 
impact on the child's bladder training program, the children were informed to first act on their own full-bladder sensation and training instructions. Consequently, some children (especially with urge incontinence/overactive bladder or due to defecation) sometimes went to the toilet before the bladder volume reached their personalized threshold (based on their maximum voided volume). Finally, for the first two included patients (no. 1 and 2 ), the notification rate was relatively low ( $16.7 \%$ and $60.0 \%$, respectively) because their voiding behavior was significantly influenced by the fact that these patients were monitored in parallel during their inpatient bladder training. Analysis of their voiding data showed that as soon as patient no. 2 went to the toilet, patient no. 1 followed her within minutes. In combination with a strictly followed voiding schedule, these two patients both did not experience a natural bladder filling, emptying their bladder before they reached their personalized, volume-based threshold.

\section{Level of response (\%)}

From all the provided full-bladder notifications ( $n=41$ ), only twice (patient no. 1 and 11) the patients did not inform their urotherapist (or researcher). In patient no. 1, a notification was provided by the SENS-U, followed by proceeding to the toilet. Despite a clear change in facial expression (indicating the awareness of the vibration), she said that she had not felt the notification of the SENS-U. Therefore, the level of response for this particular patient was equal to zero (outlier [>1.5 $\cdot$ IQR]). Next, patient no. 11 received a notification three times of which she alerted the urotherapist two times (level of response: $66.7 \%$, outlier [>1.5 $\cdot I Q R])$. She did not alert the urotherapist because her attention was too focused on a demanding activity, playing a game. Nevertheless, she responded to the full-bladder notification naturally by going to the toilet in time and remained dry. Finally, when considering the user experience, almost all children preferred the provided vibration notification. Only one child preferred a direct notification between the device and the urotherapist (or researcher).

\section{Perspective}

Future research will focus on investigating the efficacy of the SENS-U in comparison to daily clinical practice, e.g. as a new adjunct in (inpatient or outpatient) bladder training (compared to i.e. timed voiding, alarm wrist watches) and to assist in guiding the timing for volume-dependent intermittent catheterization. 


\section{CONCLUSIONS}

This study demonstrated that the SENS-U Bladder Sensor is able to monitor the natural bladder filling in children during activities of daily living and to notify them of a full bladder with a median notification rate of $92.9 \%$ (based on a personalized volume-based threshold) and a median level of response equal to $100 \%$, supporting the initial hypothesis that the SENS-U would be equally accurate during activities of daily living as during (video) urodynamics. Despite the generally high clinical performance of the SENS-U, childhood obesity and accurate sensor positioning are factors of influence which should be considered. Future research will focus on investigating the efficacy of the SENS-U compared to daily clinical practices.

\section{Acknowledgments}

The authors would like to thank all the pediatric urologists, urotherapists, and nurses at the Department of Pediatric Urology in the Wilhelmina Children's Hospital UMC Utrecht (Utrecht, the Netherlands) for their help in the recruitment of the patients and their assistance during the study procedure.

\section{Ethical approval}

This study was approved by the Local Ethical Committee of the University Medical Centre Utrecht.

\section{Funding}

This work was supported by Pontes Medical (Utrecht, The Netherlands, www.pontesmedical. com), Novioscan (Nijmegen, The Netherlands, www.novioscan.com). This work is partly funded in the ULIMPIA project funded by PENTA under grant number PENTA-2017-Call216101-ULIMPIA. www.ulimpia-project.eu.

\section{Competing interests}

This pilot study was performed by a technical physician P.G. van Leuteren in close collaboration with the Department of Pediatric Urology,Wilhelmina Children's Hospital UMC Utrecht (Utrecht, The Netherlands). He is also an employee of Novioscan. The other authors have no conflict of interest to declare. 


\section{REFERENCES}

1 Nederlandse Vereniging voor Urologie (NVU). Richtlijn Urine incontinentie bij kinderen. 2008. https://www.nvu.nl/en-us/kwaliteit/richtlijnen/actuelerichtlijnen.aspx

2 Chang S-J, Van Laecke E, Bauer SB, von Gontard A, Bagli D, Bower WF, et al. Treatment of daytime urinary incontinence: A standardization document from the International Children's Continence Society. Neurourol Urodyn 2017; 36: 43-50.

3 van Leuteren PG, Klijn AJ, de Jong TPVM, Dik P. SENS-U: Validation of a wearable ultrasonic bladder monitor in children during urodynamic studies. J Pediatr Urol 2018; 14: 569.e1-e6.

4 Vijverberg MAW, Stortelder E, De Kort LMO, Kok ET, De Jong TPVM. Long-term follow-up of incontinence and urge complaints after intensive urotherapy in childhood (75 patients followed up for 16.2-21.8 years). Urology 2011; 78: 1391-6.

5 Moore C, Carter R. Recommendations for planning pilot studies in clinical and translational research. Clin Trans/ Sci 2011; 4: 332-7.

6 National Center for Health Statistics in collaboration with the National Center for Chronic Disease Prevention and Health Promotion (2000). 2 to 20 years Boys: Body mass index-forage percentiles. https://www.cdc.gov/growthcharts/

7 Austin PF, Bauwer SB, Bower W, et al. The standardization of terminology of lower urinary tract function in children and adolescents: Update report from the Standardisation Committee of the International Children's Continence Society. Neurourol Urodyn 2016; 36: 471-81. 



\section{Pelvic floor rehabilitation in children with functional LUTD: Does it improve outcome?}

Anka J. Nieuwhof-Leppink*

Frank-Jan van Geen*

Elise M. van de Putte

Marja A.G.C. Schoenmakers

Tom P.V.M. de Jong

Renske Schappin

* These authors contributed equally to this work. 
Introduction: If children do not experience satisfactory reliefof lower urinary tract dysfunction (LUTD) complaints after standard urotherapy is provided, other treatment options need to be explored. To date, little is known about the clinical value of pelvic floor rehabilitation in the treatment of functional voiding disorders.

Objective: Therefore, we compared pelvic floor rehabilitation by biofeedback with anal balloon expulsion (BABE) to intensive urotherapy in the treatment of children with inadequate pelvic floor control and functional LUTD.

Study design: A retrospective chart study was conducted on children with functional incontinence and inadequate pelvic floor control. All children referred for both intensive inpatient urotherapy and pelvic floor rehabilitation between 2010 and 2018 were considered for inclusion. A total of 52 patients were eligible with 25 children in the group who received BABE before inpatient urotherapy, and 27 children in the group who received BABE subsequently to urotherapy. Main outcome measurement was treatment success according to International Children's Continence Society criteria measured after treatment rounds and follow-up.

Results: Baseline characteristics demonstrate no major differences between the BABE and control group. There was a significant difference in improvement between BABE and inpatient urotherapy after the first and second round of treatment (round 1: BABE vs urotherapy; $12 \%$ vs $70 \%$, respectively, round 2 : urotherapy vs BABE; $92 \%$ vs $34 \%$, respectively, both $P<0.001$ ). In both cases, the urotherapy group obtained greater results (Figure 5.1). When the additional effect of BABE on urotherapy treatment is assessed, no significant difference is found $(P=0.355)$ in the children who received BABE; 30 (58\%) showed improvement on pelvic floor control.

Discussion: Our findings imply that training pelvic floor control in combination with inpatient urotherapy does not influence treatment effectiveness on incontinence. Intensive urotherapy contains biofeedback by real-time uroflowmetry; children receive direct feedback on their voiding behaviour. Attention offered to the child and achieving cognitive maturity with corresponding behaviour is of paramount importance. It is known that combining several kinds of biofeedback does not enhance the outcome. However, our results do not provide a conclusive answer to the effectiveness of pelvic floor physical therapy in the treatment of children with LUTD because we specifically investigated BABE.

Conclusion: In this study, we could not prove that pelvic floor rehabilitation by BABE has an additional effect on inpatient urotherapy on incontinence outcomes. Considering the invasive nature of $B A B E$, the use of $B A B E$ to obtain continence should therefore be discouraged.

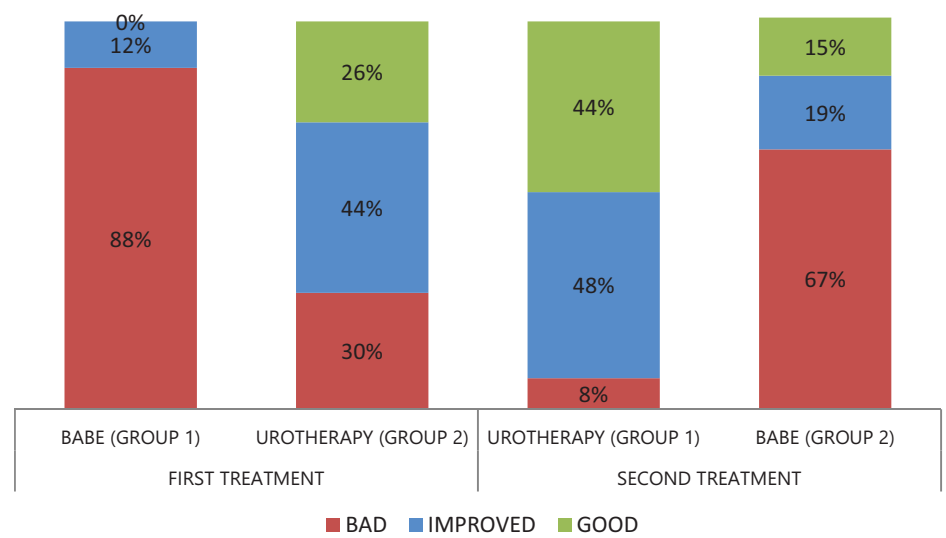

Figure 5.1: Treatment outcome (ICCS criteria). 


\section{INTRODUCTION}

Lower urinary tract dysfunction is an umbrella term for filling and voiding disorders that, if untreated, can come with urinary incontinence and/or recurrent urinary tract infections, compromised self-esteem and eventually even renal impairment. ${ }^{1-4}$ As stated by the International Children's Continence Society (ICCS), standard urotherapy is considered to be the first-line therapy in the treatment of children with functional lower urinary tract dysfunction (LUTD). ${ }^{4}$ This conservative-based therapy aims on rehabilitating the lower urinary tract and encompasses five key elements. ${ }^{4,5}$ First, age-appropriate information is provided to achieve demystification of the underlying dysfunction. Second, instructions are given on voiding and bowel habits encouraging behavioural modification. Third, selfawareness is created by the use of a bladder diary. Fourth, life-style advices are provided as foothold to enhance therapy compliance. Finally, support is offered during the whole process to patients and caregivers. ${ }^{4,5}$ First-line therapy comprising the aforementioned elements of standard urotherapy has been provided for decades by a wide range of healthcare professionals. ${ }^{5,6}$

If children do not experience satisfactory relief of LUTD complaints after standard urotherapy is provided, other treatment options need to be explored. Specific interventions within urotherapy that can be considered include diverse techniques of pelvic floor biofeedback, cognitive behavioural therapy and other forms of psychological treatment. ${ }^{4}$ Several publications describe the effect of pelvic floor biofeedback, wherein authors assume that (re-)establishing voluntary pelvic floor control can be of added value in the treatment of LUTD. ${ }^{7-11}$ Children can learn to encounter imperative urge by making use of the perineal-detrusor inhibitory reflex, suppressing a detrusor contraction by an active contraction of the pelvic floor muscles, whereas a dysfunctional voiding pattern can be avoided by voluntary pelvic floor relaxation. ${ }^{1,12-14}$ The ability to localize the pelvic floor muscles (PFMs), or proprioception, is deemed crucial when performing such a voluntary contraction or relaxation. ${ }^{9,10}$ Although the relationship between pelvic floor function and incontinence in adults has been portrayed in detail, in children, this relationship remains unclear. ${ }^{15,16}$ It is tempting to believe that, albeit the cause of incontinence in adults is thought to be different, improving active control over PFM can be essential in both. In current clinical practice, the elements of standard urotherapy and pelvic floor rehabilitation (PFR) programs are already regularly being combined. ${ }^{1,6,8-10,17,18}$

At our institution, an inpatient intensive urotherapy program is offered to children who received unsuccessful standard urotherapy alone or in combination with a PFR program with pelvic floor exercises provided by a physiotherapist in general practice. This 10-day 
cognitive behavioural bladder training is considered to be the most intensive form of urotherapy and embraces both pelvic floor biofeedback by real-time uroflowmetry as well as extensive behavioural modification provided by urotherapists.

Being a tertiary referral centre, children with refractory complaints are frequently referred for paediatric urological treatment to our outpatient clinic. As part of our standard protocol, a perineal ultrasonography is performed to determine whether the child can control its PFM at will. ${ }^{7}$ In case of inadequate control of the pelvic floor, children are sometimes referred to the physiotherapist for additional physical therapy in the form of intensive PFR by Biofeedback with Anal Balloon Expulsion (BABE). In an earlier study, the effectiveness of this treatment has been reported but it was noted that the clinical value of adequate pelvic floor control in the treatment of LUTD, in terms of decrease in number of wettings, was still unclear. ${ }^{7}$ The aim of this study was to assess the added value of PFR by BABE in the urotherapeutic treatment of children with refractory LUTS and the inability to control their PFM at will. We hypothesized that establishing voluntary pelvic floor control before inpatient urotherapy would significantly enhance treatment outcome.

\section{MATERIALS AND METHODS}

The institutional review board committee classified the present study as exempt of the Medical Research Involving Human Subjects Act. Data from medical charts have been retrospectively collected and anonymized. All children who were referred for both intensive inpatient urotherapy and additional pelvic floor rehabilitation by BABE between 2010 and 2018 were assessed for inclusion. This is only a selective group of children treated for incontinence in our centre. Exclusion criteria were non-functional causes of LUTD (i.e. neurologically or anatomically), normal voluntary pelvic floor control, surgery for urological anatomical abnormalities other than endoscopic de-obstruction of posterior urethral valves or meatus correction and referral for other reasons than LUTD treatment. In addition, children who were still in training and children who could not be trained by standard protocol because of behavioural problems were also excluded. This resulted in 52 eligible children (Figure 5.2).

Children were retrospectively divided into two groups based on treatment order. In the "BABE first" group ( $n=25)$, children who received BABE before inpatient urotherapy were included. All "BABE first" patients received inpatient urotherapy subsequently. In the "urotherapy first" group $(n=27)$, only children with insufficient response to inpatient urotherapy who received BABE treatment subsequently were included. 


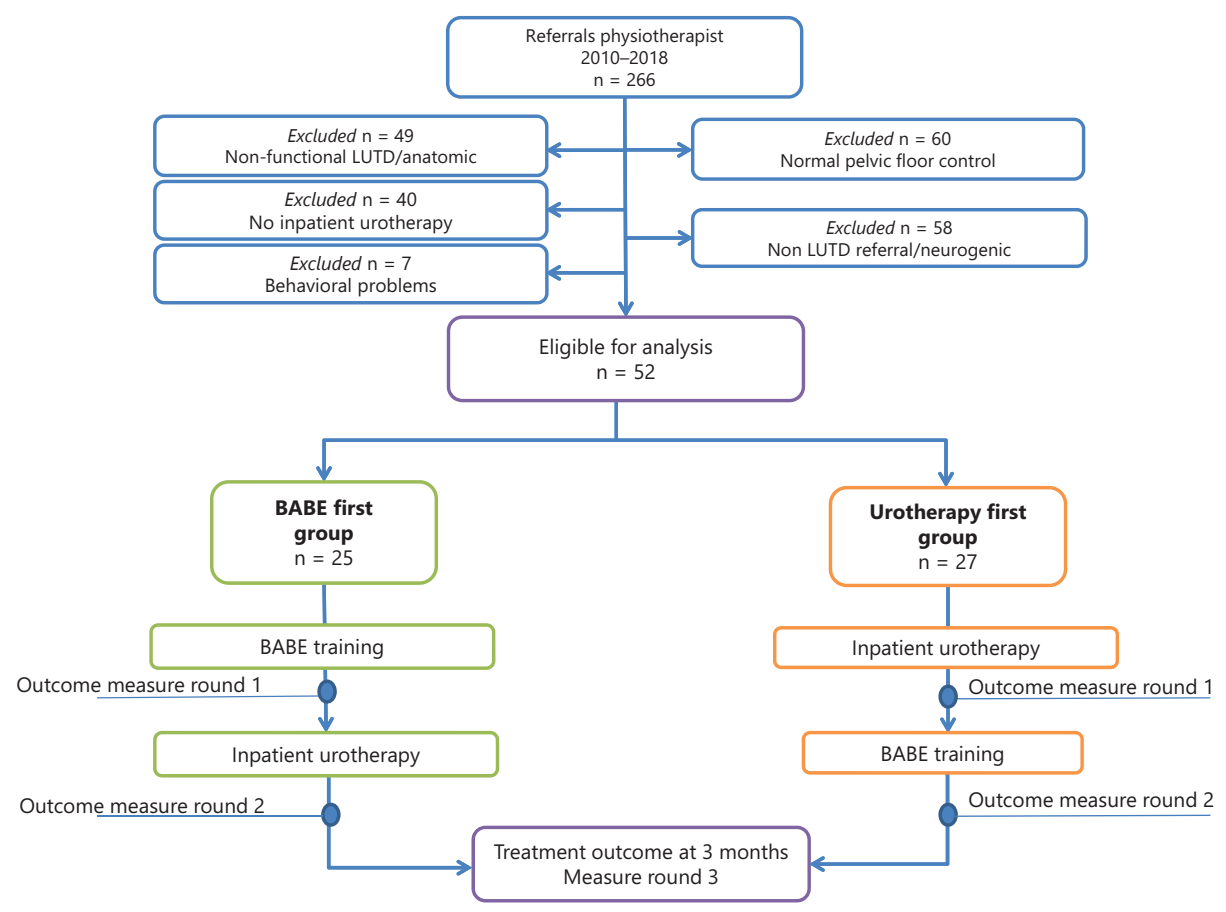

Figure 5.2: Flowchart inclusion.

Functional LUTD and underlying pathophysiology were diagnosed from voiding history, uroflowmetry patterns and the presence of PVR as measured by ultrasound immediately after voiding. The diagnosis was not routinely confirmed by urodynamic studies. For our refractory LUTS population, uroflowmetry and PVR alone are not sufficient to diagnose inadequate pelvic floor control. Electromyography can be unreliable and was therefore used only when results from other diagnostic instruments were not conclusive. A perineal ultrasonography therefore forms part of our standard protocol. Inadequate control of the pelvic floor was assumed if confirmed by both the urologist and physiotherapist. Children with all types of LUTS were included because we did not assess a specific diagnosis but a symptom complex. Therefore, the main outcome of the study was overall symptom reduction.

\section{Perineal ultrasonography}

Perineal ultrasonography was performed in all children and interpreted as described in a previous study. ${ }^{7}$ PFM control is determined by assessing the change in length of the urethra and the displacement of the urethral structures when the patient is asked to 
voluntarily contract the PFM. Adequate command of the pelvic floor is present when a displacement of the bladder neck towards the inferoposterior margin of the symphysis pubis and a simultaneous elongation of the urethra is observed. ${ }^{7,19} \mathrm{~A}$ combined downward movement of the bladder neck towards the sacrum and shortening of the urethra is defined as the pelvic floor paradox. ${ }^{7}$ If a displacement cannot be sustained for several seconds, is of insufficient force (i.e. $<50 \mathrm{mmHg}$ ) or is completely absent, the presence of inadequate pelvic floor control is diagnosed.

\section{BABE training}

Before the PFM is assessed by a physical therapist, age-appropriate information about the problem is given to patients and parents. To exclude underlying neurological pathophysiology, the lumbosacral neurology is examined. Anal sphincter and pelvic floor contractions are examined rectally by digital examination. If manual examination indicates inadequate pelvic floor control, explanation of the physiological PFM function is provided and biofeedback treatment by anal pressure balloon expulsion is offered.

During the 1-h consultation, the patient is instructed on how to perform an adequate PFM contraction, while being supported by biofeedback due to real-time pressure registration by anal balloon. If normalization of the pelvic floor control is not achieved during the first visit, children are granted a portable biofeedback device for a three-week home training program with subsequent re-assessment by the physical therapist. Treatment effect on the pelvic floor is regarded positive if children are able to perform a voluntary, adequate pelvic floor contraction of sufficient force $\left(50-100 \mathrm{~mm} \mathrm{Hg}\right.$ ) for several seconds. ${ }^{7}$

\section{Inpatient urotherapy}

Children refractory to first-line therapy are offered a 10-day inpatient urotherapy program with intensive supervision by experienced urotherapists. ${ }^{20}$ This urotherapy program emphasizes bladder awareness and is classified as a form of intensive urotherapy. In addition to the five key elements of standard urotherapy as stated by the ICCS, it encompasses specific interventions such as pelvic floor biofeedback on the urinary stream by real-time uroflowmetry and cognitive behavioural therapy. ${ }^{4}$ At the start of clinical urotherapy, all anticholinergic medication is stopped. After completion of the 10-day course, follow-up includes three months of supportive phone calls and, where needed, additional personalized instructions to encourage and maintain the child's motivation. 


\section{Treatment order}

All children included in this study received first-line therapy including standard urotherapy in general hospitals before they were referred to our tertiary referral centre (Table 5.1). For children with an inability to control their pelvic floor at will, we have two treatment options. The first is urotherapy and the second is BABE (Appendix 5.1). BABE is never considered as a first treatment option, but all referred children have at least received standard urotherapy elsewhere, and therefore, we sometimes choose to start our treatment with BABE. Retrospectively, we cannot trace back why some children received $\mathrm{BABE}$ and others received clinical urotherapy as first treatment. Clinician, parental, and child preferences probably play a role in this treatment choice.

When $B A B E$ does not give the desired results, clinical urotherapy is usually started. This was the case in all children that received $B A B E$ as first treatment in our centre. BABE is considered as an additional treatment after clinical urotherapy when children relapse

Table 5.1: Patient characteristics

\begin{tabular}{|c|c|c|}
\hline Variables & $\begin{array}{c}\text { Group } 1 \text { - BABE first } \\
\qquad n=25\end{array}$ & $\begin{array}{l}\text { Group } 2 \text { - Urotherapy first } \\
\qquad n=27\end{array}$ \\
\hline Sex (\% females) & $15(60 \%)$ & $19(70 \%)$ \\
\hline Mean age years,-date of entry (SD) & $8.9(3.8)$ & $7.9(2.4)$ \\
\hline \multicolumn{3}{|l|}{ LUTD symptoms (\%) } \\
\hline Daytime urinary incontinence (DUI) & $18(94.7 \%)$ & $21(100.0 \%)$ \\
\hline Frequency & $>9 x(40 \%)$ & $>7 x(48 \%)$ \\
\hline Urgency & $18(72 \%)$ & $21(78 \%)$ \\
\hline Post-void residual & $8(32 \%)$ & $13(48 \%)$ \\
\hline Recurrent urinary tract infections & $10(40 \%)$ & $16(59 \%)$ \\
\hline Constipation & $11(44 \%)$ & $16(59 \%)$ \\
\hline Enuresis & $15(60 \%)$ & $16(59 \%)$ \\
\hline \multicolumn{3}{|l|}{ Flowmetry } \\
\hline Bell-shaped & $8(32 \%)$ & $4(15 \%)$ \\
\hline Staccato-shaped & $13(52 \%)$ & $16(59 \%)$ \\
\hline Other & $4(16 \%)$ & $7(26 \%)$ \\
\hline \multicolumn{3}{|l|}{ Diagnosis (\%) } \\
\hline Overactive bladder (OAB) & $15(60 \%)$ & $8(30 \%)$ \\
\hline Dysfunctional voiding (DV) & $4(16 \%)$ & $6(22 \%)$ \\
\hline Combined OAB/DV & $4(16 \%)$ & $10(37 \%)$ \\
\hline Other & $2(8 \%)$ & $3(11 \%)$ \\
\hline \multicolumn{3}{|l|}{ Treatment before referral } \\
\hline Urotherapy & $20(80 \%)$ & $15(56 \%)$ \\
\hline Physiotherapy & $15(60 \%)$ & $10(37 \%)$ \\
\hline Anticholinergics & $17(68 \%)$ & $10(37 \%)$ \\
\hline
\end{tabular}


and are still unable to control their pelvic floor at will. This represents a select group of children in our centre because usually when children relapse after urotherapy, they receive urotherapy again. Nonetheless, $74 \%$ of children become dry after one clinical urotherapy training. ${ }^{20,23}$

Because the aforementioned policy has created a group of patients with the same diagnosis who has received two treatments in a different order, we have a natural experiment.

\section{Outcome measures}

Outcome is assessed by the evaluation of changes in five predetermined variables (number of wettings, urgency, frequency, flow pattern and the existence of urinary tract infections) and quantified in accordance with the ICCS standardization paper, resulting in the categories good, improved and bad..$^{5}$ To compare treatment effect between groups, outcome was dichotomized into good/improved and bad. Outcome was assessed at three moments, as shown in Figure 5.2.

\section{Statistical analysis}

Statistical analyses were performed using IBM Statistical Package for Social Sciences software (version 25; SPSS). Categorical data between both groups were compared using Fisher's exact test. In all tests, the level of statistical significance was predefined at $P<$ 0.05 (two-sided).

\section{RESULTS}

Data of the 52 included children are presented in Table 5.1; child characteristics are given by group. The mean age at the start of treatment was 9.6 years $(S D=3.0)$ in the BABE first group and 9.4 years $(S D=1.8)$ in the urotherapy first group.

During intake at the outpatient clinic visit, a staccato voiding pattern was found in half of the children, equally divided over both groups. Ninety-two percent of children in the BABE first group and $89 \%$ in the urotherapy first group had an overactive bladder (OAB), dysfunctional voiding (DV) or a combination of those. One of the urologists referred most of the children $(n=29)$ to the physical therapist for PFR by BABE.

When outcome is compared after the first treatment round, $12 \%$ improved after BABE and $70 \%$ achieved an improved or good result after inpatient urotherapy. The group that received $B A B E$ first received urotherapy immediately after finishing $B A B E$. The group 
that received inpatient urotherapy first had BABE when their results declined, which was about a year after the start of urotherapy. When outcome is compared after the second treatment round, 34\% achieved an improved or good result after BABE and $92 \%$ gained a comparable result after intensive urotherapy. After both the first and second treatment rounds, results were significantly better for the urotherapy group. After follow-up, when both groups had received both BABE and inpatient urotherapy, no significant difference is found between groups (Table 5.2). There are no large differences in outcomes for each individual diagnosis (Table 5.3).

Table 5.2: Treatment result

\begin{tabular}{|c|c|c|c|c|}
\hline Variables & $\begin{array}{c}\text { Group } 1 \text { - BABE first } \\
\qquad n=25\end{array}$ & $\begin{array}{l}\text { Group } 2 \text { - Urotherapy first } \\
\qquad n=27\end{array}$ & $\begin{array}{l}\text { Fisher's } \\
\text { exact test }\end{array}$ & $P$ \\
\hline First treatment & BABE & Urotherapy & & \\
\hline Age, mean y (SD) & $9.6(3.0)$ & $9.4(1.8)$ & & \\
\hline Treatment result (ICCS) & & & 18.12 & $<0.001$ \\
\hline Good & - & $7(26 \%)$ & & \\
\hline Improved & $3(12 \%)$ & $12(44 \%)$ & & \\
\hline Bad & $22(88 \%)$ & $8(30 \%)$ & & \\
\hline \multicolumn{5}{|l|}{ PFR results } \\
\hline Good & $14(56 \%)$ & - & & \\
\hline Improved & $4(16 \%)$ & - & & \\
\hline Bad & $7(28 \%)$ & - & & \\
\hline Second treatment & Urotherapy & BABE & & \\
\hline Age, mean y (SD) & $9.8(3.6)$ & $10.8(1.7)$ & & \\
\hline Treatment result (ICCS) & & & 18.88 & $<0.001$ \\
\hline Good & $11(44 \%)$ & $4(15 \%)$ & & \\
\hline Improved & $12(48 \%)$ & $5(19 \%)$ & & \\
\hline Bad & $2(8 \%)$ & $18(67 \%)$ & & \\
\hline \multicolumn{5}{|l|}{ PFR results } \\
\hline Good & - & $16(59 \%)$ & & \\
\hline Improved & - & $5(19 \%)$ & & \\
\hline Bad & - & 5 (19\%) & & \\
\hline \multicolumn{5}{|l|}{ Long-term effect ( $3 \mathrm{~m})$} \\
\hline Treatment result (ICCS) & & & 1.38 & 0.355 \\
\hline Good & $12(48 \%)$ & $6(22 \%)$ & & \\
\hline Improved & $6(24 \%)$ & $11(41 \%)$ & & \\
\hline Bad & $5(20 \%)$ & $10(37 \%)$ & & \\
\hline Unknown & $2^{a}$ & - & & \\
\hline
\end{tabular}

a Still in follow-up. 
Table 5.3: Outcome treatment per individual diagnosis

\begin{tabular}{|c|c|c|c|c|}
\hline \multirow{2}{*}{$\begin{array}{l}\text { Variables } \\
\text { Result first treatment }\end{array}$} & \multicolumn{2}{|c|}{$\begin{array}{c}\text { Group } 1 \text { - BABE first } \\
\qquad n=25\end{array}$} & \multicolumn{2}{|c|}{$\begin{array}{l}\text { Group 2- Urotherapy first } \\
\qquad n=27\end{array}$} \\
\hline & Bad & Good & Bad & Good \\
\hline \multicolumn{5}{|l|}{ Per diagnosis } \\
\hline$O A B$ & $12(48 \%)$ & $3(12 \%)$ & $2(74 \%)$ & $6(22 \%)$ \\
\hline DV & $4(16 \%)$ & - & $3(11 \%)$ & $3(11 \%)$ \\
\hline Combined OAB/DV & $4(16 \%)$ & - & $3(11 \%)$ & $7(26 \%$ \\
\hline Other & $2(8 \%)$ & $3(12 \%)$ & $2(7 \%)$ & $3(11 \%)$ \\
\hline Result second treatment & Bad & Good & Bad & Good \\
\hline \multicolumn{5}{|l|}{ Per diagnosis } \\
\hline $\mathrm{OAB}$ & $1(4 \%)$ & $14(56 \%)$ & $2(19 \%)$ & $3(11 \%)$ \\
\hline DV & - & $4(16 \%)$ & $2(7 \%)$ & $4(15 \%)$ \\
\hline Combined OAB/DV & $1(4 \%)$ & $3(12 \%)$ & $8(30 \%)$ & $2(7 \%)$ \\
\hline Other & - & $2(8 \%)$ & $3(11 \%)$ & - \\
\hline Result long term & Bad & Good & Bad & Good \\
\hline \multicolumn{5}{|l|}{ Per diagnosis } \\
\hline$O A B$ & $2(9 \%)$ & $11(48 \%)$ & $2(7 \%)$ & $6(22 \%)$ \\
\hline DV & $1(4 \%)$ & $3(13 \%)$ & $3(11 \%)$ & $3(11 \%)$ \\
\hline Combined OAB/DV & $1(4 \%)$ & $3(13 \%)$ & $3(11 \%)$ & $7(26 \%)$ \\
\hline Other & $1(4 \%)$ & $1(4 \%)$ & $4(15 \%)$ & $1(4 \%)$ \\
\hline
\end{tabular}

We also explored the additional effect of BABE on urotherapy, by comparing the results of $B A B E p$ urotherapy in the BABE first group vs urotherapy alone in the urotherapy first group. No significant difference was found between these groups (Fisher's exact test = 3.91, $P=0.08)$.

\section{DISCUSSION}

Our results show that inpatient urotherapy is more effective than PFR by BABE in obtaining continence based on ICCS criteria. The effectiveness of inpatient urotherapy was in line with an earlier study on children with first-line therapy refractory OAB. ${ }^{20}$ Inpatient urotherapy does not seem to improve pelvic floor functioning. No additional clinical value was found of neither before nor after inpatient urotherapy. Our findings imply that the presence or absence of adequate pelvic floor control does not seem to influence urotherapy effectiveness.

To date, the exact relationship between voluntary pelvic floor control and incontinence complaints in children has still not been clarified. ${ }^{15,16}$ In a report ${ }^{13}$ that assessed a norma- 
tive population of children free of bladder and bowel disorders, it was described that $30 \%$ of the children showed an inappropriate displacement direction of the pelvic floor during voluntary contraction. The researchers concluded that the displacement direction and coordination of the pelvic floor in healthy children is highly variable. ${ }^{13}$ Although several studies report on the existence of inadequate or absent pelvic floor command, they do not mention the clinical relevance of their findings nor the effect of PFM rehabilitation on LUTD symptomatology. ${ }^{1,8,9,21}$ A prospective study on children with functional LUTD showed that improvement of the pelvic floor function was statistically significant after an inpatient urotherapy program that includes biofeedback by anal plug EMG and realtime uroflowmetry. ${ }^{1}$ An additional evaluation of the long-term effects of treatment after 32 months noted that, albeit the incontinence complaints did not increase, voluntary pelvic floor control had significantly declined. ${ }^{2}$ Although the authors did report on pelvic floor control and its rehabilitation, the influence of voluntary pelvic floor control on the treatment outcome was not discussed.

To evaluate and compare our results, it is essential to consider the context of the study. We assessed therapy refractory children who were unable to command the pelvic floor at will. Before being referred to our tertiary referral centre, most children had received standard urotherapy alone or in combination with a PFR program provided by a physiotherapist. There is some difference in both groups between the length and the diversity of treatment before referral to our centre, with longer treatment in the BABE first group. This may introduce some bias; however, we do not know in which direction. Children who received longer first-line treatment could be more refractory or more eager to receive third-line care. We note that our study includes a select patient group, as only 52 children in eight years received specialized physical therapy in the form of PFR by BABE in combination with inpatient urotherapy, while 90 children are yearly admitted to our inpatient urotherapy program. Though not stated in our standard protocol, the urologist may consider enhancing proprioception by additional PFR preparatory to inpatient urotherapy.

Additional PFR by BABE did not enhance the outcome of our inpatient urotherapy program that also includes biofeedback (i.e. real-time uroflowmetry). At long-term follow-up, there was no significant difference between the group that received $B A B E$ before urotherapy and the group that received BABE after urotherapy. Although not significant, the BABE first group performed somewhat better. This may be because in their case, the follow-up measure took place more shortly after finishing urotherapy. Our findings are in line with a previous study that concluded that the biofeedback method of choice is of no interest for the treatment outcome and that applying several kinds of biofeedback does not influence the outcome. ${ }^{22}$ If LUTD complaints cannot be satisfactorily relieved, the burden of 
functional LUTD is high. Whereas adequate treatment is paramount, we must conclude that our results on additional intensive PFM rehabilitation must incite to re-evaluate the need for this invasive treatment. Because several reports with heterogeneous methodologies have shown mutually comparable results, making it difficult to determine the key to success, we consider that minimal invasiveness needs to be a major consideration in the choice of treatment. ${ }^{9,14,22,23}$ In the group of children with LUTD, attention to all aspects of the child's problem seems to be the cornerstone of therapy. ${ }^{21}$ Achieving cognitive maturity with corresponding behaviour might be what counts most. ${ }^{24,25}$

Our study is the first to report on the added value of specialized physical therapy in the form of PFR by BABE in the urotherapeutic treatment of children with functional LUTD. Our findings indicate that rehabilitation of voluntary pelvic floor mobility, in combination with urotherapy seems to have no influence on training outcome. Nevertheless, our results do not provide a conclusive answer to the place of conventional pelvic floor physical therapy in the treatment of children with LUTD because we specifically investigated BABE. Although Wennergren and Oberg ${ }^{26}$ introduced pelvic floor exercises for children in 1995, to date, no standard protocol is available. To our knowledge, pelvic floor exercise has always been combined with elements of standard urotherapy or biofeedback methods. ${ }^{1,8,9,17,27-29}$ Limitations to our study include the retrospective, nonrandomized assessment of data. Because of the retrospective study design, a perineal ultrasonography was not routinely performed during follow-up. This is a shortcoming of our study because no statement can be made with reference to the effect of inpatient urotherapy on voluntary pelvic floor mobility. Another limitation is the small sample size, although all children with LUTS who received $B A B E$ in our centre in the last decade were included. The small sample may reduce the power of our findings. Nevertheless, we consider our study as a valuable addition to existing literature; it displays the daily clinical practice in our incontinence university clinic.

\section{CONCLUSION}

Based on these results, we conclude that PFR by BABE is significantly less effective than inpatient urotherapy and does not improve the effect of inpatient urotherapy. Considering the invasive nature of $B A B E$, use of $B A B E$ should therefore be discouraged.

\section{Ethical approval}

The study was exempt from the Medical Research Involving Human Subject Act. 


\section{Funding}

None declared.

\section{Competing interests}

None declared. 


\section{REFERENCES}

1 Hoebeke P, Renson C, De Schryver M, De Schrijver L, Leenaerts E, Schoenaers A, et al. Prospective Evaluation of Clinical Voiding Reeducation or Voiding School for Lower Urinary Tract Conditions in Children. J Urol 2011; 186: 648-54.

2. Van Den Broeck C, Roman De Mettelinge T, Deschepper E, Van Laecke E, Renson C, Samijn B, et al. Prospective evaluation of the long-term effects of clinical voiding reeducation or voiding school for lower urinary tract conditions in children. J Pediatr Urol 2016; 12: 37.e1-e6.

3. SURESHKUMAR P, BOWER W, CRAIG JC, KNIGHT JF. Treatment of Daytime Urinary Incontinence in Children: A Systematic Review of Randomized Controlled Trials. J Urol 2003; 170: 196-200.

4. Chang S-J, Van Laecke E, Bauer SB, von Gontard A, Bagli D, Bower WF, et al. Treatment of daytime urinary incontinence: A standardization document from the International Children's Continence Society. Neurourol Urodyn 2017; 36: 43-50.

5. Austin PF, Bauer SB, Bower W, Chase J, Franco I, Hoebeke P, et al. The standardization of terminology of lower urinary tract function in children and adolescents: Update report from the standardization committee of the International Children's Continence Society. Neurourol Urodyn 2016; 35: 471-81.

6. Reilly M, Homsy Y. Treatment of a Child with Daytime Urinary Incontinence. Pediatr Phys Ther 2008; 20: 185-93.

7. de Jong TPVM, Klijn AJ, Vijverberg MAW, de Kort LM, van Empelen R, Schoenmakers MAGC. Effect of Biofeedback Training on Paradoxical Pelvic Floor Movement in Children with Dysfunctional Voiding. Urology 2007; 70: 790-3.

8. De Paepe H, Renson C, Van Laecke E, Raes A, Vande Walle J, Hoebeke P. Pelvic-floor therapy and toilet training in young children with dysfunctional voiding and obstipation. BJU Int 2000; 85: 889-93.

9. De Paepe H, Hoebeke P, Renson C, Van Laecke E, Raes A, Van Hoecke E, et al. Pelvic-floor therapy in girls with recurrent urinary tract infections and dysfunctional voiding. $\mathrm{Br} J \mathrm{Urol}$ 1998; 81 Suppl 3: 109-13. Available from: http://www.ncbi.nlm.nih.gov/pubmed/9634033

10. Hoebeke P, Walle J Vande, Theunis M, De Paepe H, Oosterlinck W, Renson C. Outpatient pelvic-floor therapy in girls with daytime incontinence and dysfunctional voiding. Urology 1996; 48: 923-7.

11. Paepe H De, Renson C, Hoebeke P, Raes A, Laecke E Van, Walle J Vande. The Role of PelvicFloor Therapy in the Treatment of Lower Urinary Tract Dysfunctions in Children. Scand J Urol Nephrol 2002; 36: 260-7.

12. de Jong TPVM, Klijn AJ, Vijverberg MAW, de Kort LMO. Ultrasound imaging of sacral reflexes. Urology 2006; 68: 652-4.

13. Bower WF, Chase JW, Stillman BC. Normative Pelvic Floor Parameters in Children Assessed by Transabdominal Ultrasound. J Urol 2006; 176: 337-41.

14. Yamanishi T, Yasuda K, Murayama N, Sakakibara R, Uchiyama T, Ito H. Biofeedback training for detrusor overactivity in children. J Urol 2000; 164: 1686-90.

15. Chase J, Schrale L. Childhood incontinence and pelvic floor muscle function: Can we learn from adult research? J Pediatr Urol 2017; 13: 94-101.

16. Dumoulin C, Hunter KF, Moore K, Bradley CS, Burgio KL, Hagen S, et al. Conservative management for female urinary incontinence and pelvic organ prolapse review 2013: Summary of the 5th International Consultation on Incontinence. Neurourol Urodyn 2016; 35: 15-20.

17. Ladi Seyedian SS, Sharifi-Rad L, Ebadi M, Kajbafzadeh AM. Combined functional pelvic floor muscle exercises with Swiss ball and urotherapy for management of dysfunctional voiding in children: a randomized clinical trial. Eur J Pediatr 2014; 173: 1347-53. 
18. Vesna ZD, Milica L, Stanković I, Marina V, Andjelka S. The evaluation of combined standard urotherapy, abdominal and pelvic floor retraining in children with dysfunctional voiding. $J$ Pediatr Urol 2011; 7: 336-41.

19. Dietz HP, Wilson PD, Clarke B. The use of perineal ultrasound to quantify levator activity and teach pelvic floor muscle exercises. Int Urogynecol J Pelvic Floor Dysfunct 2001; 12: 166-9.

20. Meijer EFJ, Nieuwhof-Leppink AJ, Dekker-Vasse E, de Joode-Smink GCJ, de Jong TPVM. Central inhibition of refractory overactive bladder complaints, results of an inpatient training program. J Pediatr Urol 2015; 11: 21.e1-e5.

21. Klijn AJ, Uiterwaal CSPM, Vijverberg MAW, Winkler PLH, Dik P, de Jong TPVM. Home Uroflowmetry Biofeedback in Behavioral Training for Dysfunctional Voiding in School-Age Children: A Randomized Controlled Study. J Urol 2006; 175: 2263-8.

22. Schulman SL, Von Zuben FC, Plachter N, Kodman-Jones C. Biofeedback methodology: does it matter how we teach children how to relax the pelvic floor during voiding? J Urol 2001; 166: 2423-6.

23. Vijverberg MA, Elzinga-Plomp A, Messer AP, van Gool JD, de Jong TP. Bladder rehabilitation, the effect of a cognitive training programme on urge incontinence. Eur Urol 1997; 31: 68-72.

24. van Gool JD, de Jong TPVM, Winkler-Seinstra P, Tamminen-Möbius T, Lax H, Hirche H, et al. Multi-center randomized controlled trial of cognitive treatment, placebo, oxybutynin, bladder training, and pelvic floor training in children with functional urinary incontinence. Neurourol Urodyn 2014; 33: 482-7.

25. Hoebeke P. Twenty years of urotherapy in children: What have we learned? Eur Urol 2006; 49: 426-8.

26. Wennergren $\mathrm{H}$, Oberg B. Pelvic floor exercises for children: a method of treating dysfunctional voiding. Br J Urol 1995; 76: 9-15.

27. Yang SSD, Wang CC. Outpatient biofeedback relaxation of the pelvic floor in treating pediatric dysfunctional voiding: A short-course program is effective. Urol Int 2005; 74: 118-22.

28. McKenna PH, Herndon CD, Connery S, Ferrer FA. Pelvic floor muscle retraining for pediatric voiding dysfunction using interactive computer games. J Urol 1999; 162(3 Pt 2): 1056-62; discussion 1062-3.

29. Vasconcelos M, Lima E, Caiafa L, Noronha A, Cangussu R, Gomes S, et al. Voiding dysfunction in children. Pelvic-floor exercises or biofeedback therapy: a randomized study. Pediatr Nephrol 2006; 21: 1858-64. 


\section{APPENDIX 5.1}

\section{Diagnostics and treatment Physiotherapy Wilhelmina's Children Hospital}

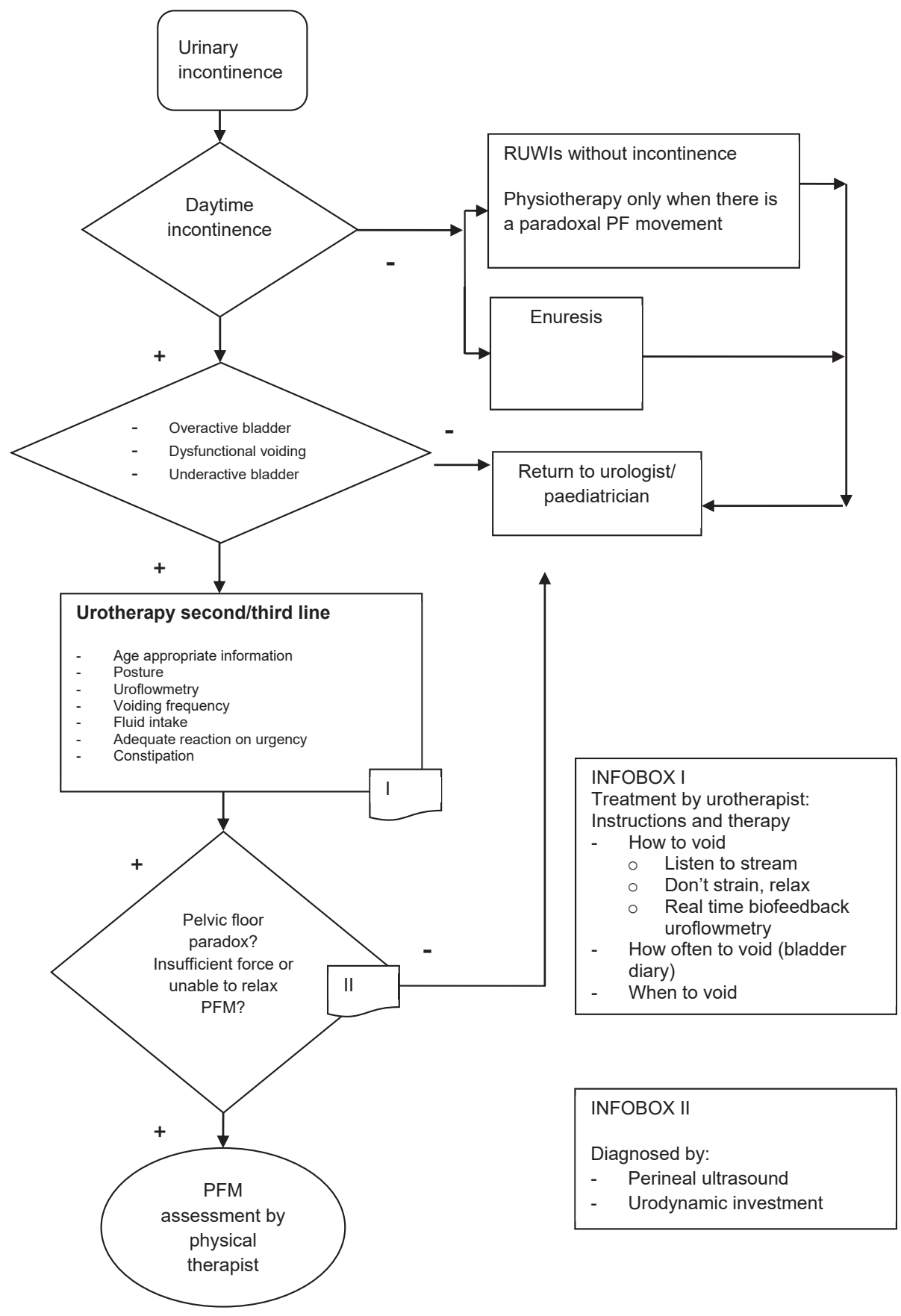





\section{Does a serious game increase intrinsic motivation in children receiving urotherapy?}

Anka J. Nieuwhof-Leppink Tom P.V.M. de Jong Elise M. van de Putte Renske Schappin 
Introduction: Urotherapy is considered the treatment of choice for children suffering daytime urinary incontinence (DUI). Urotherapy intends to improve bladder dysfunction for children with DUI. For children with refractory DUI, an intensive inpatient bladder training program exists, which focuses on relearning, concentration on, and awareness of the bladder. Children's motivation and adherence are key determinants of a successful training outcome. It is hypothesized that motivation endurance throughout the treatment process may be enhanced by a serious game training tool, which could make the training more appealing and rewarding.

Objective: The study explores intrinsic motivation in children receiving bladder training for DUI and whether using a serious game improves their intrinsic motivation.

Study design: In this pragmatic study, 50 children were allowed to choose among receiving bladder training with (intervention group) or without the application of a serious game (control group). At 4, 8, and 12 weeks of training, children and parents were asked to complete the Intrinsic Motivation Inventory (IMI). Children also completed the Pediatric Urinary Incontinence Quality of Life Tool (PinQ) before the start of the training and 6 months thereafter. At 6-month follow-up, patients were ask to participate in two focus groups, wherein the children discussed how they used the serious game and which improvements they would prefer.

Results: Children who received standard bladder training with the addition of a serious game did not differ in terms of intrinsic motivation from children who underwent standard bladder training only. Training results were equal in both the groups, with $80 \%$ good or improved. Incontinence-related quality of life (QoL) improved accordingly.

Discussion: In contrast to the study expectations, this game did not increase intrinsic motivation. Findings on training and QoL results are consistent with those of previous studies in both interventions. Although a randomized design could have yielded more valid results than this preference-based approach, the latter is more congruent with clinical practice. In contrast to existing bladder diary apps, this game offers a combination of child-friendly instructions, explanation of bladder (dys)function, and keeping a bladder diary. Mobile devices are playing an increasingly important role in health care; therefore, an urotherapy app can be a complementary therapeutic tool.

Conclusion: Most children find it attractive to combine bladder training with a serious game. However, no added value was found regarding intrinsic motivation and training results. All children with persistent DUI in this cohort were highly motivated to complete an intensive bladder training program.

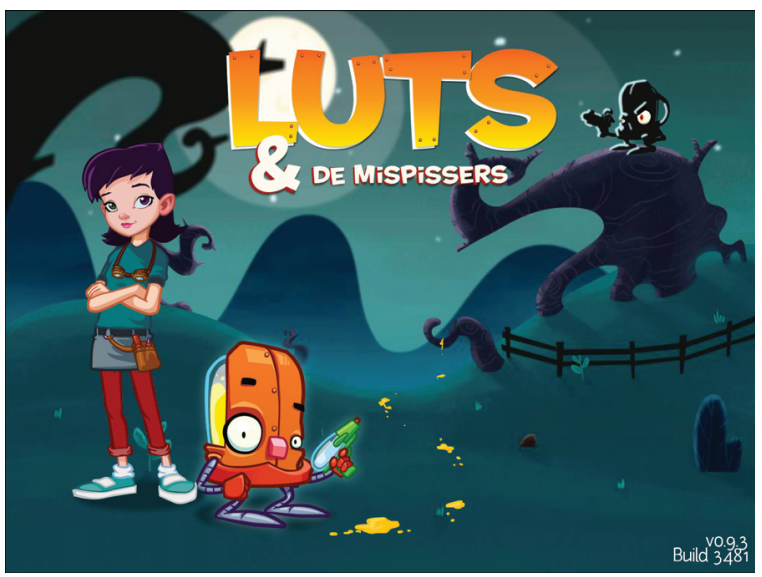

Start page game; Luts \& the 'Leaky Cauldrons'. 


\section{INTRODUCTION}

Lower urinary tract (LUT) dysfunction is one of the most common conditions in children. ${ }^{1}$ Between 7 and $10 \%$ of school-aged children have recurrent urinary tract infections and/or incontinence. Daytime urinary incontinence (DUI) has been shown to have a detrimental impact on children's quality of life (QoL). ${ }^{2,3}$ It is conceived as a physical impairment that generates feelings of shame, sadness, and depression. Incontinence negatively impacts children's body image, self-esteem, and their social interactions. However, these can be improved significantly with urotherapy, alleviating not only incontinence problems but also associated negative psychosocial consequences. ${ }^{2-4} \mathrm{~A}$ positive treatment outcome is associated with improvement of QoL in all different types of incontinence. ${ }^{4}$ Therefore, improved QoL is an important treatment outcome after a child has successfully completed urotherapy. $^{5}$

For children suffering from functional DUI, urotherapy is considered the treatment of choice. Urotherapy is a conservative treatment that intends to improve bladder dysfunction for children with LUT dysfunction symptoms. Standard urotherapy includes psycho-education regarding bladder function, instructions about voiding habits, toileting position, and treatment and prevention of constipation and urinary tract infections. ${ }^{1,6}$ Specific interventions within urotherapy include pelvic floor biofeedback, neuromodulation, behavioral modifications, and psychotherapy. ${ }^{1,6,7}$ Furthermore, specific cognitive bladder training programs exist for children with refractory DUI which focus on relearning, concentration on, and awareness of the bladder. ${ }^{6,8,9}$ In the study hospital, the specific outpatient urotherapy program usually exists as guided training at home for 12 weeks. When outpatient urotherapy is unsuccessful, patients are offered inpatient urotherapy. This 10-day cognitive training program is the most intensive form of urotherapy and is reserved for therapy-resistant patients. The added value of cognitive training has been demonstrated in various studies. ${ }^{9,10}$

For successful completion of training, motivation and adherence are essential, as in all forms of cognitive behavior therapy (CBT). ${ }^{11}$ Urotherapy has integrated many components of CBT, focusing on irrational and dysfunctional cognitions, thoughts, and beliefs. In CBT, motivation to comply with treatment recommendations is crucial for successful treatment, and a lack of motivation is associated with less favorable treatment outcomes, poor treatment adherence, and premature termination of treatment. ${ }^{11}$ Because CBT and specific urotherapy are closely intertwined, the same crucial importance of motivation in urotherapy is expected, especially because it is lengthy and usually requires much effort from the child and his/her parents. ${ }^{6}$ Elementary principles and techniques for motivation 
are necessary to induce and maintain the child's adherence to training. For example, during the training phase at home, the child receives weekly supportive phone calls from the urotherapist, trying to increase the child's motivation to follow instructions, reducing the risks of non-adherence, and improving training outcomes.

Increased motivation to follow training instructions could be achieved by making training more appealing and rewarding. Serious games may satisfy these requirements and seem viable alternatives for traditional forms of therapy in terms of effectiveness. ${ }^{12}$ Serious games are interactive applications designed as a game but developed for 'serious' purposes: to educate and motivate users in educational, health, and other settings. If executed properly, serious games are hypothesized (support training programs) by making the learning process more enjoyable and increasing motivation by providing incentives. Serious games can contribute toward a winning attitude; children want to 'win the game'. ${ }^{13,14}$ Game-based approaches in health care are in an early developmental phase. Initial studies suggest potential benefits for psychological and behavioral changes and subsequent symptom relief. ${ }^{15}$ Serious gaming has 'engaging potential' by using various mechanisms for change, including therapeutic processes and gaming features. ${ }^{12,16}$ Evidence for the effectiveness of games in the treatment of DUI is not available yet. It is not known whether serious games can contribute to a higher intrinsic motivation for treatment.

The study's aim is to investigate whether urotherapy using a serious game is more motivating for children in contrast to the traditional form of training with a pen and paper. Higher motivation and consequently improved treatment results and QoL were expected in the serious game group.

\section{METHODS}

\section{Participants}

Children starting urotherapy at the urotherapy clinic of the Wilhelmina Children's Hospital between January 2015 and July 2016 were invited to participate in this study. Children were eligible if they aged between 8 and 14 years and if they and their parents were able to complete Dutch questionnaires. 


\section{Intervention}

Children in the intervention and control group both received urotherapy according to a standard protocol. In the intervention group, children additionally used a serious game (see screenshots, Appendix 6.1). The voiding diary plays a key role during the training, being a crucial feedback tool that makes the child aware of his or her voiding behavior. The difference between both the groups was that children who play the game get an extra incentive because they gain points by keeping the diary and extra points when they do not leak for a whole day. With the gathered points, as a reward, children can play a game at the end of each training day.

\section{Procedure}

The study was exempt from the Medical Research Involving Human Subject Act according to the institutional review board. Children and parents were invited by their urotherapist to participate in the study. If interested, parents and children (>11 years) signed informed consent. The allocation between groups was preference based, provided that the family had an iPad at hand, needed for the serious game. If families did not have an iPad, they could only train with a pen and paper.

Questionnaires, including the Pediatric Incontinence Questionnaire (PINQ), Parental Motivation Inventory (PMI), and Intrinsic Motivation Inventory (IMI), were completed at 5 different time points. Before the start of the bladder training, the child completed the PINQ and parents completed the PMI. After 4, 8, and 12 weeks of training, the child and parents completed the IMI. When training was completed, 6 months after the start, the child completed the PINQ again.

One year after introducing the serious game, school-aged children and adolescents were stratified into two separate groups. Subsequently, interviews were conducted to investigate how children used the serious game and which improvements they would prefer.

\section{Instruments}

\section{Pediatric Incontinence Questionnaire}

Children's incontinence-related QoL was measured with the PINQ. ${ }^{17}$ The Dutch version of the questionnaire consists of 28 items with a 5-point scale ranging from ' $0=$ never' to ' 4 = always'. Total scores range from 0 to 112, with higher scores indicating lower QoL. 


\section{Parental Motivation Inventory}

Parents' motivation to participate in their child's bladder training was assessed with the PMI. ${ }^{11}$ The PMI consists of 25 items with a 5-point scale ranging from ' 1 = strongly disagree' to ' 5 = strongly agree'. Items are, for example, 'I am willing to work in changing my own behavior as it relates to manage my child bladder problem'. The PMI has three subscales: parents' desire for the child to change ( 7 items), readiness to change parenting behavior (14 items), and parents' perceived ability to change parenting behaviors (4 items). High scores indicate more motivation.

\section{Intrinsic Motivation Inventory}

Children's motivation was measured with the IMI. ${ }^{18}$ The original IMI is used to assess motivational structures for targeted activities such as sports, school, and medical treatment. Originally, the IMI is a self-report questionnaire, so a parent-proxy version of the IMI was constructed by replacing 'I' with 'my child'. The IMI consist of 7 subscales of which the enjoyment subscale ( 5 items) and the effort subscale ( 7 items) were used for both children and parents. Items have a 5 -point scale ranging from ' $1=$ not true' to ' 5 = true'. Example items are 'I enjoy doing this training very much' and 'I put much effort in this training'. Higher scores indicate more motivation.

\section{Sample size calculation}

The sample size was based on the possibility to detect a group difference of 1 point on the IMI subscales at the last measurement. Based on a standard deviation of 1.24 derived from the literature, ${ }^{19} 80 \%$ power, and $5 \%$ significance (two-sided), this results in 26 children per group. With an estimated attrition rate of $50 \%$, a minimum sample size of 52 children per group was needed.

\section{Analysis}

The difference between groups on the IMI was assessed using linear mixed models with baseline correction. Fixed effects were included for treatment group and time of measurement; no random effects were included. Effect size Cohen's d was used to quantify the difference between the groups on the IMI at the last measurement. ${ }^{20}$ An effect size of 0.2 reflects a small effect, 0.5 a medium, and 0.8 a large effect. ${ }^{21}$ For the PINQ and PMI, group differences were analyzed using analysis of variance. In all analyses, a $P$-value < 0.05 was considered significant. Analyses were performed in IBM SPSS, version 21.0. ${ }^{22}$ 


\section{RESULTS}

\section{Patient characteristics}

After invitation, 89 children and parents agreed to participate, but only 50 children and both their parents returned a complete informed consent form. These 50 children did not differ fromthe 89 original children on demographic ormedical characteristics, except for low number of divorces in the consenting group. A large proportion (64\%) of children had earlier unsuccessful treatment elsewhere. After inclusion, 27 children trained with the serious game (intervention), and 23 children trained with pen and paper (control) (Figure 6.1). Baseline characteristics of both groups are presented in Table 6.1.

\section{Treatment results}

Training results were measured in accordance with International Children's Continence Society (ICCS) standards. ${ }^{1}$ Training results were similar between groups: In the intervention group, $52 \%(n=14)$ had good results, $33 \%(n=9)$ improved, $11 \%(n=3)$ had bad results, and $4 \%(n=1)$ stopped training. In the control group, $48 \%(n=11)$ had good results, $30 \%$ $(n=7)$ improved, $13 \%(n=3)$ had bad results, and $9 \%(n=2)$ stopped.

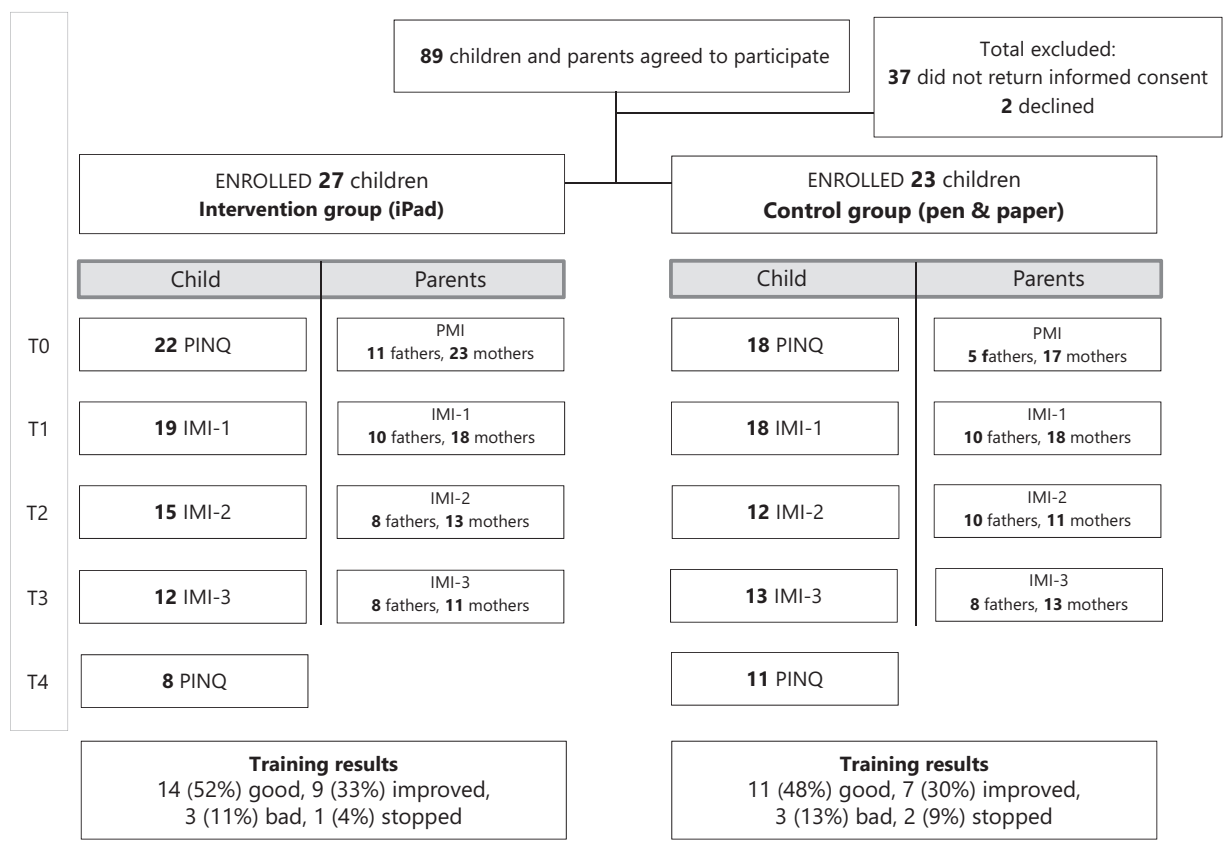

Figure 6.1: Participant flow.

IMI, Intrinsic Motivation Inventory; PMI, Parental Motivation Inventory; PINQ, Pediatric Incontinence Questionnaire. 
Table 6.1: Baseline characteristics

\begin{tabular}{lcc}
\hline Child characteristics & $\begin{array}{c}\text { Intervention group } \\
(\mathrm{n}=27)\end{array}$ & $\begin{array}{c}\text { Control group } \\
(\mathrm{n}=23)\end{array}$ \\
\hline Age, mean (SD) & $9.0(1.5)$ & $9.7(1.6)$ \\
Girls & $11(41 \%)$ & $10(44 \%)$ \\
Diagnosis & & $13(57 \%)$ \\
$\quad$ Overactive bladder (OAB) & $9(33 \%)$ & $7(30 \%)$ \\
Dysfunctional voiding (DV) & $12(44 \%)$ & $3(13 \%)$ \\
Postponement (PP) & $6(22 \%)$ & $16(70 \%)$ \\
Failed urotherapy elsewhere & $16(59 \%)$ & $22(92 \%)$ \\
Family situation & & $2(8 \%)$ \\
$\quad$ Nuclear family & $25(93 \%)$ & 1 \\
Step family & $2(7 \%)$ & $22(96 \%)$ \\
School situation & & $36.1(12.4)$ \\
Regular elementary school & $27(100 \%)$ & - \\
Special education & $35.5(6.0)$ & \\
PINQ score, mean (SD) & & \\
\hline
\end{tabular}

PINQ, Pediatric Incontinence Questionnaire; SD, standard deviation.

\section{Quality of life}

At baseline, the intervention group had a score of 35.5 (standard deviation [SD] $=6.0$ ) points on the PINQ, and the control group had a score of 36.1 (SD =12.4) points. In both the groups, scores decreased after 6 months to a score of $23.4(S D=8.0)$ points in the intervention group and a score of 31.7 (SD = 14.9) in the control group. In both the groups, this was a statistically significant improvement in the $\operatorname{QoL}(F(1,55)=7.85, P<0.001)$, with a mean improvement of 13 points on the PINQ per month. Although the raw data seem to suggest a faster increase of QoL in the intervention group, analysis showed no significant interaction effect $(F(1,55)=1.73, P<0.194)$.

Because the PINQ has no clinical norms, total scores are difficult to interpret. Nonetheless, $50 \%$ of all children reported that they would feel better about themselves if they did not have their bladder problem. The PINQ also contains a question on how children expect to feel after they complete training (the same/a bit better/much better/completely better). These scores were related to children's total outcomes on the PINQ. Children who indicated at baseline that they would feel a bit better had a total score of 32.4 after completion of training. Children who indicated that they would feel much better had a total score of 26.4, and children who indicated that they would feel completely better had a score of 23.2. This suggests that children can adequately estimate the effect that training will have on their QoL (Appendix 6.2). 


\section{Parental motivation}

Parental motivation was high in both the groups, with PMI scores around 4 on a scale of 1-5 (Table 6.2). Both mothers and fathers estimated their ability to change their parenting behaviors somewhat lower than their desire for the child to change and their readiness to change their parenting behavior. There were no statistically significant differences between the intervention and control group in parental motivation.

Table 6.2: Parental motivation in the intervention and control group measured at baseline with the PMI

\begin{tabular}{|c|c|c|c|c|c|c|c|c|c|c|c|c|}
\hline \multirow[b]{3}{*}{ Subscales PMI } & \multicolumn{6}{|c|}{ Mother } & \multicolumn{6}{|c|}{ Father } \\
\hline & \multicolumn{3}{|c|}{ Intervention } & \multicolumn{3}{|c|}{ Control } & \multicolumn{3}{|c|}{ Intervention } & \multicolumn{3}{|c|}{ Control } \\
\hline & $n$ & Mean & SD & $n$ & Mean & SD & $n$ & Mean & SD & $\mathrm{n}$ & Mean & SD \\
\hline $\begin{array}{l}\text { Desire } \\
\text { (7 items) }\end{array}$ & 24 & 4.1 & 0.5 & 18 & 4.1 & 0.5 & 11 & 4.2 & 0.5 & 5 & 4.0 & 0.7 \\
\hline $\begin{array}{l}\text { Readiness } \\
\text { (14 items) }\end{array}$ & 23 & 4.3 & 0.4 & 18 & 4.2 & 0.4 & 11 & 4.2 & 0.5 & 6 & 4.1 & 0.7 \\
\hline $\begin{array}{l}\text { Ability } \\
\text { (4 items) }\end{array}$ & 24 & 3.7 & 0.6 & 18 & 3.7 & 0.6 & 11 & 3.9 & 0.6 & 6 & 3.4 & 0.8 \\
\hline
\end{tabular}

\section{Child motivation}

Children self-reported effort in both the groups was high with scores around 4 on a scale of 1-5. Children who expected to obtain a good treatment result on the PINQ also scored higher on motivation $(r=0.44, P<0.05)$. Parent reports of child effort were a bit lower, with fathers having lower estimates than mothers. The same correlation was found for enjoyment, although all scores were somewhat lower than those for effort.

Table 6.3 shows that there were no significant differences between the groups on childreported effort and enjoyment. Furthermore, both effort and enjoyment remained stable during the training period. For child motivation reported by mothers, there were no significant effects for effort and enjoyment. For father-reported effort of the child, no significant effects were found, but there was a significant effect for father-reported enjoyment. Fathers in the intervention group showed reduced enjoyment at 8 weeks, whereas fathers in the control group scored unchanging enjoyment during the training period. For all models, the effect sizes were small (Cohen's $d=0.2-0.44$ ). 


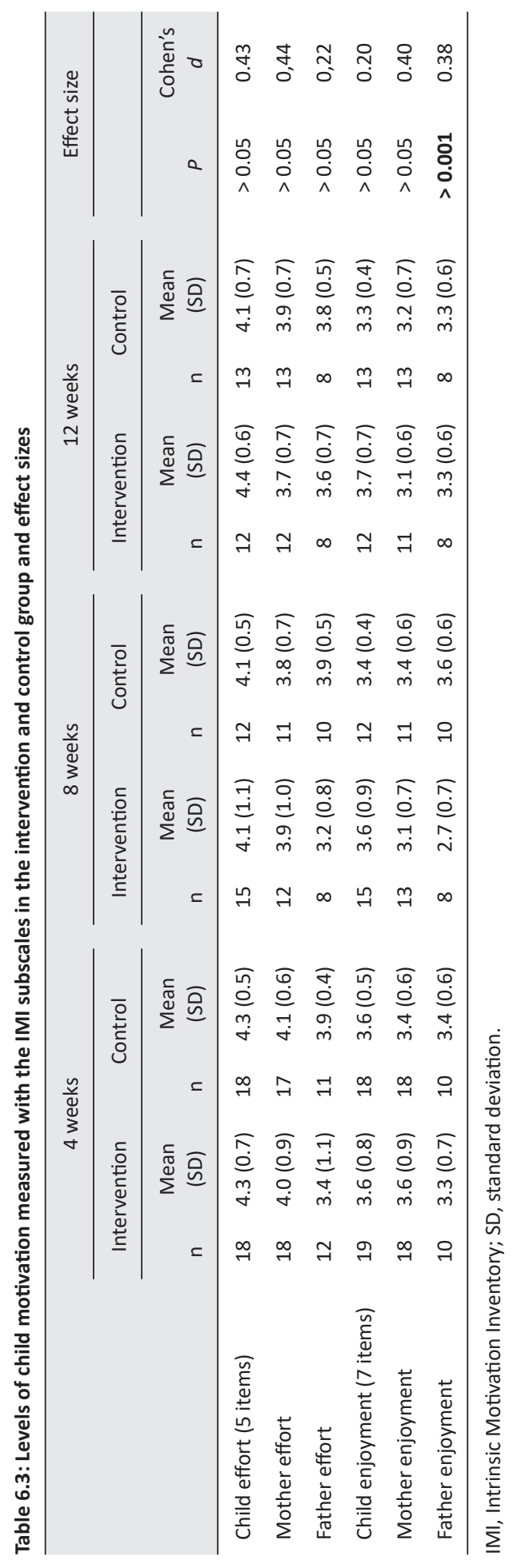




\section{Focus group}

Both school-aged children and adolescents in the focus groups reported to like training with the serious game. They would like to get updates of their training progress during the game. The adolescents would like to have detailed information about their bladder problem included in the game.

\section{DISCUSSION}

Over the years, several studies have been conducted to improve urotherapy effectiveness in children. ${ }^{8}$ The present study investigated whether the addition of a serious game might increase motivation. No significant differences were found in intrinsic motivation between children after urotherapy with a serious game or pen and paper. Training results in both the groups were also similar.

The study findings on training results are consistent with those of previous studies, which demonstrated cure or improvement rates after urotherapy ranging from 60 till $75 \%$. $^{7-9,10}$ In this study, both the groups were trained according to a standard protocol, receiving the same instructions and weekly supportive phone calls. In this study, a serious game had no added value regarding training results.

In the both groups, children had high intrinsic motivation, and parents were motivated to support their child during treatment. The study center is a last resort for refractory incontinence, and this might explain the high intrinsic motivation. Application of the serious game in another setting with less motivated patients before treatment might influence treatment results, especially the added value of a serious game.

With support and therapy, self-esteem can improve. The cognitive components of this urotherapy program address incontinence and associated negative psychosocial consequences. Incontinence-related QoL in the both groups was found to be improved significantly after six months of urotherapy. These findings are consistent with those of other studies reporting on QoL in children with incontinence. ${ }^{17,23,24}$ The extensive improvement of QoL in the study sample may reflect the severity of children's bladder problems because their QoL was severely affected before intervention by having years of bladder problems. Others have showed that children with higher incontinence frequencies have a more significant improvement of QoL after treatment than children with lower incontinence frequencies. ${ }^{4}$ In addition, multiple studies reported comparable improvements in self-confidence and impact on the families in relation to a child with bladder problem. ${ }^{1,3,23}$ 
In contrast to the authors' expectations, no significant differences were found between the groups on the intrinsic motivation components effort and enjoyment. This serious game, in its current form, has no added value over standard practice. Many children prefer to train with a serious game, but it did not increase their motivation or training results. However, the functional value of the application was not examined, which also can predict engagement in a positive way. Research into a bladder diary app showed higher engagement of children, although impact on treatment results remains unknown. ${ }^{16}$ The benefits of serious games in terms of motivation and engagement are often attributed to their entertainment aspect. ${ }^{13,16}$ However, the game element in this serious training was probably not sufficiently entertaining to increase motivation. Information from the focus groups showed that children preferred a more active game that keeps track of their training progress. Furthermore, instead of playing the same game repeatedly, they would like to play a game with a storyline with cliff-hangers at the end of each day.

\section{Strengths and limitations}

The strength of this study is that this is the first study into the effectiveness of a serious game to complement standard urotherapy. In addition, not only training results but also important factors in the process of achieving these results by longitudinal measurements of intrinsic motivation of children and parents during treatment were looked at.

The most important limitation of this study is the reduced statistical power because the calculated sample size was not reached due to loss to follow-up. Owing to the reduced power, a difference between the serious game and pen and paper group was not detected although it exists in the population (type II error). However, small effect sizes in motivation were found; therefore, it is expected that with a larger sample size and accurate power, group effects will remain modest.

A second limitation is the fact that longitudinal measurements were hampered by study dropout. Another limitation is the enrollment of the children. The inclusion was preference based and depended partly on the availability of an iPad. A randomized design could have yielded different results, but the preference-based design resembles clinical practice in which only children with a suitable device use the serious game. Therefore, the results obtained by this preference-based approach are valid for clinical care. The use of medical apps is becoming more prevalent and is a typical example of the impact technology has on medical practice nowadays..$^{12,13}$ Several apps exist to capture bladder diaries, but no gaming apps are available which offer a combination of child-friendly instructions, explanations of lower urinary tract function, and keeping a bladder diary. 


\section{Perspective}

Although this serious game had no beneficial effects, serious games could be a promising new tool for urotherapy. ${ }^{12,13}$ The combination of serious and fun components provide a playful interaction and give the child a playful insight into complex subject matters. In current society, serious games are welcome complementary tools for standard urotherapy, and they can bring support for children in situations during which they receive less intensive treatment of an urotherapist.

\section{CONCLUSION}

Children with persistent bladder problems are highly motivated to complete a bladder training program. Although children find a serious game attractive, no added value was found regarding intrinsic motivation or training results in a tertiary urotherapy center. Training results were good in both the groups, with $80 \%$ good or improved. Incontinencerelated QoL improved accordingly. Children indicated that certain aspects of the game could be improved to increase its motivational strength. However, as it is now, this serious game has no added value in the treatment of lower urinary tract symptoms in children.

\section{AUTHOR STATEMENTS}

\section{Acknowledgments}

The authors gratefully thank all children and parents for participation in the study.

\section{Ethical approval}

None sought.

\section{Funding}

The development of the game was supported by the NutsOhra Foundation [grant number 1206-009]; and the Friends of the Wilhelmina Children's Hospital Foundation [no grant number provided].

\section{Competing interests}

None declared. 


\section{REFERENCES}

1 Austin PF, Bauer SB, Bower W, Chase J, Franco I, Hoebeke P, et al. The standardization of terminology of lower urinary tract function in children and adolescents: update report from the standardization committee of the International Children's Continence Society. Neurourol Urodyn 2016; 35: 471-81.

2 Thibodeau BA, Metcalfe P, Koop P, Moore K. Urinary incontinence and quality of life in children. J Pediatr Urol 2013; 9: 78-83.

3 Wocn J, Bower WF. Self-reported effect of childhood incontinence on quality of life. J Wound Ostomy Cont Nurs 2008; 35: 617-21.

4 Equit M, Hill J, Hübner A, Von Gontard A. Health-related quality of life and treatment effects on children with functional incontinence, and their parents. J Pediatr Urol 2014; 10: 922-8.

5 Brownrigg N, Braga LH, Rickard M, Farrokhyar F, Easterbrook B, Dekirmendjian A, et al. The impact of a bladder training video versus standard urotherapy on quality of life of children with bladder and bowel dysfunction: a randomized controlled trial. J Pediatr Urol 2017; 13: 374.e1-8.

6 Chang S, Van Laecke E, Bauer S, von Gontard A, Bagli D, Bower W, et al. Treatment of daytime urinary incontinence: a standardization document from the International Children's Continence Society. Neurourol Urodyn 2017;36:43e50.

7 Bachmann CJ, Heilenkötter K, Janhsen E, Ackmann C, Thomä M, Lax H, et al. Long-term effects of a urotherapy training program in children with functional urinary incontinence: a 2-year follow-up. Scand J Urol Nephrol 2008; 42: 337-43.

8 Klijn AJ, Uiterwaal CSPM, Vijverberg MAW, Winkler PLH, Dik P, de Jong TPVM. Home uroflowmetry biofeedback in behavioral training for dysfunctional voiding in school-age children: a randomized controlled study. J Urol 2006; 175: 2263-8.

9 Meijer EFJ, Nieuwhof-Leppink AJ, Dekker-Vasse E, De Joode-Smink GCJ, De Jong TPVM. Central inhibition of refractory overactive bladder complaints, results of an inpatient training program. J Pediatr Urol 2015; 11: 21.e1-5.

10 Vijverberg MAW, Stortelder E, De Kort LMO, Kok ET, De Jong TPVM. Long-term follow-up of incontinence and urge complaints after intensive urotherapy in childhood (75 patients followed up for 16.2-21.8 years). Urology 2011; 78: 1391-6.

11 Nock MK, Photos V. Parent motivation to participate in treatment: assessment and prediction of subsequent participation. J Child Fam Stud 2006; 15: 333-46.

12 Fleming TM, Bavin L, Stasiak K, Hermansson-Webb E, Merry SN, Cheek C, et al. Serious games and gamification for mental health: current status and promising directions. Front Psychiatr 2017; 7: 215.

13 Erhel S, Jamet E. Digital game-based learning: impact of instructions and feedback on motivation and learning effectiveness. Comput Educ 2013; 67: 156-67.

14 Boendermaker WJ, Prins PJM, Wiers RW. Cognitive bias modification for adolescents with substance use problems - can serious games help? J Behav Ther Exp Psychiatr 2015; 49: 13-20.

15 Fernández-Aranda F, Jiménez-Murcia S, Santamaría JJ, Gunnard K, Soto A, Kalapanidas E, et al. Video games as a complementary therapy tool in mental disorders: PlayMancer, a European multicentre study. J Ment Health 2012; 21: 364-74.

16 Myint M, Adam A, Herath S, Smith G. Mobile phone applications in management of enuresis: the good, the bad, and the unreliable! J Pediatr Urol 2016; 12: 1-112.

17 Bower WF, Wong EMC, Yeung CK. Development of a validated quality of life tool specific to children with bladder dysfunction. Neurourol Urodyn 2006; 25: 221-7.

18 Monteiro V, Mata L, Peixoto F. Intrinsic motivation inventory: psychometric properties in the context of first language and mathematics learning. Psicol Reflexão E Crítica 2015; 28: 434-43. 
19 Chen G, Stevens K, Rowen D, Ratcliffe J. From KIDSCREEN-10 to CHU9D: creating a unique mapping algorithm for application in economic evaluation. Health Qual Life Outcome 2014; 12: 134.

20 Feingold A. Effect siaefor growth-modeling analysis for controlled clinical trials in the same metric for classical analysis. Psychol Meth 2009; 14: 43-53.

21 Cohen J. Statistical power analysis for the behavioral sciences. 2nd ed. Lawrence Erlbaum Associates; 1988.

22 IBM Corp. Released. IBM SPSS statistics for windows. Armonk NIC; 2012, Version 21.0.

23 Wocn J, Bower WF. Self-reported effect of childhood incontinence on quality of life. 2008.

24 Bachmann C, Lehr D, Janhsen E, Steuber C, Gabël E, Von Gontard A, et al. German version of the pediatric incontinence questionnaire for urinary incontinence health related quality of life. J Urol 2009; 182: 1993-8.

\section{FURTHER READING}

25 Hoebeke P. Twenty years of urotherapy in children: what have we learned? Eur Urol 2006; 49: 426-8. 


\section{APPENDIX 6.1: EXPLANATION OF THE SERIOUS GAME}

The serious game is based on the cognitive behavioral aspects of the specific urotherapy program as given in the Wilhelmina Children's Hospital, a tertiary reference center. Looking for new ways to improve therapy adherence by stimulating children's agency and self-efficacy, we asked a game developer to design the app. The voiding diary plays a key role during urotherapy and has been made digital and interactive. Printed graphics and rules about training and bladder function were converted into digital educational animations, providing information on how the bladder and pelvic area function and what causes incontinence.

The game is based on a layered story in which the child has to save princess Mina. At the start of the game, princess Mina is kidnapped by monsters. The child can fight these monsters to free Mina at the end of the game (which is the end of the treatment). Depending on how well the child battles the monsters, he or she gains coins. With these coins the child can buy equipment to become a better fighter. Lives can be gained by completing the voiding diary every day. If children stay dry and void sufficiently, they gain more lives. Important is that children are always rewarded for completing the diary.

Below we will walk you through screenshots of the game.

\section{Screenshots game}
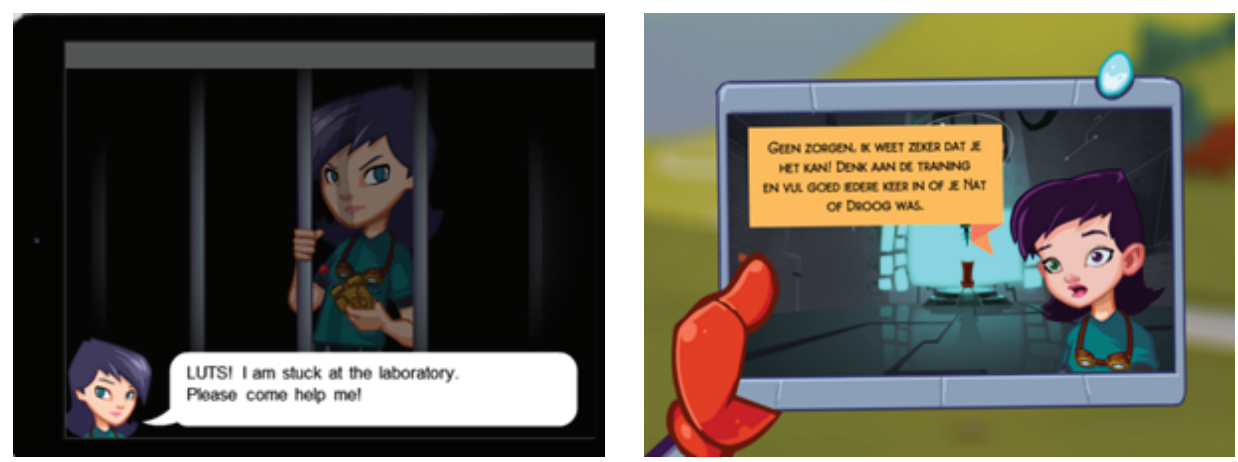

Storyline, princess Mina explains the how the game works and bladder training strategies. 

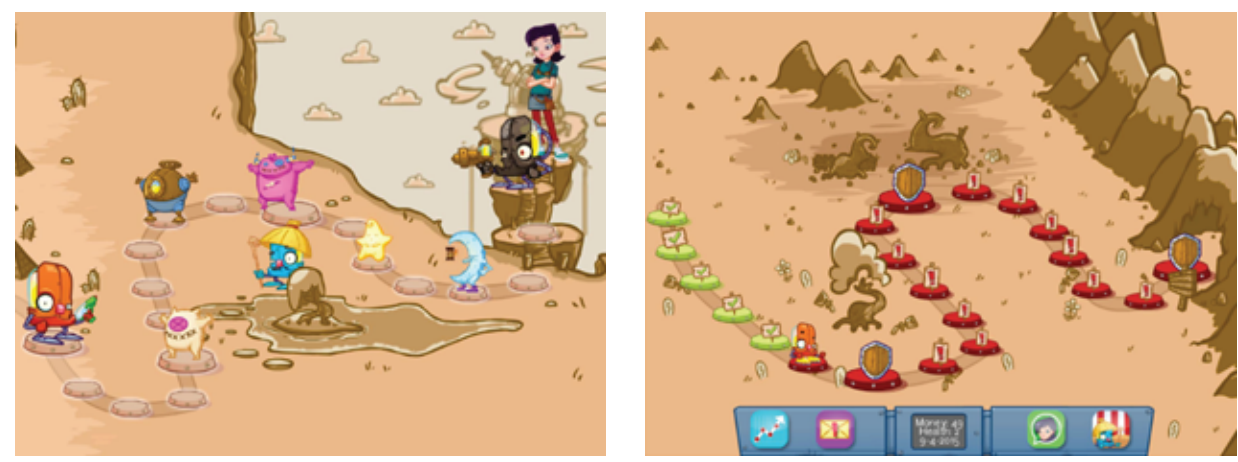

Start page, each bullet is a training day (90 bullets $=3$ months training). The child crosses a landscape during training. After each week of training, there is a new monster to fight and the landscape changes.

After a click on the bullet the bladder diary appears.

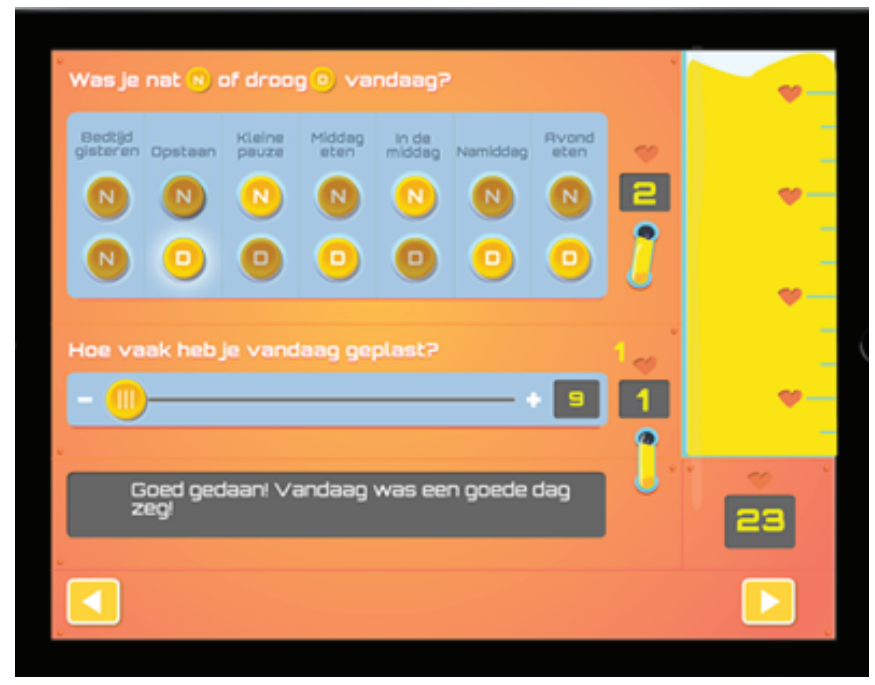

When the child stays dry or voids more than 7 times during the day, the child will gain extra bonus hearts = lives for the battle and also written compliments appears (grey box) as positive reinforcement. After filling out the bladder diary the child has to play the battle. 


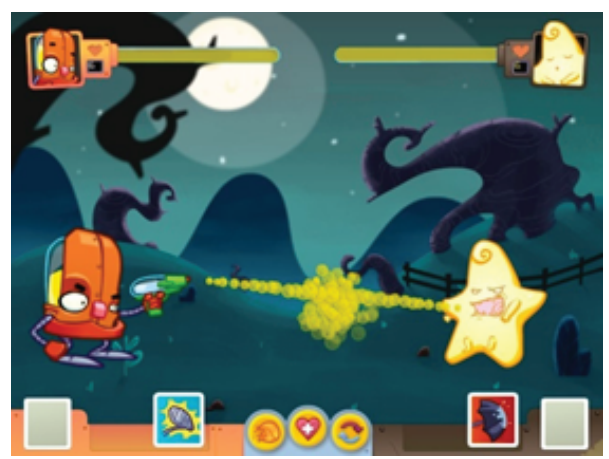

After keeping the bladder dairy the child plays the battle against the monsters to free Princess Mina.

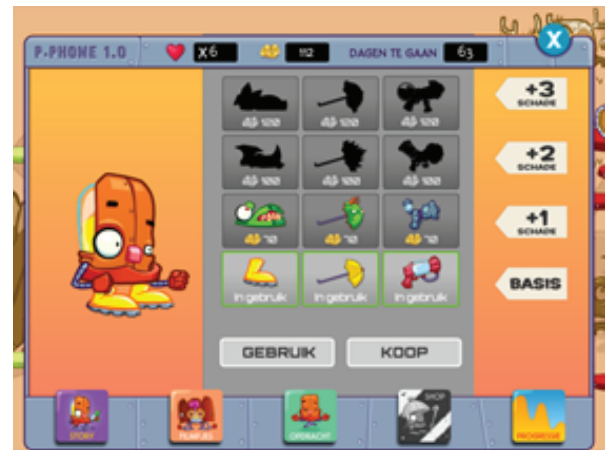

Shop to buy equipment.

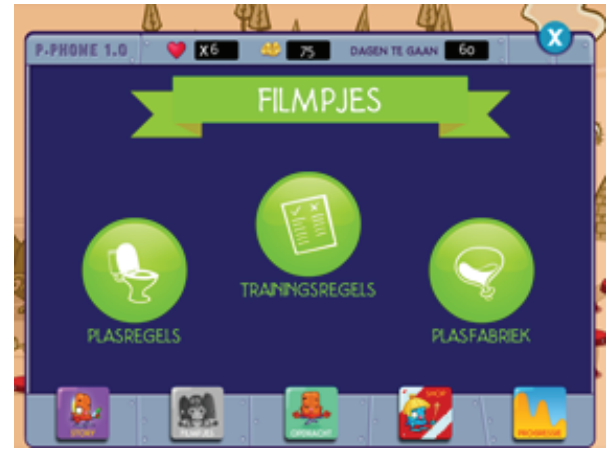

Menu to bladder function animations, voiding rules, and training rules.

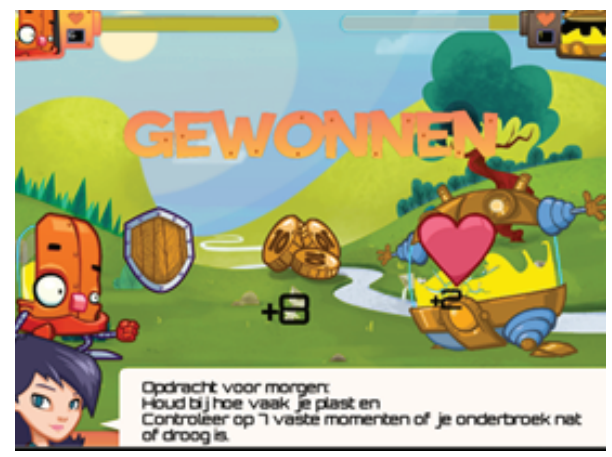

You have won, Mina encourages the child to hold on to the training rules.

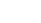
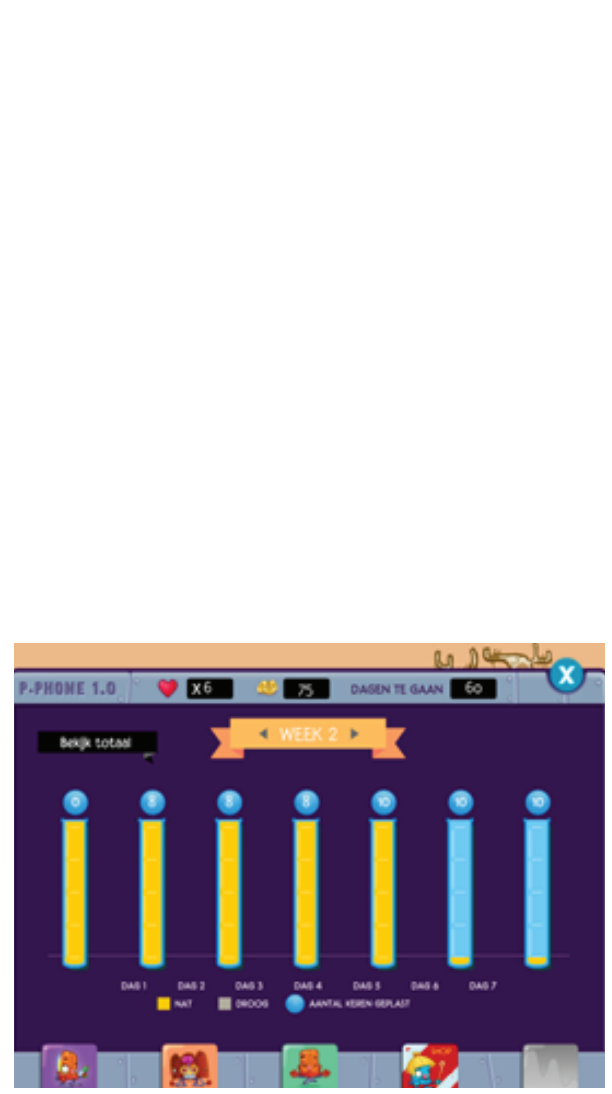

Screenshot of training progress; each training week can be evaluated by voiding frequencies and wetting accidents per day. 


\section{APPENDIX 6.2}

Quality of life items on which most children indicate problems

\begin{tabular}{lcc}
\hline & Answer 'often' or 'always' (\%) \\
\hline $\begin{array}{l}\text { Do you think that you would feel better about yourself if } \\
\text { you didn't have a bladder problem? }\end{array}$ & Before training & After training \\
$\begin{array}{l}\text { Does your bladder problem ever make you feel bad about } \\
\text { yourself? }\end{array}$ & $34 \%$ & $6 \%$ \\
$\begin{array}{l}\text { How often does your bladder problem make you feel } \\
\text { different to other people? }\end{array}$ & $30 \%$ & $8 \%$ \\
$\begin{array}{l}\text { Do you think that dad or mum worry about you because } \\
\text { of your bladder problem? }\end{array}$ & $28 \%$ & $10 \%$ \\
$\begin{array}{l}\text { Do you get embarrassed because of your bladder } \\
\text { problem? }\end{array}$ & $28 \%$ & $8 \%$ \\
$\begin{array}{l}\text { How often do you think that the bladder problem will } \\
\text { never go away? }\end{array}$ & $18 \%$ & $16 \%$ \\
\hline
\end{tabular}




General discussion

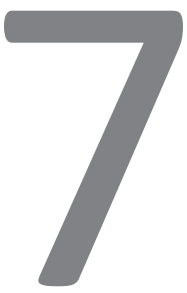





\section{GENERAL DISCUSSION}

In the following part of this thesis, the previous chapters are summarized and discussed in a broader perspective. This thesis concerns urotherapy, which is an essential part of treatment for children with daytime incontinence, constipation, and bedwetting. Functional daytime urinary incontinence is a common problem in school-aged children and a frequently presenting condition in pediatric health care. ${ }^{1,2}$ Over the last decades, insight into pathophysiology, clinical symptoms, and treatment of this problem has increased. The major change has been from routine referral for psychological or behavioral problems up till the early 1990s into the realization that incontinence is a multifactorial problem that can be solved. Nowadays, diagnostic and therapeutic pathways are clear and applicable to most of the children with functional incontinence. ${ }^{3-5}$ Many studies have established the effectiveness of urotherapy. However, the effects of individual components of urotherapy need to be studied in more detail, to provide more efficient approaches tailored to the needs of individual children.

\section{Incontinence: a multifactorial etiology}

There is high variability in the reported prevalence of day-and nighttime urinary incontinence. Although, consensus as to what constitutes a wet episode, the definitions of deviant voiding frequency, the severity of complaints, and urgency in the diagnosis of functional incontinence varies. For example, regarding the definition of daytime incontinence Sureshkumar et al. classify all children with a wet episode once every 6 months as incontinent, whilst Swithinbank et al. classify children as incontinent when they are wet $\geq 2$ per week. ${ }^{6,7}$ This makes it difficult to combine studies in a review. Furthermore, the studies include different ages, are mainly based on proxy-reports by parents, and the majority is cross-sectional in design. Variations in incontinence prevalence may also result from societal norms and cultural differences. In several non-Western countries, for example, parents start toilet training at a much earlier age than parents in Western countries, due to tradition and because of a lack of diapers. ${ }^{8}$

No single factor can be identified as a cause of functional incontinence. The etiology of functional incontinence is multifactorial and there are complex interactions between different causes. There is evidence for demographic, environmental, genetic, physical, and behavioral causes. ${ }^{9}$ Children with children with Autism Spectrum Disorder (ASD) may be at risk for incontinence due to their sensory and attention problems. ${ }^{10}$ Dirty toilets in school may increase this risk for dysfunctional voiding because children may avoid going to the toilet. Also bladder anomalies may play an important role. A better understanding 
of the unique role of each risk factor is important for early recognition and prevention, and for more efficient and effective personalized treatment.

Up to now, we do not know why some children with functional incontinence are refractory to treatment. Older studies regarded incontinence as a behavioral problem, while current research focusses primarily on genetic and neurobiological factors contributing to incontinence. ${ }^{11-13}$ We propose that some neurobiological factors such as sensory problems may physically influence incontinence and may also elicit behavior that contributes to incontinence. ${ }^{14}$ Although, not in this thesis because inclusion is not complete, we are currently investigating the role of sensory problems in the etiology of functional incontinence.

\section{Urotherapy: a multidisciplinary approach}

The best treatment approach to functional incontinence is in a multidisciplinary team. Specific indications for treatment are established during a multidisciplinary intake leading to a clinical diagnosis. For most children with functional incontinence, a standard diagnostic assessment is sufficient to detect incontinence and comorbid disorders and to rule out organic causes. This standard assessment consists of a physical examination, uroflowmetry, ultrasound, a bladder diary, micturition anamnesis, and psychosocial anamnesis. The diagnostic process should result in the identification of a specific subtype of incontinence and comorbid physical and psychosocial problems. ${ }^{15}$ Apart from diagnostics and diagnosis, the multidisciplinary approach comprises prescription of pharmaceutical medication for constipation, overactive bladder and, when present, urinary tract infections by the attending physician. In select cases, botulinum-toxine injections in the detrusor muscle may be considered and some may try alpha blocking agents for dysfunctional voiding. ${ }^{16}$ The evaluation of the effects of this medication and the need to adapt treatment schedules is coordinated by the urotherapist in cooperation with the physician. Urotherapy is performed by trained healthcare professionals with a nursing, physiotherapeutic, psychological, and/or medical background.

Urotherapy is a treatment that addresses all aspects of incontinence, leading to the best clinical outcome. This includes somatic, psychosocial, and behavioral problems and quality of life. The latter is an important indicator of the severity of incontinence and comorbidities. ${ }^{17}$ Although urotherapy is becoming the gold standard as the treatment of functional incontinence, it is still not a standardized treatment. ${ }^{17}$ The pitfall of this lack of standardization is that every professional practices urotherapy according to their own profession, thereby ignoring aspects of the problem that are beyond their own specialization. 
The most elaborate form of urotherapy is specific urotherapy. In this form of urotherapy, knowledge from different professions is combined to treat children refractory to standard urotherapy. ${ }^{18}$ Biofeedback, cognitive behavioral therapy, psychotherapy, and education are essential elements of specific urotherapy. These elements help children to learn how to void, when to void, and how often to void. Repeated practice is necessary to habituate the new voiding behavior. Our study in Chapter 3 on the outcomes of clinical bladder training shows that 10 days of direct feedback and support from the urotherapist contributes to a successful outcome.

Within specific urotherapy, the focus is often on pelvic floor rehabilitation using biofeedback training. The theoretical benefit of biofeedback is that children are able to directly visualize the activity of their pelvic floor muscles by EMG or uroflow curve. ${ }^{19}$ This helps them to adequately relax the pelvic floor, thereby decreasing their dysfunctional voiding pattern. But it is a misunderstanding that biofeedback alone is sufficient to achieve continence. In practice, professionals inadvertently combine biofeedback with education and instructions. By doing this, they also provide behavioral modification whilst thinking that they only provide biofeedback training. In urotherapy, biofeedback is merely one of the elements of treatment, type of biofeedback is not a decisive factor in treatment outcome. ${ }^{20}$ Our study in Chapter 5 showed that biofeedback with anal balloon expulsion was significantly less effective than specific urotherapy with real-time uroflow biofeedback and that anal balloon expulsion did not improve the effect of this specific urotherapy treatment

A unique element of specific urotherapy in the Wilhelmina Children's Hospital is the central inhibition training for children with a refractory overactive bladder and/or small bladder volume, as described in Chapter 3. The first step in central inhibition training is remaining dry by maintaining a high voiding frequency, without the use of anticholinergics. Secondly, when the children are confident that they can stay dry, they are instructed to gradually increase the time to hold their urine (inhibit their urge). Central inhibition training is an intensive treatment, but the psychological benefits for children are large and they usually show a steep learning curve. As far as we know, other centers do not provide central inhibition training. They often treat children with overactive bladder with urotherapy in combination with medication suppressing bladder overactivity, botulinum toxin injections and/or neuromodulation. ${ }^{21-23}$ Although also effective, this method does not give children the satisfaction of overcoming their problems themselves, as central inhibition training does.

When standard or specific urotherapy is not effective, the reason has to be identified. In our experience, the reason for failed training is often that children were too young in 
development to benefit from the treatment, thus immature at the start of urotherapy. When the child reaches school age, parents experience social pressure about the incontinence of their child (Chapter 2). In the Netherlands, this means that children are expected to be continent at the age of four years whilst urotherapy is only possible from the age of six onwards. Despite this, many therapists are inclined to address parents' problems by starting urotherapy at too early age. Most parents can be satisfied by reassuring them that there is no threatening medical problem and that treatment is less frustrating and more successful when the child is more mature. In Chapter 3 and from literature, we found that a higher age during specific urotherapy was a predictor for a good treatment outcome.

\section{The role of pelvic floor rehabilitation in urotherapy}

In Chapter 5, we describe that pelvic floor rehabilitation by biofeedback with anal balloon expulsion is significantly less effective than specific inpatient urotherapy and does not improve the effect of specific inpatient urotherapy. This question arose because opinions in our team were divided on the effect of intensive pelvic floor rehabilitation on different types of incontinence. Our findings imply that the presence or absence of adequate pelvic floor control does not influence the severity of incontinence. Other studies corroborated these findings. ${ }^{20,24,25}$ However, physiotherapists generally provide pelvic floor rehabilitation exercises for incontinence complaints. When the exercises are properly understood and executed by the child, voluntary control of the pelvic floor may be reached. In general, physiotherapeutic treatment is then completed. This does not mean that children achieved continence since up till now it is unclear whether there is a relation between adequate pelvic floor control and incontinence. Approximately $30 \%$ of the normative population has inadequate pelvic floor control without being incontinent. ${ }^{26}$ In our opinion, pelvic floor rehabilitation is one of the tools in urotherapy to teach children to recognize feelings of urgency and to empty their bladder in a proper way. Gaining complete control of the pelvic floor is not a goal in itself.

\section{Innovations in urotherapy}

The rapid development of new technologies in healthcare also influences treatment opportunities for incontinence. Usually, existing treatment practices are translated into digital solutions. An example of this is the development of our serious game for urotherapy (Chapter 6). This game encompasses education, instructions, bladder diaries, and feedback in a playful environment. The purpose of the game was to motivate children to maintain their bladder training over a 3-month period. In Chapter 6 we found that the game in its 
current form had no added value over the standard practice. Although children prefer to train with a serious game, it did not increase their motivation. Probably, the game did not fulfill the children's expectations. In general, games for healthcare purposes lack the graphics and storyline that children expect based on their experience with commercial games. In our opinion, effective serious games need the same level of expertise and resources as the professional gaming industry. Furthermore, they should not be a direct translation of the healthcare practices, but be developed based on game design principles.

In urotherapy, it is important that technological innovations support the therapeutic process and do not take over functions. An example of the difficult balance between these two mechanisms is seen in the pilot study of the SENS-U bladder sensor (Chapter 4). The SENS-U measures bladder filling and alarms the child when it is time to go to the toilet. Although the device functions well, there is a high risk that children become dependent on the device instead of learning how to change their voiding behavior. This reflects the different insights between health technicians and healthcare professionals. In the urotherapy practice, the SENS-U will be used differently than the intended use by the developers. In our opinion, it is not the final solution for functional incontinence, but can be a valuable new tool that spurs the learning process of the child to timely react upon the bladder signal.

\section{Urotherapy in science and society}

In the Netherlands, by now, urotherapy is an established treatment in most general hospitals. However, urotherapy protocols differ between providers and therefore results are difficult to compare. Furthermore, treatment outcomes are reported rarely. Because of this, there is a lack of knowledge about best treatment practices in terms of outcome and cost-effectiveness. The group of children with incontinence is very heterogeneous which complicates scientific research because it is difficult to gather large uniform samples with sufficient power. The usual solution for research with small samples is a multicenter design. Due to differences in diagnostics, treatment protocols, and the definition of a good outcome, multicenter studies do not completely solve this problem. To enable research into the etiology of incontinence and the effectiveness of urotherapy, standardization of diagnostics, urotherapeutic treatment, and registration is paramount. Currently the ICCS is writing a standardization paper on urotherapy protocols.

Given the above-mentioned problems, the literature on the etiology of incontinence and the effectiveness of urotherapy is sparse and many questions remain unanswered. ${ }^{11}$ Thus, urotherapy relies on the literature on cognitive behavioral therapy, physiotherapy, 
and pediatric urology and nephrology. It is important to gather knowledge on new insights in these disciplines and constantly consider whether they may have an added value for urotherapy. The ultimate goal is to develop urotherapy into an evidence-based specialization. Therefore, there is a need for more scientifically educated urotherapists and continuous education for urotherapists is essential.

Besides educating specialized professionals such as urotherapists, enhancing knowledge about incontinence in both the general population and professionals working with children is important. For example, primary schools refuse children that are not toilet trained, whilst part of the children is not physically and/or developmentally mature enough to be completely continent at this age. Furthermore, in school classes children are often not allowed to go to the toilet at will which can lead to postponement behavior and makes them stand out in the group if they need to go often. ${ }^{27}$ Part of health care professionals lack knowledge about functional incontinence, resulting in referrals that may be either too early or too late. Nonetheless, except for major congenital anomalies, diagnosing incontinence at a young age remains difficult, because the diagnostic criteria are not clear cut. ${ }^{28}$ The research outcomes could facilitate the diagnostic process by enabling early detection of incontinence through the determination of risk-factors. In the last decades, we gathered a lot of knowledge that improved the way to treat incontinence in children. Many questions remain unexplored and will be a source for future studies. 


\section{REFERENCES}

1. Vaz GT, Vasconcelos MM, Oliveira EA, Ferreira AL. Prevalence of lower urinary tract symptoms in school-age children. Pediatr Nephrol 2012; 27(4): 597-603.

2. Austin PF, Bauer SB, Bower W, Chase J, Franco I, Hoebeke P, et al. The standardization of terminology of lower urinary tract function in children and adolescents: Update report from the standardization committee of the International Children's Continence Society. Neurourol Urodyn 2016; 35(4): 471-81.

3. Chang S, Laecke E Van, Bauer SB, Gontard A Von, Bagli D, Bower WF, et al. Treatment of Daytime Urinary Incontinence: A Standardization Document From the International Children's Continence Society. Neurourol Urodyn 2017; 36(1): 43-50.

4. Schäfer SK, Niemczyk J, von Gontard A, Pospeschill M, Becker N, Equit M. Standard urotherapy as first - line intervention for daytime incontinence : a meta - analysis. Eur Child Adolesc Psychiatry 2018; 27(8): 949-64.

5. Buckley BS, Sanders CD, Kwong JSW, Kilpatrick KA, Anderson CA. Conservative treatment for functional daytime urinary incontinence in children. Cochrane Database Syst Rev 2016; (9): CD012367.

6. Sureshkumar P, Craig JC, Roy LP, Knight JF. Daytime urinary incontinence in primary school children : A population-based survey. J Pediatr 2000; 137(6): 814-8.

7. Swithinbank L V., Heron J, Von Gontard A, Abrams P. The natural history of daytime urinary incontinence in children: A large British cohort. Acta Paediatr Int J Paediatr 2010; 99(7): 1031-6.

8. Duong TH, Jansson UB, Holmdahl G, Sillén U, Hellstrom AL. Development of bladder control in the first year of life in children who are potty trained early. J Pediatr Urol 2010; 6(5): 501-5.

9. Von Gontard A, De Jong TPVM, Badawi JK, O'Connell KA, Hanna-Mitchell AT, NieuwhofLeppink $A$, et al. Psychological and physical environmental factors in the development of incontinence in adults and children: A comprehensive review. J Wound Ostomy Continence Nurs 2017; 44(2): 181-7.

10. Niemczyk J, Wagner C, von Gontard A. Incontinence in autism spectrum disorder: a systematic review. Eur Child Adolesc Psychiatry 2018; 27(12): 1523-37.

11. Labrie J, de Jong TPVM, Nieuwhof-Leppink A, van der Deure J, Vijverberg MAW, van der Vaart $\mathrm{CH}$. The Relationship Between Children With Voiding Problems and Their Parents. J Urol 2017; 183(5): 1887-91.

12. Joinson C, Heron J, Gontard A Von, Butler U, Golding J, Emond A. Early Childhood Risk Factors Associated with Daytime Wetting and Soiling in School-age Children. J Pediatr Psychol 2008; 33(7): 739-50.

13. Fitzgerald MP, Thom DH, Wassel-Fyr C, Subak L, Brubaker L, Van Den Eeden SK, et al. Childhood urinary symptoms predict adult overactive bladder symptoms. J Urol 2006; 175(3): 989-93.

14. Cupelli ET, Escallier L, Galambos N, Xiang S, Franco I. Sensory processing differences and urinary incontinence in school-aged children. J Pediatr Urol 2014; 10(5): 880-5.

15. Hoebeke P, Bower W, Combs A, De Jong T, Yang S. Diagnostic Evaluation of Children With Daytime Incontinence. J Urol 2010; 183(2): 699-703.

16. Chang S-J, Van Laecke E, Bauer SB, von Gontard A, Bagli D, Bower WF, et al. Treatment of daytime urinary incontinence: A standardization document from the International Children's Continence Society. Neurourol Urodyn 2017; 36(1): 43-50.

17. Joinson C, Heron J, von Gontard A. Psychological Problems in Children With Daytime Wetting. Pediatrics 2006; 118(5): 1985-93. 
18. Nieuwhof-Leppink AJ, Schroeder RPJ, van de Putte EM, de Jong TPVM, Schappin R. Daytime urinary incontinence in children and adolescents. Lancet Child Adolesc Health 2019; 3(7): 492-501.

19. Chase J, Austin P, Hoebeke P, McKenna P. The Management of Dysfunctional Voiding in Children: A Report From the Standardisation Committee of the International Children's Continence Society. J Urol 2010; 183(4): 1296-302.

20. Chase J, Schrale L. Childhood incontinence and pelvic floor muscle function: Can we learn from adult research? J Pediatr Urol 2017; 13(1): 94-101.

21. Tourinho R, Hoebeke P, Chase J. Electrical Stimulation for Lower Urinary Tract Dysfunction in Children : A Systematic Review of the Literature. Neurourol Urodyn 2011; 30(8): 1429-36.

22. Hagstroem S, Mahler B, Madsen B, Djurhuus JC, Rittig S. Transcutaneous Electrical Nerve Stimulation for Refractory Daytime Urinary Urge Incontinence. J Urol 2009; 182(4): 2072-8.

23. Newgreen D, Bosman B, Hollestein-Havelaar A, Dahler E, Besuyen R, Sawyer W, et al. Solifenacin in Children and Adolescents with Overactive Bladder: Results of a Phase 3 Randomised Clinical Trial. Eur Urol 2017; 71(3): 483-90.

24. Schulman, S.L, Von Zuben, F.C, Plachter, N. Kodman-Jones C. Biofeedback methodology: does it matter how we teach children how to relax the pelvic floor during voiding? J Urol 2001; 166(6): 2423-6.

25. De Paepe H, Renson C, Hoebeke P, Raes A, Van Laecke E, Vande Walle J. The role of pelvicfloor therapy in the treatment of lower urinary tract dysfunctions in children. Scand $J$ Urol Nephrol 2002; 36(4): 260-7.

26. Bower WF, Chase JW, Stillman BC. Normative Pelvic Floor Parameters in Children Assessed by Transabdominal Ultrasound. J Urol 2006; 176(1): 337-41.

27. Vernon S, Lundblad B, Hellstrom AL. Children's experiences of school toilets present a risk to their physical and psychological health. Child Care Health Dev 2003; 29(1): 47-53.

28. Joinson C, Heron J, von Gontard A, Butler U, Emond A, Golding J. A prospective study of age at initaition of toilet training and subsequent day time bladder control in school-aged children. J Dev Behav Pediatr 2009; 30(5): 385-93. 



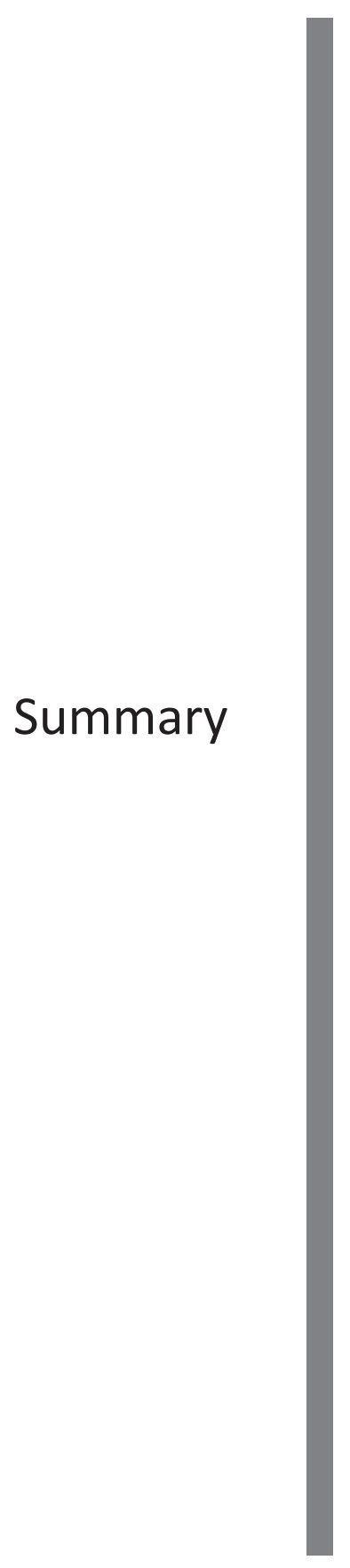





\section{SUMMARY}

The aim of this thesis was to study specific urotherapy as treatment of functional incontinence in children, in order to improve of care for incontinent children. Daytime urinary incontinence is a common problem in school-aged children and severely affects quality of life. Urotherapy is an effective treatment for all forms of functional incontinence, it has a success rate of $56 \%$ within one year, compared to a spontaneous recovering rate $15 \%$ per year.

In Part I, What is functional incontinence and how to treat it, we described the etiology, definition, and treatment of daytime urinary incontinence. Chapter 2: Daytime incontinence in children and adolescents is a review on functional incontinence and its treatment from a urological, pediatric, and urotherapeutic point of view. Daytime urinary incontinence is common in the pediatric population and affects approximately $8 \%$ of 7-year-old children. Risk factors for incontinence can be genetic, demographic, environmental, behavioral, and physical. There are several subtypes of daytime incontinence, which are classified according to their relation to the storage and/or voiding phase of bladder function. These subtypes are overactive bladder, dysfunctional voiding, underactive bladder, voiding postponement, stress incontinence, giggle incontinence, and nocturnal enuresis. Treatment of functional incontinence is multidisciplinary and complex due to the intertwined causes of incontinence and an adequate diagnosis is needed to be successful. Diagnostic instruments are the medical history, bladder diaries, questionnaires, flowmetry, and ultrasonography. Urotherapy is the first treatment of choice for all types of functional incontinence. It combines education, instructions, demystification, behavioral modification, lifestyle advice regarding fluid intake, registration of voiding frequencies, voiding volumes and incontinence episodes, added with support and encouragement to children and their parents. Comorbid problems, like constipation, urinary tract infections, and behavioral problems should be treated before and during urotherapy. For some comorbidities and severe bladder overactivity, medication may be necessary. Although usually effective, urotherapy does not always resolve incontinence. More specific diagnostics, specific urotherapy and in special cases surgical treatment may be necessary.

In Part II, Results of specific urotherapy, we evaluated the outcome of specific inpatient urotherapy for children with overactive bladder. Chapter 3: Central inhibition of refractory overactive bladder complaints, results of an inpatient training program concerns children with an overactive bladder ( $O A B)$, a subtype of incontinence that is characterized by symptoms of urgency, often combined with frequent urgency urinary incontinence or nocturnal enuresis. Approximately $20 \%$ of children with OAB are considered to be therapy 
resistant for urotherapy. In our hospital, we have developed inpatient urotherapy with cognitive and biofeedback training, for refractory incontinence. Essential part of this training is teaching the children central inhibition of bladder signals to suppress bladder overactivity. We evaluated the effect of inpatient urotherapy for children with OAB after failed urotherapy elsewhere. For 70 children, we evaluated the training results 6 months and 2 years after completion. Refractory OAB complaints were cured or improved in $74.3 \%$ of participating children 6 months after training. After 2 years, 70.5\% of children were cured or improved according to International Children's Continence Society (ICCS) criteria. A higher age during inpatient urotherapy was found to be a predictor for better training outcome.

In Part III, A critical appraisal of innovations in urotherapy we discussed current practices and innovations in urotherapy. In Chapter 4: Pelvic floor rehabilitation in children with functional LUTD: does it improve outcome? we compared specific urotherapy with and without pelvic floor rehabilitation by biofeedback with anal balloon expulsion (BABE). We included 52 children with functional incontinence and inadequate pelvic floor control. The group that received BABE prior to inpatient urotherapy consisted of 25 children, and the group that received $B A B E$ after inpatient urotherapy consisted of 27 children. There was no significant additional effect of BABE on specific inpatient urotherapy, based on treatment success according to ICCS criteria. Of the children that received $B A B E, 58 \%$ showed improvement on pelvic floor control. This implies that training pelvic floor control in combination with inpatient urotherapy does not influence treatment effectiveness on incontinence. Our results do not provide a conclusive answer to the effectiveness of pelvic floor physical therapy in the treatment of children with LUTD, since we specifically investigated $B A B E$. Considering the invasive nature of $B A B E$, the use of $B A B E$ to obtain continence should therefore be discouraged.

A potential new tool for urotherapy is described in Chapter 5: SENS-U: clinical evaluation of a full-bladder notification - a pilot study the feasibility of the SENS-U as a full-bladder notification system in active children during inpatient urotherapy is investigated. The SENS-U is a small, wireless ultrasonic sensor, which continuously monitors the bladder filling and provides a personalized notification when it is time to go to the toilet. As soon as the personalized threshold (almost full bladder, 90\%) is reached, the SENS-U provides a signal. Fifteen children participated one day each and in total 41 notifications were sent by the SENS-U. In some cases, children voided before the threshold to get a signal was reached. Children responded positively to the notification of the SENS-U every time, except once when a child was distracted. The SENS-U provided a notification at a median bladder filling of $92.9 \%$. The SENS-U was able to monitor the natural bladder filling, during regular physical activity in children as required. 
The contribution of apps to adherence to urotherapy is studied in Chapter 6: Does a serious game increase intrinsic motivation in children receiving urotherapy? In this chapter, we investigate whether a bladder training app improves intrinsic motivation to comply with urotherapy, which is a key determinant of a successful outcome. A serious game could make the training more appealing and rewarding. We included 50 treatment refractory incontinent children that were allowed to choose between receiving specific inpatient urotherapy with or without the application of a serious game. Children who received standard bladder training with the addition of a serious game did not differ in terms of intrinsic motivation from children who underwent standard bladder training only. Results of the motivation questionnaire showed that all children were highly motivated to train. Training results were equal in both groups, with $80 \%$ good or improved according to ICCS criteria. Incontinence related quality of life improved accordingly. Most children found it attractive to combine bladder training with a serious game. Children indicated that certain aspects of the game could be improved to increase its motivational strength. However, as it is now, our serious game has no added value in urotherapy.

In Chapter 7: Summary and general discussion we discussed the multifactorial etiology of incontinence and the importance of a multidisciplinary treatment approach. Different aspects of urotherapy such as pelvic floor rehabilitation, biofeedback, and technological tools are considered. We conclude that specific urotherapy is a successful treatment for children with functional incontinence. It addresses all aspects of incontinence, requires expert knowledge, and leads to the best clinical outcome. Urotherapy has become the gold standard for treatment of functional incontinence, although it is still not a standardized treatment. The ultimate goal is to develop urotherapy into an evidencebased specialization within the multidisciplinary treatment of incontinence. 

Samenvatting

(Summary in Dutch) 



\section{SAMENVATTING}

In dit proefschrift onderzoeken we specifieke urotherapie als behandeling voor functionele incontinentie voor urine bij kinderen, met als doel het verbeteren van de zorg voor deze kinderen. Incontinentie overdag is een veel voorkomend probleem bij kinderen in de basisschoolleeftijd en heeft een negatieve invloed op kwaliteit van leven. Urotherapie is een effectieve behandeling voor alle vormen van functionele incontinentie, met een succesvolle uitkomst van $56 \%$ binnen één jaar, tegenover een spontaan herstel van $15 \%$ per jaar.

In Deel I, Wat is functionele incontinentie en hoe wordt het behandeld beschrijven we de etiologie, definitie en behandeling van urine-incontinentie overdag. Hoofdstuk 2: Incontinentie overdag bij kinderen en adolescenten is een literatuurstudie naar functionele incontinentie en de behandeling daarvan, vanuit urologisch, kindergeneeskundig en urotherapeutisch perspectief. Incontinentie overdag komt voor bij ongeveer $8 \%$ van de 7-jarigen en veel van deze kinderen worden verwezen naar de kinderarts. Genetische, demografische, omgevings-, gedragsmatige en lichamelijke factoren kunnen een risico zijn voor het ontwikkelen van functionele incontinentie. Er wordt onderscheid gemaakt tussen problemen met blaasopslag en blaaslediging. Gebaseerd op dit onderscheid is er een verdeling in verschillende subtypen van incontinentie: overactieve blaas, dysfunctional voiding, onderactieve blaas, uitstelgedrag, stress-incontinentie, giechel-incontinentie en bedplassen. De behandeling van functionele incontinentie is multidisciplinair en vaak complex vanwege de onderlinge verwevenheid van de oorzaken. Om functionele incontinentie succesvol te kunnen behandelen is een adequate diagnose noodzakelijk. Diagnostische instrumenten zijn de medische anamnese, plasdagboek, vragenlijsten, uroflowmetrie (registratie van de plasstraal) en echografie van nieren, blaas, endeldarm en bekkenbodem. Urotherapie is de eerstelijnsbehandeling voor alle vormen van functionele incontinentie. Het bestaat uit uitleg van normale en abnormale werking van de urinewegen, instructies, demystificatie, gedragsverandering, leefstijladvies over vochtgebruik, registratie van plasfrequentie, plasvolumes, natte incidenten en ondersteuning van kind en ouders. Bijkomende problemen zoals obstipatie, urineweginfecties en gedragsproblemen moeten vooraf of tijdens de urotherapie behandeld worden. Bij sommige bijkomende zaken zoals obstipatie en bij ernstige klachten van een kramperige blaas kan medicatie noodzakelijk zijn. Urotherapie is vaak effectief. Als kinderen met urotherapie niet continent worden kan meer uitgebreide diagnostiek, specifieke urotherapie, extra medicatie en soms chirurgie nodig zijn.

In Deel II, Resultaten van specifieke urotherapie evalueren we de uitkomsten van klinische urotherapie voor kinderen met een overactieve blaas. Hoofdstuk 3: Centrale 
inhibitietraining voor therapieresistente kinderen met een overactieve blaas, uitkomsten van klinische urotherapie gaat over kinderen met een overactieve blaas (OAB). Dit is een subtype van incontinentie met als hoofdkenmerk symptomen van onbeheersbare plasdrang en eventueel in combinatie met een hoge plasfrequentie en/of bedplassen. Ongeveer $20 \%$ van de kinderen met OAB zijn therapieresistent voor urotherapie. Voor deze kinderen hebben we in ons ziekenhuis een klinische training ontwikkeld op basis van cognitieve gedragstherapie en biofeedback. Een essentieel onderdeel van deze training is het leren onderdrukken van signalen van aandrang van een overactieve blaas. Dit noemen we centrale inhibitietraining. We onderzochten de effectiviteit van de klinische training bij 70 kinderen met therapieresistente OAB. Uitkomsten werden gemeten volgens International Children's Continence Society (ICCS) criteria. Zes maanden na het afsluiten van de training was $74,3 \%$ van de kinderen genezen of waren de klachten van $O A B$ verbeterd. Twee jaar na de behandeling bleek dat bij $70,5 \%$ van de kinderen de klachten waren verdwenen of verbeterd. De leeftijd van het kind bleek de uitkomst van de training mede te voorspellen, hoe ouder het kind, hoe beter de uitkomst.

In Deel III, Een kritische evaluatie van innovaties in urotherapie bespreken we de huidige praktijk en innovaties binnen de urotherapie. In Hoofdstuk 4: Bekkenbodemtraining voor kinderen met functionele LUTD: verbetert het uitkomsten? Vergelijken we specifieke klinische urotherapie met en zonder bekkenbodemtraining met anale ballon biofeedback (BABE). We includeerden 52 kinderen met functionele incontinentie en een onvermogen om op commando hun bekkenbodem te sturen/aan te spannen. Eén groep bestond uit 25 kinderen en kreeg BABE voor start van de klinische urotherapie. De andere groep kreeg $B A B E$ na klinische urotherapie en bestond uit 27 kinderen. Het toevoegen van BABE had geen significant effect op de uitkomsten van specifieke klinische urotherapie, gemeten volgens ICCS criteria. BABE had wel effect op de bekkenbodem, bij 58\% van de kinderen verbeterde de aansturing. Dit suggereert dat het trainen van de bekkenbodem in combinatie met specifieke urotherapie geen aanvullend effect heeft op het bereiken van continentie. Omdat we alleen naar BABE hebben gekeken, kunnen de resultaten van deze studie niet naar andere vormen van bekkenbodemtraining in de behandeling van incontinente kinderen worden gegeneraliseerd. Omdat BABE een invasieve behandeling is, ontmoedigen we het gebruik van $B A B E$ in de behandeling van incontinentie.

Een potentieel nieuw hulpmiddel voor de urotherapie is beschreven in Hoofdstuk 5: De SENS-U: klinische evaluatie van een blaassensor - een pilotstudie. Tijdens klinische urotherapie werd bij normaal actieve kinderen de bruikbaarheid van de SENS-U onderzocht. De SENS-U is een draagbare echografische sensor, die continu de vulling van de blaas meet en een signaal geeft als de blaas vol is en het kind naar het toilet moet. Er kan 
vooraf een persoonlijk niveau van blaasvulling worden ingesteld (bijvoorbeeld een bijna volle blaas, 90\%) waarop de SENS-U een signaal geeft. Aan deze pilot deden 15 kinderen ieder één dag mee en werden in totaal 41 signalen gegeven door de SENS-U. De signalen werden soms niet gegeven omdat kinderen naar het toilet gingen voordat het ingestelde niveau van blaasvulling was bereikt. Kinderen reageerden vrijwel altijd adequaat op de signalen van de SENS-U, op één keer na toen een kind was afgeleid. De SENS-U gaf bij een blaasvulling met een mediaan van $92,2 \%$ een signaal. De conclusie is dat de SENS-U in staat is om bij actieve kinderen de stand van zaken van de blaasvulling vast te leggen.

De bijdrage van apps aan therapietrouw in urotherapie wordt onderzocht in Hoofdstuk 6: Verhoogt een serious game de intrinsieke motivatie van kinderen die urotherapie krijgen? in dit hoofdstuk onderzoeken we of een blaastraining-app de intrinsieke motivatie van kinderen verhoogt om urotherapie vol te houden. Intrinsieke motivatie en therapietrouw zijn beide essentieel voor een succesvolle uitkomst. Een serious game kan helpen om de blaastraining aantrekkelijker en belonend te maken. Aan deze studie deden 50 therapieresistente kinderen mee. De kinderen konden zelf kiezen tussen specifieke klinische urotherapie met of zonder ondersteuning van de serious game. Er is geen verschil in intrinsieke motivatie gemeten tussen kinderen die met of zonder serious game werden getraind. Uit de motivatievragenlijst bleek dat alle kinderen een hoge motivatie hadden om te trainen. De trainingsresultaten waren gelijk in beide groepen, bij $80 \%$ van de kinderen waren de klachten verdwenen of verbeterd (volgens ICCS criteria) en verbeterde de kwaliteit van leven. De meeste kinderen vonden het aantrekkelijk om met de serious game te trainen. Ze gaven aan dat bepaalde onderdelen van de game verbeterd zouden kunnen worden om de motivatie te verhogen. Hoewel aantrekkelijk in opzet bleek de serious game in zijn huidige staat geen toegevoegde waarde te hebben voor de positieve uitkomst van urotherapie.

In Hoofdstuk 7: Algemene discussie bespreken we de veelheid van mogelijke oorzaken van incontinentie voor urine en het belang van een multidisciplinaire benadering. Verschillende aspecten van urotherapie zoals bekkenbodemtraining, biofeedback en technische hulpmiddelen passeren de revue. We kunnen concluderen dat specifieke urotherapie een succesvolle behandelmethode voor kinderen met functionele incontinentie is. Het omvat alle aspecten van incontinentie, vereist specialistische kennis en draagt bij aan de best mogelijke klinische uitkomst. Urotherapie wordt steeds meer gezien als de gouden standaard in de behandeling van functionele incontinentie. Toch is urotherapie nog steeds geen gestandaardiseerde behandeling. Het ultieme doel is om urotherapie te ontwikkelen tot een zelfstandige evidence-based specialisatie, binnen de multidisciplinaire behandeling van incontinentie. 

Dankwoord 



\section{DANKWOORD}

Graag wil ik een aantal mensen bedanken die direct en indirect hebben bijgedragen aan dit proefschrift. Het schrijven van dit proefschrift gebeurde naast en als onderdeel van mijn werk als urotherapeut. Veel mensen hebben mij de afgelopen jaren bij dit werk trouw ondersteund, gemotiveerd en warme belangstelling getoond. Ik had nooit verwacht dat ik zou promoveren en zonder alle steun was ik niet geslaagd in deze onderneming.

Terwijl ik dit dankwoord schrijf, beheerst de Coronacrisis ons dagelijks leven en is het nog niet zeker of deze geplande promotieplechtigheid in zijn normale vorm door kan gaan. Het kan zijn dat de situatie of aanwezigheid van personen anders zal zijn dan dat ik me nu voorstel.

In de eerste plaats wil ik al de kinderen en hun ouders bedanken die hebben meegewerkt aan verschillende onderzoeken. Bedankt voor jullie deelname en alle moeite voor het invullen van vragenlijsten.

Prof. dr. T. P.V.M de Jong, beste Tom, dank je wel voor de fijne samenwerking en voor alles wat ik van je geleerd heb op het gebied van kinderurologie en incontinentie. Je hebt me geïnspireerd om de weg van de wetenschap in te slaan. "Eventjes een artikel schrijven" is voor mij niet weggelegd, maar met veel geduld en inzet lukt het ook. Jouw aansporingen, het vertrouwen dat je had in een goede afloop, zijn fundering geweest van dit proefschrift. Bedankt voor je vertrouwen in me!

Prof. dr. E.M. van de Putte, beste Elise, bedankt dat je zo enthousiast ermee instemde om mijn promotor te worden. Urotherapie was voor jou deels onbekend terrein, maar jouw inbreng en kijk leidde tot interessante en soms stevige discussies. Jouw nauwkeurigheid en kritisch houding hebben eraan bijgedragen dat het proefschrift nog beter is geworden. Je feedback is leerzaam voor me geweest, dank daarvoor.

Dr. R. Schappin, beste Renske, dank voor alles, je was voor mij, zeker in laatste en ook de meest moeilijke fase een 'running mate'. Zonder jou had ik het zeker niet gered. Ik wil je bedanken voor de ruimte en aanmoediging die je me hebt gegeven om mezelf op academisch vlak verder te ontwikkelen. Je was een steun en toeverlaat bij het opzetten van onderzoek, de statistische analyse en bij het schrijven van artikelen. Jouw enthousiasme voor kwalitatief goed onderzoek doen heb je overgedragen, ik begin er zelfs aardigheid in te krijgen. Ik hoop dat ondanks verschillende werkplekken onze samenwerking nog niet eindigt.

M.A.W. Vijverberg, beste Marianne, jouw werk is voor mij een belangrijke bron van kennis en inspiratie geweest. Toen ik ooit startte als urotherapeut, maakte je de opmerking dat een therapeutische rol andere vaardigheden vergt dan de verpleegkundige rol. Dit heeft 
me getriggerd om psychologie te gaan studeren. Hierdoor heb ik me kunnen ontwikkelen tot een expert binnen de urotherapie. Mede door jouw aanmoedigingen en je oprechte waardering voor de zorg voor kinderen met incontinentie heb ik dit promotietraject doorgezet. Veel dank daarvoor!

Mijn dank gaat ook uit naar de overige leden van de beoordelingscommissie die bereid waren dit manuscript te beoordelen, te weten Prof. dr. de Kort, Prof. dr. Chrzan, Prof. dr. Benninga, Prof. dr. de Jonge en Dr. Klijn. Ik wil u hartelijk bedanken voor uw tijd om mijn proefschrift te beoordelen en ook de bereidheid om zitting te nemen in de oppositie. Prof. dr. Jongmans, Prof. dr. Frenkel en Prof. dr. Hoebeke dank om als één van de opponenten, hier of online, aanwezig te zijn. Ik voel me zeer vereerd.

Beste mede-auteurs, zonder mede-auteurs geen artikelen, dank voor al jullie tijd, inzet en hulp.

Natuurlijk wil ik graag de collega's en ook mijn voormalige collega 's van het Urotherapieteam bedanken. Beste Edith, Martine, Lottie en Welmoed, dank voor jullie collegialiteit, gezelligheid en belangstelling, het is een voorrecht met jullie te werken aan een thema dat ons na aan het hart ligt. Ook veel dank voor de momenten dat jullie mijn zorg aan patiënten hebben overgenomen, als ik weer eens moest schrijven of weer eens op weg was om presentaties te geven.

Graag bedank ik het team van kinderurologen; beste Aart, Keetje, Rogier, George, en assistenten, jullie altijd warme steun en betrokkenheid bij al mijn inspanningen heb ik bijzonder gewaardeerd. Dank voor jullie adviezen en momenten, om tijdens een bakje koffie het hart te kunnen luchten.

En niet te vergeten, beste overige collega's binnen de urologie; medewerkers van de polikliniek, stafsecretariaat, verpleegkundige specialisten, afdelingsverpleegkundigen, verpleegkundigen functiekamer, nefrologen, collega's fysiotherapie en collega's kinderurologie Amsterdam UMC, dank voor jullie belangstelling en de prettige jaren van samenwerking.

Zonder co-auteurs geen artikelen, zonder stagiaires geen hulp bij verwerking van gegevens. Beste stagiaires; Eelco Meijer, Frank van Geen, Roxanne Yanegh, Annemarie Wobben, Milly Schakel, Nienke Idsardi, Jorinde Kortenbout, Jildou van de Zwaag, Iris Boot, Hung Wong en Sophie Wijnen, dank voor jullie inzet voor het onderzoek binnen het WKZ Urotherapieteam.

Beste Paul van Leuteren, onze wegen kruisten met dank aan Pieter Dik zijn ideeën, die leidden tot innovaties waar jij vooral, ik in een hele kleine rol, aan kon bijdragen. Dank voor de discussies en de gezamenlijk projecten. 
Collega's van Monkey Bizniz, dank voor de prettige samenwerking, voor het ontwikkelen van de urotherapie apps, LUTS en de misspissers, Luts Uro app en Luts en de plasacademie. Beste Dimme, dank voor de illustraties en vooral dank voor alle gezellige kletsmomenten, onder het genot van koffie en gebak.

Beste collega's urotherapeuten, oud-stagiaires, uit heel Nederland, in het bijzonder Marloes en Marleen, dank voor alle collegiale momenten, voor jullie aandacht en steun.

Beste oud-bestuursleden van de Vereniging Urotherapie (nu NVCK), dank voor de fijne samenwerking.

Dear colleagues from the ESPU Nurse group, the ICCS Board and ESPU research team; it is an honour and privilege working with true experts in the field. Thank you for the fruitful collaboration, the meetings, discussions and knowledge conveyed.

Beste Jet Strijker, dank je wel voor de steun en ruimte die je me gegeven hebt om dit proefschrift tot stand te brengen.

Beste Mariëlle en Lisette, dank voor jullie steun tijdens het plannen en organiseren van de opleiding urotherapie en de jaarlijks terugkerende bijscholingsdagen. Jullie zijn een topteam!

Beste collega's van de afdeling medische psychologie en maatschappelijk werk, dank voor jullie interesse en tips van collega's die dit pad al eerder hebben bewandeld.

Natuurlijk wil ik hierbij ook mijn paranimfen Marjanne Cordia-de Haan en Anita Reinders heel erg bedanken dat jullie deze dag van zo dichtbij met mij willen delen! Marjanne, had je ooit gedacht dat wij, sinds dat we 10 -jarige schoolmeisjes waren, vreugde- en soms droevige momenten mochten delen en vele uren konden kletsen over alles wat ons bezighoudt, nu samen in het Academiegebouw zouden staan bij mijn promotie?

Beste Anita, je was ooit die ene medestudent tijdens een statistiekopdracht, we kregen een goede klik en vervolgens hebben we ons gezamenlijk door de studie psychologie heengeslagen. Samen studeren en met veel stress op weg naar de tentamens. Samen de teleurstellingen en vreugdemomenten beleven, van het net niet of juist wel halen van de tentamens en uiteindelijk tegelijk onze masterthesis afronden.

Lieve Renske, inmiddels ben je veel meer dan een collega een fijne vriendin geworden! Lieve (schoon)familie, ik heb mijn promotietraject altijd een beetje onder de radar gehouden, niet te veel aandacht, dat gaf ook niet zoveel stress. Ik ben heel gelukkig en dankbaar dat jullie deze verdediging meevieren. 
Lieve pa en ma, ik weet; jullie vinden me een 'dappere meid', maar dat was ik nooit geweest zonder jullie vertrouwen, lieve zorgen, nuchterheid en fijne aandacht. Dank voor alles!

Lieve Mart en lieve Florian, ik ben trots op twee van zulke stoere jongens. Jullie hebben me eigenlijk wel eens moeten missen, maar gelukkig was er ook altijd tijd voor ons samen, voor humor en plezier, voor muziek, voor samen eten, voor al die fijne fantastische mooie vakanties en wederzijdse lieve zorgen. Dank dat jullie me de steun gaven om vol passie mijn werk te doen. Er komen vast rustiger tijden, hoewel... jullie kennen me vast beter! Lieve Klaas, je stimuleerde en volgde de vorderingen van al mijn studies - van kinderverpleegkundige tot aan psycholoog-, en nu dit promotietraject met tomeloos geduld en met een altijd bevrijdende relativering. Ik kreeg alle ruimte om te doen waarvan ik meende dat gedaan moest worden, op voorwaarde dat het ons goed bleef gaan. Zonder jouw belangeloze steun, aanmoediging en liefde was dit proefschrift niet geschreven. Dank! Dankbaar ben ik voor alle zegeningen in mijn leven. 

About the author 



\section{CURRICULUM VITAE}

Anka Nieuwhof-Leppink (1975) is the coordinator of a team of Urotherapists working in the Wilhelmina Children's Hospital (part of UMC Utrecht). This team is responsible of the inpatient and outpatient coordination of care of children with lower urinary tract symptoms. Furthermore, she coordinates the education programme for Urotherapists, nationally and internationally.

She started her career as nurse in 1996. She was certified as a Pediatric Nurse 1998, and subsequently worked at the Pediatric Urology and Haematology department of the Wilhelmina Children's Hospital. In 2004 she received her bachelor's degree in Management of Healthcare. From 2004 to 2007, she was a senior nurse at the Pediatric Urology and Haematology ward.

In 2007, she specialized as an Urotherapist. Together with Marianne Vijverberg she was determined to improve the treatment of children with lower urinary tract symptoms (LUTS) in the Wilhelmina Children's Hospital as well as on a national and international level. Their commitment to the subject resulted in the founding of the Dutch Urotherapy Society in 2012. In 2011 she started to study psychology at Open University and received her master degree in clinical psychology five years later. From 2010-2017 she was board member of the ESPU nurses, from 2013 she was the president.

Currently, she is board member of the ICCS, member of the ESPU research committee and she holds a position as associate editor of UROLUTS Bedwetting Edu Platform. 


\section{PUBLICATIONS}

Nevéus T, Fonseca E, Franco I, Kawauchi A, Kovacevic L, Nieuwhof-Leppink A, Raes A, Tekgül S, Yang SS, Rittig S. Management and treatment of nocturnal enuresis - an updated standardization document from the International Children's Continence Society. J Pediatr Urol; in press.

Nieuwhof-Leppink AJ, van Geen FJ, van de Putte EM, Schoenmakers MAGC, de Jong TPVM, Schappin R. Pelvic floor rehabilitation in children with functional LUTD: does it improve outcome? J Pediatr Urol 2019; 15: 530.e1-e8.

Nieuwhof-Leppink AJ, Schroeder RPJ, van de Putte EM, de Jong TPVM, Schappin R. Daytime urinary incontinence in children and adolescents. Lancet Child Adolesc Health 2019; 3: 492-501.

van Leuteren PG, Nieuwhof-Leppink AJ, Dik P. SENS-U: Clinical evaluation of a full bladder notification- a pilot study. J Pediatr Urol 2019; 15: 381.e1-e5.

Nieuwhof-Leppink A, de Jong TPVM, van de Putte EM, Schappin R. Does a serious game increase intrinsic motivation in children receiving urotherapy? J Pediatr Urol 2019; 15: 36.e1-36.e7.

Nieuwhof-Leppink A, Vijverberg MAW. Cognitive Behavioral Therapy on the Basis of Urotherapy. In G Mosiello, G Del Popolo, JG Wen, M De Gennaro (Eds.), Clinical Urodynamics in Childhood and Adolescence (Chapter 14). New York: Springer.

Dobrowolska-Glazar BA, Groen LA, Nieuwhof-Leppink A, Klijn AJ, de Jong TPVM, Chrzan R. Open and Laparoscopic Colposuspension in Girls with Refractory Urinary Incontinence. Front Pediatr 2017; 5: 284.

Yang S, Chua ME, Bauer S, Wright A, Brandström P, Hoebeke P, Rittig S, De Gennaro M, Jackson E, Fonseca E, Nieuwhof-Leppink A, Austin P. Diagnosis and management of bladder bowel dysfunction in children with urinary tract infections: a position statement from the International Children's Continence Society. Pediatr Nephrol 2018; 33(12): 2207-19.

von Gontard A, de Jong TP, Rantell A, Nieuwhof-Leppink A, Badawi JK, Cardozo. Do we manage incontinence in children and adults with special needs adequately? ICI-RS 2014. Neurourol Urodyn 2016; 35(2): 304-6.

Klijn AJ, de Jong TPVM, Nieuwhof-Leppink A, Chrzan R, Kuijper CF, de Mooij KL, Dik P. Luts bij kinderen. Tijdschrift voor Urologie 2015; 5: 13-8. 
Meijer EJF, Nieuwhof-Leppink AJ, Dekker-Vasse E, de Joode-Smink GWJ, de Jong TPVM. Central inhibition of refractory overactive bladder complaints, results of an in-patient training program. J Pediatr Urol 2015; 11(1): 21.e1-e5.

Nieuwhof A, Vijverberg M. Urotherapy \& Lowerurinary tract symptoms (Urotherapie voor lagere urinewegproblemen). Magazine Kinderverpleegkunde 2012; 18(4).

Labrie J, De Jong TPVM, Nieuwhof-Leppink AJ, Vijverberg MAW, Van den Vaart H. The relationship between children with voiding problems and their parents. J Urol 2010; 183(5): 1887-91. 

$e^{\circ}$

。

$e^{\ominus}$

-
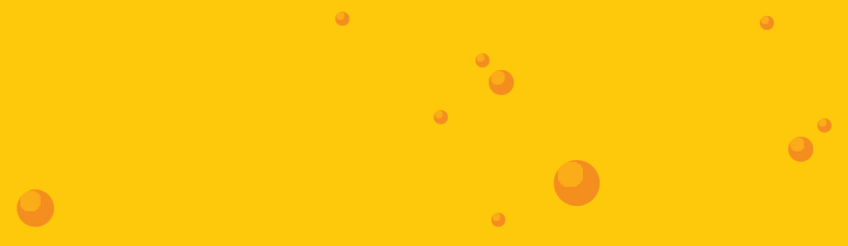

。

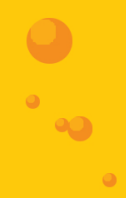

-
。

$+0$

-

0

-

。

- $0^{\circ}$

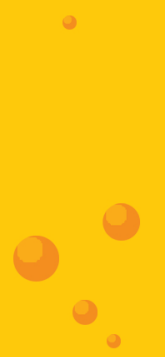

-

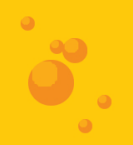

○

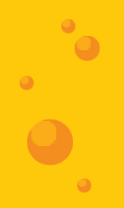

○

-

- 

0

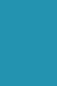

